Genome-wide analysis of goat genetic diversity and production systems in Uganda 


\section{Thesis committee}

\section{Promotor}

Prof. Dr M. A. M. Groenen

Professor of Animal Breeding and Genomics

Wageningen University \& Research

\section{Co-promotors}

Dr E. Kanis

Assistant Professor, Animal Breeding and Genomics

Wageningen University \& Research

Dr R. P. M. A. Crooijmans

Assistant Professor,. Animal Breeding and Genomics

Wageningen University \& Research

\section{Other members}

Prof. Dr. E. N. Stassen, Wageningen University \& Research

Dr S. J. Oosting, Wageningen University \& Research

Dr W. F. van Hooft, Wageningen University \& Research

Dr J. A. Lenstra, Utrecht University

This research was conducted under the auspices of the Graduate School of Wageningen Institute of Animal Sciences (WIAS). 


\title{
Genome-wide analysis of goat genetic diversity and production systems in Uganda
}

\author{
Robert Boyle Onzima
}

\section{Thesis}

submitted in fulfillment of the requirements for the degree of doctor

at Wageningen University

by the authority of the Rector Magnificus

Prof. Dr A. P. J. Mol,

in the presence of the

Thesis Committee appointed by the Academic Board

to be defended in public

on Friday May 03, 2019

at 11 a.m. in the Aula. 
Onzima, R. B.

Genome-wide analysis of goat genetic diversity and production systems in Uganda. 188 pages

PhD thesis, Wageningen University, Wageningen, The Netherlands (2019)

With references, with summaries in English and Dutch

ISBN: 978-94-6343-907-7

DOI: https://doi.org/10.18174/472434 


\begin{abstract}
Onzima, R. B. (2019). Genome-wide analysis of goat genetic diversity and production systems in Uganda. PhD thesis, Wageningen University \& Research, Wageningen, The Netherlands.

The need to promote sustainable utilization and conservation of indigenous livestock genetic resources has increased over the last century. Genetic diversity is a prerequisite for adaptation in the face of future challenges, therefore highlighting the need to ensure that animal genetic resources remain available to promote food security for future generations. The advances in genotyping technology provide unique opportunities for in-depth assessment of genetic diversity and to prioritize breeds for conservation and sustainable use. The aim of the research described in this thesis was therefore to characterize production systems and goat genetic resources in Uganda. First, using participatory approaches in defining breeding goal traits, smallholder farmers identified adaptation traits to be critical in an ideal goat breed for smallholder production systems. Subsequently, three indigenous goat breeds were assessed for their variation in resistance/resilience to the gastrointestinal nematode Haemonchus contortus. A weakly significant difference among breeds in faecal egg count (FEC) and packed cell volume (PCV) was observed suggesting potential differences in resistance to Haemonchus contortus. Secondly, using the caprine SNP50 BeadChip, the genetic diversity, population structure and admixture in Ugandan goat breeds was assessed. Moderate to high genetic variability was observed among the Ugandan indigenous goat breeds. The breeds exhibit a weak population structure and limited admixture with the exotic breed Boer. Genome-wide scans for selection signatures identified regions of the genome enriched with genes directly or indirectly associated with environmental adaptation such as immune response and thermo-tolerance. Genomic inbreeding values were generally low in the indigenous goat breeds. We conclude that the use of participatory approaches in identifying breeding objectives is crucial for successful implementation of breeding programs. Genome-wide SNP markers provide in-depth information about the genetic diversity and can be useful in promoting conservation and sustainable use of indigenous goat genetic resources.
\end{abstract}


To my family and smallholder farmers from whom i drew inspiration for this study 


\section{Contents}

5 Abstract

11 1-General introduction

232 - Production system and participatory identification of breeding objective traits for indigenous goat breeds of Uganda

513 - Between-breed variations in resistance/resilience to gastrointestinal nematodes among indigenous goat breeds in Uganda

$694-$ Genome-wide population structure and admixture analysis reveals weak differentiation among Ugandan goat breeds

1035 - Genome-wide Characterization of Selection Signatures and Runs of Homozygosity in Ugandan Goat Breeds

137 6-General Discussion

161 Summary

165 Samenvatting

169 About the author

173 List of publications

177 Training and Education

183 Acknowledgements

187 Colophon 
1

General Introduction 


\subsection{Introduction}

In developing countries like Uganda, goats make a significant contribution to the livelihood of resource constrained farmers, particularly in rural areas. Globally, the largest number of goats lives in Asia (55.45\% of the world total), followed by Africa (38.66\%) and the Americas (3.78\%) (FAOSTAT, 2016) (Table 1.1). Goat meat production follows a similar trend with Asia leading $(73.18 \%$ of the global production), followed by Africa (22.13\%) and the Americas (3.78\%). There has generally been an upward trend in production, particularly in Asia and Africa (Figure 1.1), with some of the countries reporting doubling of numbers of goats in the last decade. This highlights the critical role played by goats in the total livestock production in developing countries in Asia and Africa. In addition to meat and milk, goats also provide skins, manure and fibre (mohair and cashmere). Goats also play important socio-cultural roles in many communities such as e.g. bride price (Kosgey and Okeyo, 2007; Onzima et al., 2018). Moreover, indigenous goats constitute a major genetic resource which is well adapted to diverse agro-ecological conditions, and together with sheep they represent the livestock species of choice for marginal areas that are not suitable for arable agriculture and in places where keeping large livestock species may not be feasible.

To exploit goat populations in a sustainable manner, there is a growing need to characterize, utilize and conserve goat genetic resources in developing countries like Uganda. The gap in knowledge about the variation in production environment as well as the diversity of goat genotypes in Uganda, is a serious constraint to sustainable utilization and conservation strategies. Characterization of breeds is considered by the FAO as one of the strategic priorities for the development of a national plan for the management of animal genetic resources (Ajmone-Marsan et al., 2014). 
Table 1.1: Number of goats in the top 15 leading countries and their percentages of global population (millions)

\begin{tabular}{lllc}
\hline Country & $\mathbf{2 0 0 6}$ & $\mathbf{2 0 1 6}$ & \% of World Population in 2016 \\
\hline China & 146.86 & 149.09 & 14.87 \\
India & 136.29 & 133.88 & 13.35 \\
Nigeria & 51.21 & 73.88 & 7.37 \\
Pakistan & 53.79 & 70.30 & 7.01 \\
Bangladesh & 43.60 & 56.08 & 5.59 \\
Sudan & 29.26 & 31.33 & 3.12 \\
Ethiopia & 18.56 & 30.20 & 3.01 \\
Kenya & 10.21 & 26.75 & 2.67 \\
Mongolia & 15.45 & 25.58 & 2.55 \\
Mali & 12.00 & 22.14 & 2.21 \\
Indonesia & 13.79 & 19.61 & 1.96 \\
Iran & 25.83 & 19.10 & 1.90 \\
Tanzania & 13.10 & 18.72 & 1.87 \\
Niger & 11.69 & 16.10 & 1.61 \\
Uganda & 8.03 & 15.59 & 1.55 \\
\hline Total for 15 countries & 589.67 & 708.35 & 70.64 \\
\hline World Total & $\mathbf{8 4 0 . 3 7}$ & $\mathbf{1 , 0 0 2 . 8 1}$ & \\
\hline Source & & & \\
\hline
\end{tabular}

Source FAOSTAT, 2016

\subsection{Domestication history}

Goats are believed to be amongst the first farm animals domesticated by man. They have had a symbiotic relationship with humans for over 10,000 years following human civilization (Ensminger and Parker, 1986). The centre of domestication of the goat is believed to be near the fertile crescent area spanning the region from eastern Anatolia (Turkey) to the Zagros mountains in present day Iran (Zeder and Hesse, 2000; Naderi et al., 2008; Zeder, 2008;Nomura et al., 2013). From the centre of domestication, goats spread west to Eastern Europe and Northern Africa and arrival in sub-Saharan Africa occurred later, about 4000 - 5000 years ago (Gifford-Gonzalez and Hanotte, 2011). The migration of goats to Uganda could have occurred through 
the Ethiopian highlands, although a central route through the Sahara desert was also suggested (Clutton-Brock, 2000).

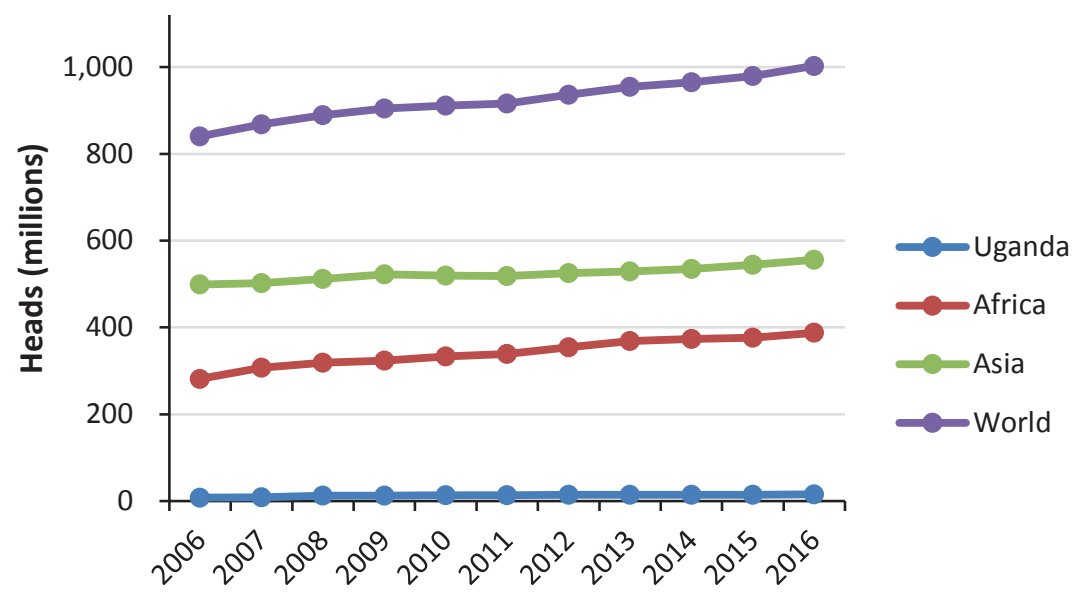

Figure 1.1: Trends in goat population globally showing increasing contribution from Asia and Africa during the period from 2006 to 2016 (FAOSTAT, 2016)

\subsection{Genetic resources and goat improvement programs in Uganda}

The current Ugandan goat populations mainly comprise three indigenous geographically isolated breeds: Mubende, Kigezi and Small East African (SEA) goats (Mason and Maule, 1960; Nsubuga, 1996; MAAIF and UBOS, 2009). Additionally, several indistinct ecotypes or geographical isolated population of indigenous goats exist including Karamojong and Sebei. These ecotypes are a result of the response of the goat genotypes to their prevailing ecological conditions. The indigenous goat breeds are generally characterized by small body size, slow growth rate and low carcass weight. However, they show resistance to gastro-intestinal parasites and local diseases, tolerance to heat and water scarcity, and ability to utilize low quantity and quality fodder. In order to improve the productivity of the indigenous goat breeds, cross-breeding with exotic Boer goats was initiated in the early 1990's (Nsubuga, 1996). Unfortunately, good as the initiative seemed, the cross-breeding was done indiscriminately and uncoordinatedly posing a threat to the existence of the resilient and adapted indigenous breeds. The indigenous and exotic goat breeds likely represent an enormous source of genetic diversity, but the benefits may only 
be fully exploited if the germplasm can be characterized, conserved and utilized in a sustainable manner under the existing and future production systems.

The prevalence of small-scale production in both intensive and extensive mixed farming systems in developing countries is expected to persist as a result of continuing fragmentation of land (Steinfeld et al., 2010). Smallholder mixed farming systems are predicted to remain the main producers of ruminants until 2050 (Herrero et al., 2014).

\subsection{Role of local goat breeds for future improvement programs}

Local breeds generally play an unprecedented role in maintaining across-breed genetic diversity in animal genetic resources (Biscarini et al., 2015). Locally adapted breeds are crucial for many livestock-keeping livelihoods, particularly as climate change progresses, and as new environmental changes arise, some of the adaptive characteristics of the animals will become critical to counter the effects of the emergent challenges (FAO, 2015). However, local breeds tend to be less productive and often being replaced by high production trans-boundary breeds. Under smallholder conditions, these breeds could represent an important genetic resource and a livelihood for the farmers. Often, the reason for their preference by smallholder farmers is their resilience and ability to survive under often extreme conditions under which they must produce. This is an inherent advantage for the resource constrained smallholder farmer, who may not have the resources to improve the production environment.

\subsection{Breed adaptation to local environment}

Animals well adapted to a specific environmental condition usually are more likely to survive longer and pass on their genes to subsequent generations (offspring). Because of this adaptation process, the population will gradually consist of more animals with the favourable alleles which are passed from one generation to another. Therefore, in a population of indigenous goats, a higher number of individuals that are adapted to the local environmental conditions would be expected. However, the successful establishment of a well-adapted population will depend on the genetic diversity present (Fisher, 1930). Selection for adaptive traits in particular, will become very relevant with the current trend in climate change (Hoffmann, 2013). Climate change which manifests in ecosystem changes may result in changes in parasite burden or heat stress and the animals will need to adapt to these changes at the genome level. Farming systems in tropical, subtropical, and arid 
regions are particularly prone to the effects of climate change. Small ruminants, particularly goats, are considered an integral part of these ecosystems. Genomic studies with adapted goats and comparing them to un-adapted goats, may provide an ideal model for the identification of genes for adaptation traits (Sejian et al., 2017; Visser, 2017).

Moreover, as a result of concerted efforts, a reference genome sequence of the domestic goat (Capra hircus) was published in 2013 (Dong et al., 2013) by the International Goat Genome Consortium (https://www.goatgenome.org/) followed later by that of the wild progenitor, Bezoar (Capra aegagrus) (Dong et al., 2015). The availability of the reference genome sequence of the goat led to advances in goat genomics such as the development of the 52K SNP chip (Tosser-Klopp et al., 2014), sold commercially by Illumina as caprine SNP50 BeadChip.

\subsection{Motivation for this thesis}

The indigenous Ugandan goat breeds are poorly characterized, and they face risk of extinction due to their typically low productivity. Because of this low production, smallholder farmers may be compelled to adopt exotic breeds on economic grounds, which increases the risk of disappearance of the well adapted and resilient local breeds. To prevent undesired loss of genetic diversity, there is a need to characterize the breeds and their production environment to properly assess the value of the Ugandan breeds and to guide decision making in livestock development and breeding programs. This need is well recognized in smallholder small ruminant production systems in East Africa (Kosgey et al., 2006).

The developments in genomics technologies like e.g. fast genotyping methods in the last decade, have created important tools for detailed genetic characterization of populations. However, detailed molecular information on its own does not capture the economic value and adaptive capacity of breeds in local conditions. There is a need to complement the molecular information with performance and pedigree information. This information is often lacking in the smallholder production systems in developing countries like Uganda due to non-existent institutional frameworks and infrastructure, and inadequate farmers' organizations at the village level to effectively participate in breeding schemes (Kosgey and Okeyo, 2007). 


\subsection{This Thesis}

The main aim of this thesis is to characterize Ugandan indigenous goat production systems and the Ugandan goat breeds to conserve and promote sustainable utilization of these breeds. To achieve these broad objectives, I undertook the following studies:

1. Assess goat production systems and define breeding objectives for indigenous goat breeds in Uganda.

2. Evaluate the variation in resistance/resilience in three indigenous goat breeds of Uganda when artificially infected with the gastrointestinal nematode Haemonchus contortus.

3. Assess the degree of genetic diversity, population structure, breed relationships and breed admixture in Ugandan goats.

4. Evaluate selection signatures and genomic inbreeding in six Ugandan goat breeds

\subsection{Outline of the thesis}

This thesis consists of 6 chapters. The general introduction (Chapter 1) provides an overview of the thesis. Using qualitative data collected from smallholder farmers and secondary literature, we assessed goat production systems and applied participatory approaches which actively involve the farmers in identification/assessment of possible breeding goal traits (Chapter 2). Subsequently, in Chapter $\mathbf{3}$ we evaluated the three main goat breeds: Kigezi, Mubende and Small East African, for variation in resistance/ resilience to the gastrointestinal parasite Haemonchus contortus, one of the key constraints to production identified by farmers. In Chapter 4 a genome-wide analysis was undertaken using the caprine SNP50 BeadChip to assess the genetic diversity, population structure and admixture in Ugandan goat breeds. In Chapter $\mathbf{5}$ we undertook a genome-wide scan to identify signatures of selection and assess genomic inbreeding based on runs of homozygosity $(\mathrm{ROH})$ in the goat genome. We further quantified the level of genomic inbreeding in the goat breeds using the number and length of ROH's. Lastly, in Chapter 6 the results from the various studies were synthesized in a general discussion including perspectives for breed improvement and utilization under the current smallholder systems and future commercially oriented production. I further discuss current strategies for conservation of genetic diversity in the current goat populations to meet current and future challenges in breed improvement. 


\section{References}

Ajmone-Marsan, P., Colli, L., Han, J.L., Achilli, A., Lancioni, H., Joost, S., Crepaldi, P., Pilla, F., Stella, A., Taberlet, P., Boettcher, P., Negrini, R., and Lenstra, J.A. (2014). The characterization of goat genetic diversity: Towards a genomic approach. Small Ruminant Research 121, 58-72.

Biscarini, F., Nicolazzi, E.L., Stella, A., Boettcher, P.J., and Gandini, G. (2015). Challenges and opportunities in genetic improvement of local livestock breeds. Frontiers in Genetics 6:33.

Clutton-Brock, J. (2000). Cattle, sheep, and goats south of the Sahara: an archaeozoological perspective. The Origins and Development of African Livestock-Archaeology, Genetics, Linguistics and Ethnography, 30-37.

Dong, Y., Xie, M., Jiang, Y., Xiao, N., Du, X., Zhang, W., Tosser-Klopp, G., Wang, J., Yang, S., Liang, J., Chen, W., Chen, J., Zeng, P., Hou, Y., Bian, C., Pan, S., Li, Y., Liu, X., Wang, W., Servin, B., Sayre, B., Zhu, B., Sweeney, D., Moore, R., Nie, W., Shen, Y., Zhao, R., Zhang, G., Li, J., Faraut, T., Womack, J., Zhang, Y., Kijas, J., Cockett, N., Xu, X., Zhao, S., Wang, J., and Wang, W. (2013). Sequencing and automated whole-genome optical mapping of the genome of a domestic goat (Capra hircus). Nature Biotechnology 31, 135-141.

Dong, Y., Zhang, X., Xie, M., Arefnezhad, B., Wang, Z., Wang, W., Feng, S., Huang, G., Guan, R., Shen, W., Bunch, R., Mcculloch, R., Li, Q., Li, B., Zhang, G., Xu, X., Kijas, J.W., Salekdeh, G.H., Wang, W., and Jiang, Y. (2015). Reference genome of wild goat (capra aegagrus) and sequencing of goat breeds provide insight into genic basis of goat domestication. BMC Genomics 16, 431.

Ensminger, M.E., and Parker, R.O. (1986). Sheep and Goat Science. Fifth Edition ed. (Danville, Illinois: The Interstate Printers and Publishers Inc.).

FAO (2015). Coping with climate change - the roles of genetic resources for food and agriculture. Rome.

FAOSTAT (2016). FAO Statistics. Retrieved on 5th February, 2018 from http://www.fao.org/faostat/en/\#data/QA. (Rome, Italy).

Fisher, R. (1930). The genetical theory of natural selection. Oxford, UK: Clarendon Press.

Gifford-Gonzalez, D., and Hanotte, O. (2011). Domesticating Animals in Africa: Implications of Genetic and Archaeological Findings. Journal of World Prehistory 24, 1-23. 
Herrero, M., Havlik, P., Mcintire, J., Palazzo, A., and Valin, H. (2014). "African livestock futures: realizing the potential of livestock for food security.", in: Poverty reduction and the environment in sub-Saharan Africa. (Geneva, Switzerland.: Office of the Special Representative of the UN Secretary General for Food Security and Nutrition and the United Nations System Influenza Coordination (UNSIC). available at: http://tinyurl.com/nj6tr8a)).

Hoffmann, I. (2013). Adaptation to climate change - exploring the potential of locally adapted breeds. Animal 7, 346-362.

Kosgey, I.S., Baker, R.L., Udo, H.M.J., and Van Arendonk, J.A.M. (2006). Successes and failures of small ruminant breeding programmes in the tropics: a review. Small Ruminant Research 61, 13-28.

Kosgey, I.S., and Okeyo, A.M. (2007). Genetic improvement of small ruminants in low-input, smallholder production systems: Technical and infrastructural issues. Small Ruminant Research 70, 76-88.

MAAIF and UBOS (2009). The National Livestock Census Report 2008. Ministry of Agriculture, Animal Industry and Fisheries (MAAIF), Entebbe/Uganda Bureau of Statistics (UBOS), Kampala, Uganda.

Mason, I.L., and Maule, J.P. (1960). "The Indigenous livestock of eastern and southern Africa.", in: Commonwealth Bureau of Animal Breeding and Genetics. (UK: CAB (Commonwealth Agricultural Bureaux)).

Naderi, S., Rezaei, H.-R., Pompanon, F., Blum, M.G.B., Negrini, R., Naghash, H.-R., Balkız, Ö., Mashkour, M., Gaggiotti, O.E., Ajmone-Marsan, P., Kence, A., Vigne, J.-D., and Taberlet, P. (2008). The goat domestication process inferred from large-scale mitochondrial DNA analysis of wild and domestic individuals. Proceedings of the National Academy of Sciences 105, 1765917664.

Nomura, K., Yonezawa, T., Mano, S., Kawakami, S., Shedlock, A.M., Hasegawa, M., and Amano, T. (2013). Domestication Process of the Goat Revealed by an Analysis of the Nearly Complete Mitochondrial Protein-Encoding Genes. PLOS ONE 8, e67775.

Nsubuga, H.S.K. (1996). Small Ruminant: Goats and Sheep in Uganda: ILRI (International Livestock Research Institute) Nairobi, Kenya. 326.

Onzima, R.B., Gizaw, S., Kugonza, D.R., Van Arendonk, J.A.M., and Kanis, E. (2018). Production system and participatory identification of breeding objective traits for indigenous goat breeds of Uganda. Small Ruminant Research, 163, 51 - 59.DOI: https://doi.org/10.1016/i.smallrumres.2017.07.007

Sejian, V., Krishnan, G., Bagath, M., Vaswani, S., Vidya, M.K., Aleena, J., Maurya, V.P., and Bhatta, R. (2017). "Adaptation Strategies to Sustain Osmanabadi Goat 
Production in a Changing Climate Scenario," in Sustainable Goat Production in Adverse Environments: Volume II: Local Goat Breeds, eds. J. Simões \& C. Gutiérrez. (Cham: Springer International Publishing), 9-27.

Steinfeld, H., Mooney, H.A., Schneider, F., and Neville, L.E. (2010). Livestock in a Changing landscape. Washington, DC: Island Press.

Tosser-Klopp, G., Bardou, P., Bouchez, O., Cabau, C., Crooijmans, R., Dong, Y., Donnadieu-Tonon, C., Eggen, A., Heuven, H.C.M., Jamli, S., Jiken, A.J., Klopp, C., Lawley, C.T., McEwan, J., Martin, P., Moreno, C.R., Mulsant, P., Nabihoudine, I., Pailhoux, E., Palhière, I., Rupp, R., Sarry, J., Sayre, B.L., Tircazes, A., Jun, W., Wang, W., Zhang, W., and the International Goat Genome, C. (2014). Design and Characterization of a 52K SNP Chip for Goats. PLOS ONE 9, e86227.

Visser, C. (2017). Adaptation of Local Meat Goat Breeds to South African Ecosystems, In: Sustainable Goat Production in Adverse Environments: Volume II: Local Goat Breeds, eds. J. Simões \& C. Gutiérrez. (Cham: Springer International Publishing), 67-76.

Zeder, M.A. (2008). Domestication and early agriculture in the Mediterranean Basin: Origins, diffusion, and impact. Proceedings of the national Academy of Sciences 105, 11597-11604.

Zeder, M.A., and Hesse, B. (2000). The Initial Domestication of Goats (Capra hircus) in the Zagros Mountains 10,000 Years Ago. Science 287, 2254-2257. 


\section{2}

\section{Production system and participatory identification of breeding objective traits for indigenous goat breeds of Uganda}

R.B. Onzima ${ }^{1,2}$, S. Gizaw ${ }^{3}$, D.R. Kugonza ${ }^{4}$, J.A.M. van Arendonk $^{5}$, E. Kanis ${ }^{1}$

\footnotetext{
${ }^{1}$ Animal Breeding and Genomics, Wageningen University and Research, P.O. Box 338, $6700 \mathrm{AH}$, Wageningen, the Netherlands; ${ }^{2}$ National Agricultural Research Organization (NARO), P.O. Box 295, Entebbe - Uganda; ${ }^{3}$ International Livestock Research Institute (ILRI), Addis-Ababa, Ethiopia; ${ }^{4}$ Department of Agricultural Production, School of Agricultural Sciences, Makerere University, P.O. Box 7062, Kampala, Uganda; ${ }^{5}$ Hendrix Genetics, P.O. Box 114, 5830 AC Boxmeer, The Netherlands.
}

Small Ruminant Research (2018) 163, 51 - 59

DOI: https://doi.org/10.1016/j.smallrumres.2017.07.007 


\begin{abstract}
The success of breeding programs in improving indigenous livestock breeds in Uganda has hitherto been limited due to lack of involvement of the key stakeholders. Thus, participatory approaches are being promoted for designing community-based improvement programs. The aim of this study was to characterize the indigenous goat production systems and assess in a participatory manner farmer preferred trait for establishing breeding objectives for indigenous goat breeds in Uganda. 217 farm households representing three goat production systems (combinations of breed and region) were individually interviewed to assess the socio-economic characteristics of the regions and the preferences of the farmers for indigenous goat breeds. The three breed/region combinations were 78 households with the Small East African breed in Arua, 81 with the Mubende breed in Mubende and 58 with the Kigezi breed in Kabale. An index-based approach was used to rank farmers' choices of traits considered important for their production systems. Descriptive statistics show that overall the production systems were not significantly different in terms of the nature of the farms and the trait preferences of the farmers. The sale of live animals was considered a primary objective for keeping goats by farmers across all the production systems studied. Adaptation traits (disease resistance, heat tolerance and survival) were considered critical in the farmers' preferred breed. Production traits (better prolificacy and faster growth rate) and marketing ease were other characteristics considered by the farmers. The results from the study are useful for designing farmer-participatory breeding programs for goats in the different production systems in Uganda.
\end{abstract}

Key words: Breed preference, Breeding objectives, breeding programs, smallholder farmers, indigenous goats, production/ adaptation traits 


\subsection{Introduction}

Goats are amongst the earliest animals domesticated and have been associated with humans symbiotically for over 10,000 years (Ensminger and Parker, 1986). They are amongst the most important livestock species used for meat production around the world producing over 5 million metric tonnes of meat (FAOSTAT, 2014).

Goats show a high degree of diversity due to their ability to adapt to varying environmental conditions and nutritional regimes. There are over 576 breeds currently documented of which Africa is home to 96 breeds (FAO, 2015). The global goat population has continued to increase over the last decade to currently over 1 billion goats, with Africa contributing 36.2\%, Asia 58.2\%, Americas 3.5\%, Europe 1.7\% and Oceania $0.4 \%$ (FAOSTAT, 2014). The goat population in Uganda is approximately 14.0 million (UBOS, 2015). Over $95 \%$ of this population is comprised of indigenous goat breeds. Furthermore, there is a small proportion of exotic breeds composed of Boer, Savannah, Anglo-Nubian, Toggenburgs and Saanen among others (UBOS and MAAIF, 2009). Goats contribute significantly to the net cash income derived from livestock production in the crop-livestock production system, although the annual meat production from goats is relatively small compared to the number of heads (MAAIF, 2011).

In Uganda, goats are mainly kept by smallholders composed of mainly the rural poor and vulnerable women headed households (Semakula et al., 2010a). They contribute substantially to the livelihoods of these households as a source of income, food (mainly meat) and non-food products like manure and skin. Goats also serve as a means of risk mitigation during crop failures, property security, monetary saving and investment, and have many other socio-economic and cultural functions such as dowry for marriage, sacrifice and in-kind payment of fines on breach of cultural norms and taboos (Kugonza et al., 2001).

The Ugandan indigenous goat breeds are generally characterized by small body size, slow growth rate and low carcass weight. However, these indigenous goat breeds have evolved in diverse and stressful environments resulting in unique adaptive traits like disease and heat resistance, water scarcity tolerance and ability to cope with poor quality feed which has enabled them to survive and remain productive in these environments. To improve the productive performance of the indigenous goats for meat, cross breeding with South African Boer goats was started in early 1990's (Nsubuga, 1996). This offered short term solutions for increasing goat meat production. However, in the long run continuous cross breeding may lead to disappearance of the resilient indigenous breeds. Anecdotal reports indicate that there might be no net gains from crossbreeding with Boer goats since a larger 
proportion of kids succumb to pre-weaning mortality arising from intestinal worm infections. The indiscriminate and unplanned cross breeding with the adapted indigenous breeds may lead to breed replacements. This may have a negative bearing on future breeding programs for goats. Although the threat level of Uganda's indigenous goats is not quantified, already $3 \%$ of the world's goat breeds is extinct, $6 \%$ is at critical level and the risk status of some $32 \%$ is unknown (FAO, 2004, 2009, 2011b). In order to qualify the uniqueness of indigenous goat breeds, there is need to characterize the breeds and their production system so as to properly assess the value of breeds and to guide decision making in livestock development and breeding programs (Kosgey et al., 2006).

The most important indigenous goat breeds of Uganda are Small East African, Mubende and Kigezi goats (Mason and Maule, 1960; Nsubuga, 1996). The Small East African (SEA) goats have an adult live body weight of 20-25 kg and are distributed extensively in the northern and eastern savannah ecological areas and drier areas of central Uganda, contributing approximately $83.3 \%$ to the total indigenous goat population. The Mubende (MUB) goats are larger animals with adult live body weight of $30-35 \mathrm{~kg}$ and popular also for their high-quality skin. They contribute approximately $14.5 \%$ to the indigenous goat herd and are mainly found in Mubende and Ssembabule district. The Kigezi (KIG) goats have an adult live body weight of 25$30 \mathrm{~kg}$ and are distributed widely in the south western highlands and make up 2.2\% of the total indigenous goat population in Uganda (UBOS and MAAIF, 2009).

As seen in many tropical developing countries, the animal production systems in Uganda are very diverse mainly due to the agro-ecological conditions and the level of commercialization (Wurzinger et al., 2006; Gizaw et al., 2010). The more market oriented commercial farmers tend to focus more on livestock production compared to the subsistence smallholder farmers. The aspirations of the farmers are also as diverse as the number of communities that may be involved in keeping the goats. Therefore, the identification and characterization of local production environment of indigenous breeds, and the associated context of their utilization and development is a first step towards breed improvement programs.

The failure of breed improvement programs in tropics in the past decades has mainly been attributed to lack of involvement of the farmers in defining the breeding objectives (Kahi et al., 2005; Wurzinger et al., 2011). The use of participatory approaches should be an integral part in defining breeding objectives (Kosgey, 2004; Duguma et al., 2010). These approaches have been used in defining breeding objectives for mixed livestock and pastoral systems for small ruminants in Kenya and Ethiopia (Kosgey et al., 2008; Bett et al., 2009b; Mirkena et al., 2012; Gebreyesus et 
al., 2013), and recently as a bench mark for defining breeding goal traits for Nile tilapia (Oreochromis niloticus) in Kenya (Omasaki et al., 2016).

In Uganda, there has hardly been any comprehensive study that describes the production environment and defines breeding objectives for indigenous goat breeds. This study was therefore designed to characterize the indigenous goat production systems and to develop a participatory definition of farmer preferred traits for establishing breeding objectives for indigenous goat breeds in Uganda.

\subsection{Materials and Methods}

\subsubsection{Study sites}

A survey was conducted in Arua $\left(3.03^{\circ} \mathrm{N}, 30.91^{\circ} \mathrm{E}\right.$ and 1157 metres above sea level (masl), Mubende $\left(0.59^{\circ} \mathrm{N}, 31.36^{\circ} \mathrm{E}\right.$ and $\left.1324 \mathrm{masl}\right)$ and Kabale $\left(1.33^{\circ} \mathrm{S}, 30.00^{\circ} \mathrm{E}\right.$, 1864 masl) districts of Uganda (Figure 1).

The average annual rainfall is $2875 \mathrm{~mm}$ in Arua, $1377 \mathrm{~mm}$ in Mubende and $1018 \mathrm{~mm}$ in Kabale. The average monthly temperatures were $26.6^{\circ} \mathrm{C}, 22.9^{\circ} \mathrm{C}$ and $17.2^{\circ} \mathrm{C}$ for Arua, Mubende and Kabale respectively. The agro-ecologies have been described by MAAIF (2010). Arua lies in the north western savannah grassland characterized by gentle undulating plains suitable for cotton, millet, sorghum, legumes (beans, groundnuts), sesame and cassava. Livestock reared includes cattle, poultry and small ruminants, but production is limited by tsetse fly infestation. Mubende is in western savannah grassland, which can be described as a banana-coffee-cattle system. Cattle is the main livestock along with small ruminants. The district belongs to the cattle corridor belt which extends from western plains to Karamoja in the north eastern Uganda. Kabale belongs to the highlands agro-ecologies, which is characterized by high population density with small land holdings, and the main crops are sorghum, potatoes, vegetables, coffee, maize and wheat. The farmers in Kabale keep small ruminants, cattle and poultry.

These districts were selected due to a large population of the particular goat breeds (UBOS and MAAIF, 2009) and to represent the production environment for SEA, MUB and KIG goats respectively. Despite the fact that the SEA are distributed throughout the country, Arua was selected for the study due to logistical reasons and it was envisaged to be a representative site for the Small East African goats production system 


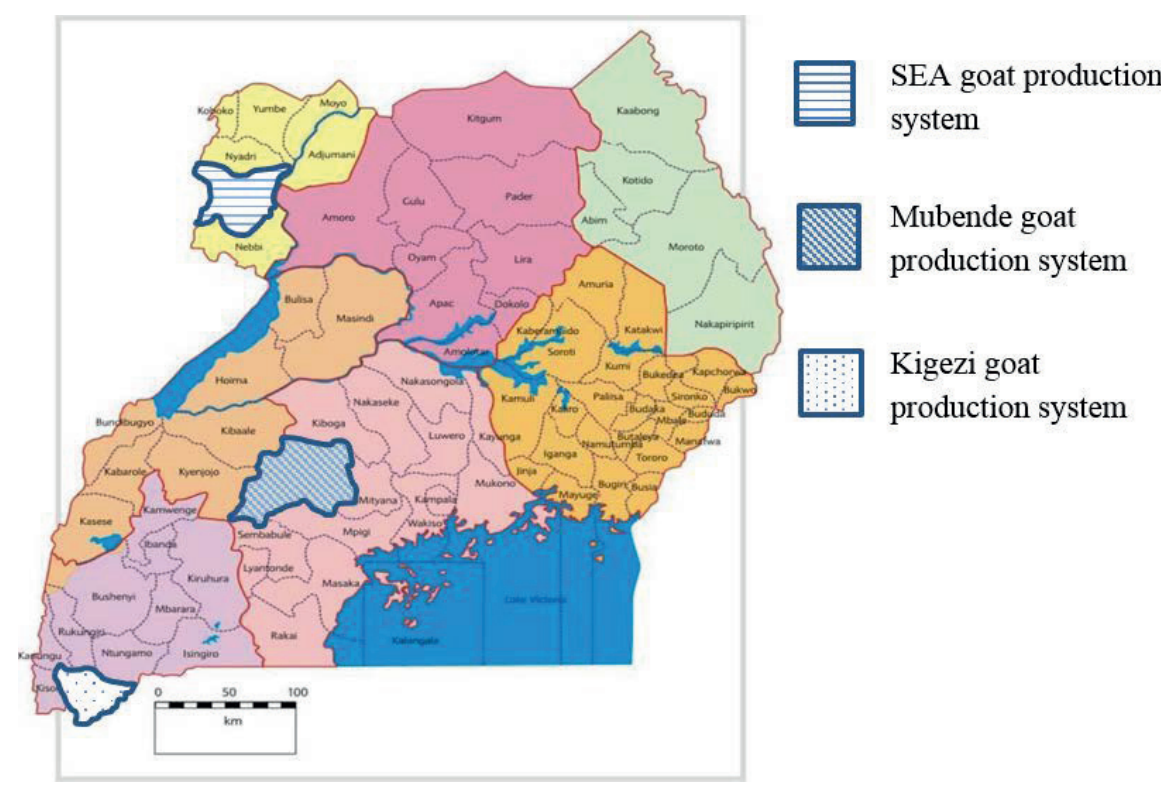

Figure 2.1 Map of Uganda showing the districts selected to characterize production systems for SEA, Mubende and Kigezi goats. 


\subsubsection{Scope of the study}

The sampling units from which interviews were conducted are presented in Table 2.1. In each district, at least one or two goat producing counties were chosen from which two sub-counties with a large population of goats were purposively selected to carry out the survey. From each sub-county a simple random sampling was done to select parishes and villages. From each village, households were then selected by random sampling to carry out individual interviews.

Table 2.1 Selected sub-counties, parishes, villages and respondents interviewed

\begin{tabular}{llllll}
\hline \multirow{2}{*}{$\begin{array}{l}\text { Production } \\
\text { system }\end{array}$} & \multicolumn{3}{l}{ Administrative sub-unit ${ }^{\text {a }}$} & & \\
\cline { 2 - 6 } & County & $\begin{array}{l}\text { Sub } \\
\text { counties }\end{array}$ & Parishes & Villages & Respondents \\
\hline Arua & Upper Madi & 2 & 5 & 10 & 78 \\
\multirow{2}{*}{ Mubende } & Okollo & & & & \\
& Kassanda & 1 & 3 & 7 & 33 \\
Kabale & Kasambya & 1 & 5 & 11 & 48 \\
& Ndorwa & 1 & 1 & 8 & 20 \\
& Rubanda & 1 & 2 & 10 & 38 \\
\hline
\end{tabular}

administrative units where the study was carried out with the numbers of sampled units in parentheses from the total numbers

In each selected sub-county, a focus group discussion (FGD) was carried out with key stakeholders in the communities (farmers, local leaders, extension agents) to obtain qualitative data in each of the three selected districts. The FGD process was guided by a set of open questions on agro-ecological conditions, goat populations, cropping systems, farmer engagements in goat production and the preferred traits considered by the farmers. These FGD's were crucial to get a better understanding of the community and helped in mapping out households selected for individual interviews, which provided the source for quantitative data. The survey was carried out by interviewers who had agricultural or veterinary training and originated from the ethnic communities of the districts selected. The interviewers filled out the questionnaires at the farm based on the oral answers to the questions given by the farmers. To have a harmonized understanding, the interviewers were trained during the pretesting sessions of the semi-structured questionnaires that were eventually used during the study. Based on the FGD's, a list of farmers with at least three goats was generated for each study site. Using a simple random sampling method, households were then selected from the village to administer the questionnaires. $A$ 
total of 78, 81 and 58 respondents were interviewed from Arua, Mubende and Kabale respectively representing the production systems for SEA, MUB and KIG goat breeds.

\subsubsection{Data collected}

Data collected during the household interview included general household characteristics on age stratum, level of education, land holding, flock structure, source of income in the household and the main activity the households were engaged in. Also, the production system descriptors based on type, reason for keeping goats, labour usage, management of stock and constraints to production were examined. Additionally, data were collected on seasonal variation in feed and water sources, production systems, goat ownership and diseases among others. On breeding, the breeding activities of the households, breeds used and preferred and reasons for preference were enumerated.

Using an individual trait preference approach, farmers ranked their preferred breeds for a set of criteria. They also ranked their flocks for traits they would desire to have in their preferred goats (breeding objectives). Briefly, the farmers were asked to rank their goats in order of preference for a predetermined list of traits and then ranked their flocks for all the traits in order of preference.

\subsubsection{Data analysis}

The data from filled out questionnaires were coded and analysed using SPSS version 23 to generate descriptive statistics (SPSS, 2015). To assess the statistical significance of the difference, chi square $\left(X^{2}\right)$ test was carried out on production system descriptors like farm size, livestock species kept, size of land, household size.

\subsubsection{Index based ranking}

Individual farmers ranked the criteria for selection of their best animals and a weighted ranking approach was adopted to determine the relative importance of each criterion. This approach was used for ranking livestock species kept, for reasons of keeping goats, ranking of important traits and constraints to production. The equations by (Bett et al., 2009b; Zonabend König et al., 2015) were adopted for the weighted criteria or indices (lj). 


$$
I_{j}=\sum_{i=1}^{3} r_{i} X_{i j} /\left(\sum_{j=1}^{n} \sum_{i=1}^{3} r_{i} X_{i j}\right)
$$

Where $X_{i j}$ is the number of respondents giving rank $i(i=1,2$ or 3$)$ to trait $j$, where $j=$ size of kids at birth, growth rate of the kids, size of adults, milking ability, carcass quality, heat tolerance, disease tolerance/resistance, kid survival, water requirement, temperament, marketing ease, prolificacy and mothering ability ( $\mathrm{n}$ traits). $r_{i}$ is the weight corresponding to rank $i$. Quantitatively, $r_{i}$ is assigned a weight of 3, 2 and 1 to $i=1,2$ and 3, respectively, to give the most important trait the highest index. The choice of (linear) weights is arbitrary and followed consistently from earlier studies on goats (Bett et al., 2009a; Bett et al., 2009b), pigs (Mbuthia et al., 2014), sheep (Mirkena et al., 2012; Zonabend König et al., 2015) and cattle (Kugonza et al., 2011). It should be noted that the index values are relative to each other with their sum $=1.00$. In words, the index value is the average relative preference or importance of an item. A spearman's rank correlation test was performed between the ranks to check for consistency in ranking within the districts by the respondents.

\subsection{Results}

\subsubsection{Farm and farmer characteristics}

Table $\mathbf{2 . 2}$ describes the characteristics of the farm and farmers. Indigenous goat production across the three districts was undertaken by households that were male dominated $(84.8 \%)$. The predominant age bracket of the household head was $30-$ 60 years $(72.8 \%)$ and most of the heads of household have had a formal education at primary school level (63.1\%). Almost two thirds of the households sampled for data collection did not consider livestock rearing as a major livelihood activity (Table 2.2) and almost half of the farm types across the three districts were categorised as communal, where the grazing land belonged to the community and animals from individual members of the community had equal access to utilizing it. However, at the individual districts level, while communal farms were predominant in Arua (82.1\%), in Mubende small scale commercial dominated.

Land is privately or communally owned with an average land holding of 10.77 ha per goat farming household. However, the average land holding in Mubende was significantly higher than in Arua and Kabale $(P<0.05)$. Average land holding per household allocated for grazing across the districts is approximately 7 ha, with a significantly higher allocation in Mubende district compared to Arua and Kabale. 
The main livestock species kept by the households included cattle, sheep, goats and poultry. The average flock size of the cattle and goats varied widely among the districts $(\mathrm{P}<0.05)$ and followed a similar pattern to the average land holding per household. Table $\mathbf{2 . 3}$ presents the ranking of livestock kept by the farmers. Goats (0.483) were the primary livestock kept by the visited smallholder farmers across all the three production systems, while cattle $(0.271)$ and poultry $(0.137)$ were ranked as secondary and third respectively. 


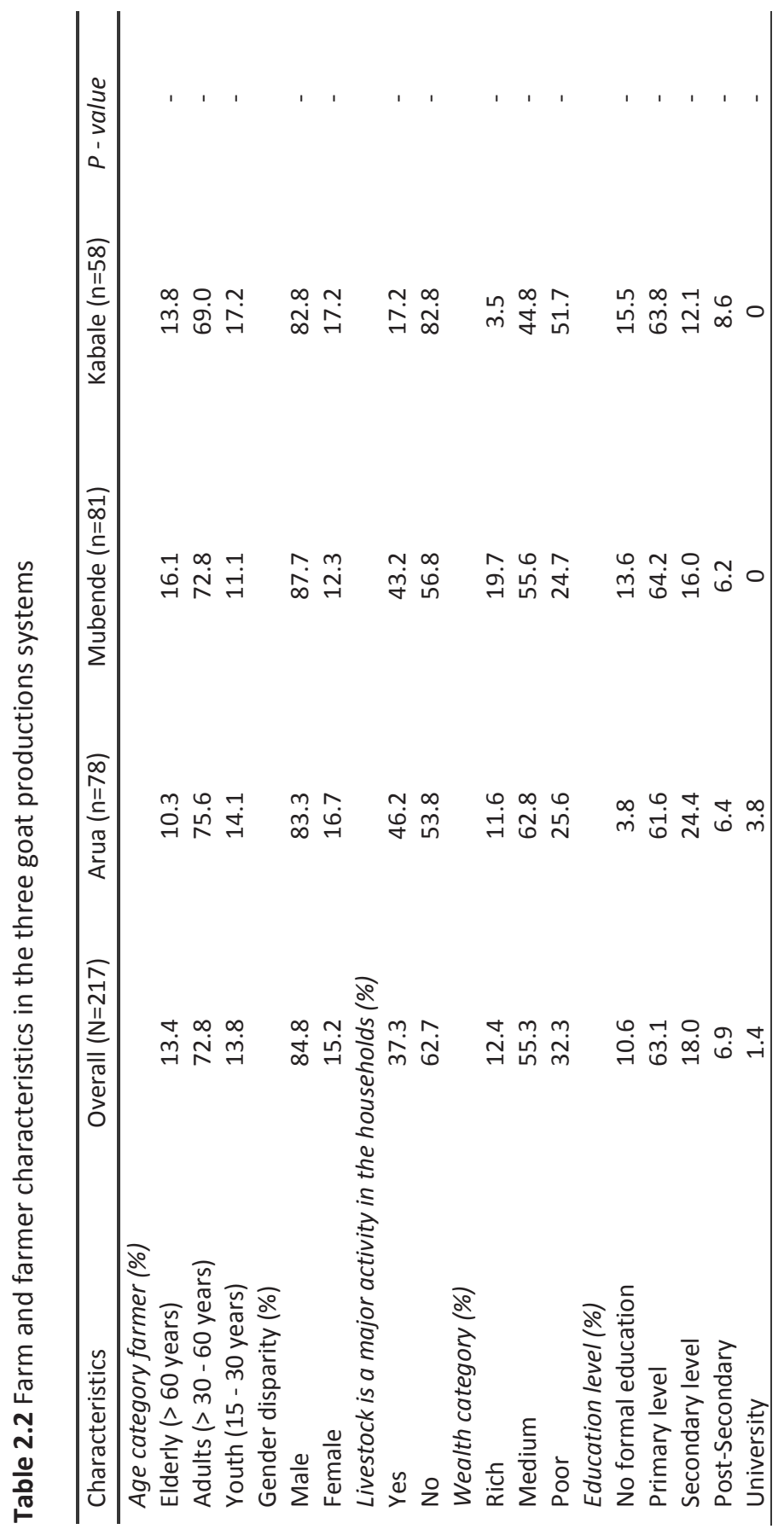




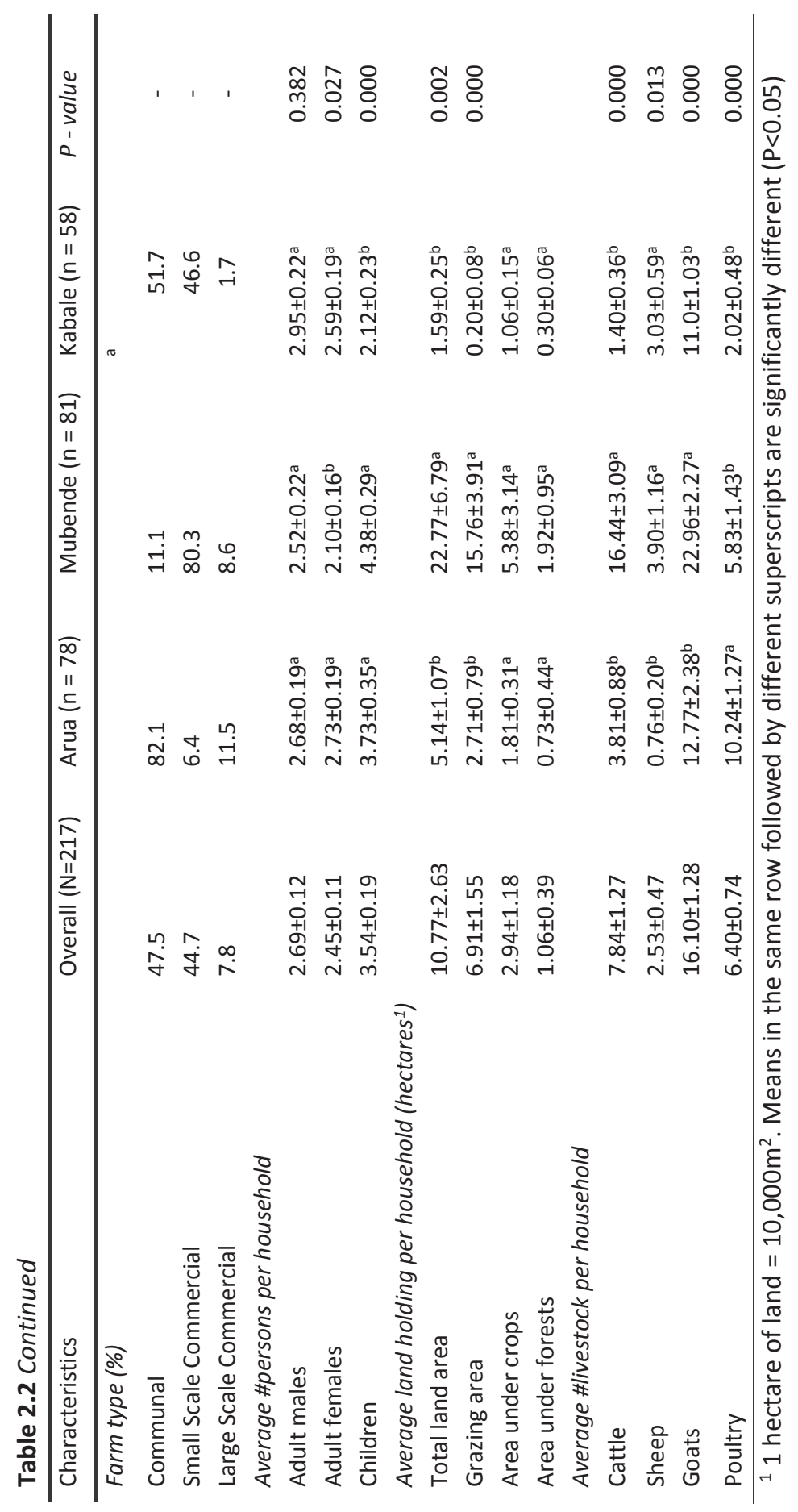


Table 2.3 Importance of livestock species kept by farmers in the three production systems

\begin{tabular}{|c|c|c|c|c|c|c|c|c|}
\hline \multirow{2}{*}{$\begin{array}{l}\text { Livestock } \\
\text { species }\end{array}$} & \multicolumn{2}{|c|}{ Overall } & \multicolumn{2}{|l|}{ Arua } & \multicolumn{2}{|c|}{ Mubende } & \multicolumn{2}{|c|}{ Kabale } \\
\hline & $W^{a}$ & Rank (I b) & $W^{a}$ & Rank (I b) & $W^{a}$ & Rank (I b) & $W^{a}$ & Rank ( $\left.{ }^{b}\right)$ \\
\hline Goats & 548 & 0.483 & 202 & 0.473 & 193 & 0.473 & 153 & 0.505 \\
\hline Cattle & 308 & 0.271 & 110 & 0.259 & 145 & 0.355 & 53 & 0.175 \\
\hline Poultry & 156 & 0.137 & 87 & 0.205 & 44 & 0.108 & 25 & 0.083 \\
\hline Sheep & 91 & 0.080 & 15 & 0.035 & 18 & 0.044 & 58 & 0.191 \\
\hline Pigs & 31 & 0.027 & 9 & 0.021 & 8 & 0.020 & 14 & 0.046 \\
\hline Rabbits & 1 & 0.001 & 1 & 0.002 & 0 & 0.000 & 0 & 0.000 \\
\hline
\end{tabular}

${ }^{a}$ WR is sum total of the product of households giving a rank to a particular livestock species

${ }^{\mathrm{b}} \mathrm{I}$ is the index value and the livestock species with the highest index value is the most important to the farmers participating in the production system.

\subsubsection{Reasons for rearing goats}

Table 2.4 presents the ranking of reasons why goats are the species of choice. The overriding reason for keeping goats in all three districts is cash derived from sale of live animals (0.442), followed distantly by socio-cultural benefits $(0.162)$ and meat for home consumption (0.152). At each production system, there was distinct use attached to the goats with cash from livestock sales overriding in Kigezi and Mubende system, while socio-cultural use was considered the most important reason for SEA in Arua. Manure was considered an important output under the Kigezi goat production system while milk production from goats was considered unimportant in all production systems. 


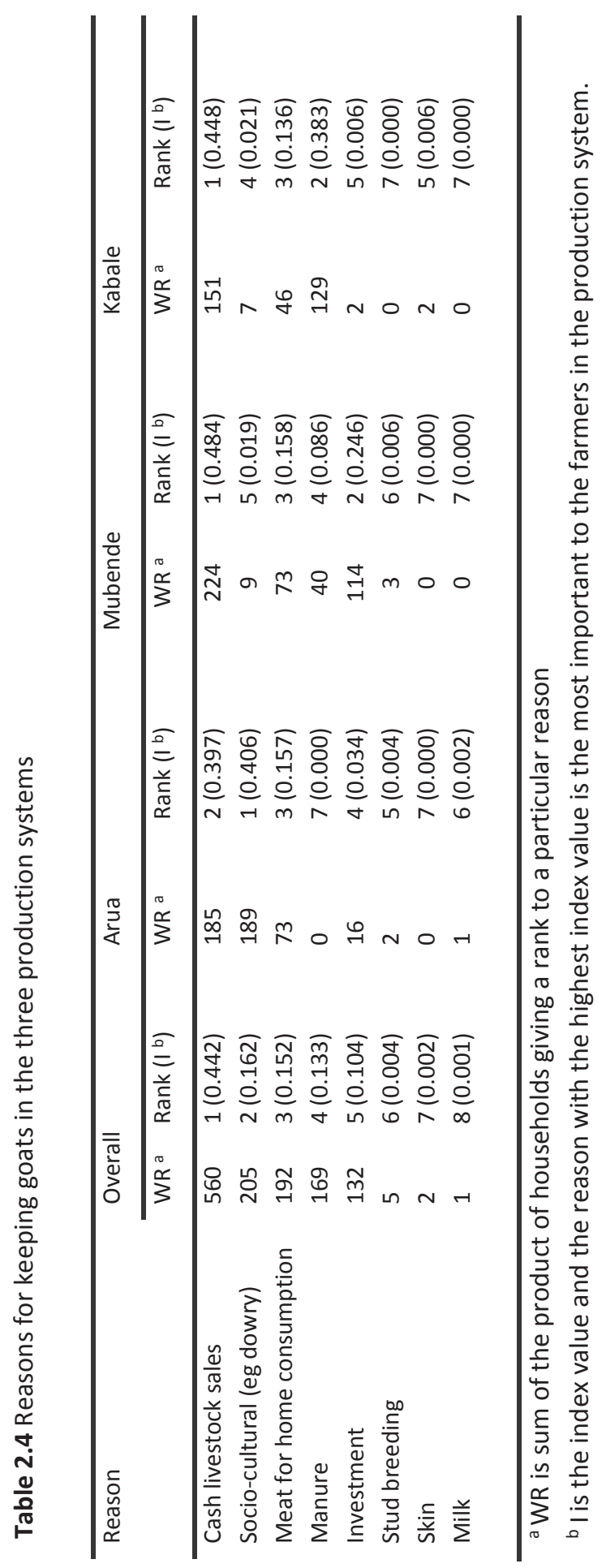




\subsubsection{Farmer preferred trait ranking}

Table 2.5 summarises the outcomes of the trait preferences by the farmers. Overall, disease tolerance/resistance (0.095) is considered the most important trait, followed closely by heat tolerance (0.093) and kid survival (0.089). Good carcass quality (0.089), good mothering ability (0.086), ease of marketing $(0.085)$, prolificacy $(0.083)$ and lower water need $(0.083)$ were some other important traits considered by the farmers across the three production systems studied. Disease tolerance was considered the primary reason for keeping goats in SEA (0.096) and Kigezi (0.097) goat production systems, while disease tolerance and heat tolerance were considered equally important Mubende goats (0.094).

Generally all traits, except milk production, were considered important, but adaptation traits were ranked higher than production traits across the three production systems studied. There was relatively high correlation in ranking across the production systems studied. The correlations in the ranks varied from 0.684 to 0.917. There highest correlation in the rankings by respondents was found in Mubende and moderate in Arua and Kabale.

\subsubsection{Constraints to goat production}

Table 2.6 summarises goat production constraints recognized by the farmers interviewed. Farmers generally consider diseases by far as the most important constraint affecting production of goats. Particularly of economic importance are diseases due to gastrointestinal nematodes Haemonchus contortus. Limited grazing areas, lack of good quality pastures, parasites and poor veterinary/ extension services were the other important reasons considered by the farmers as constraints to production of goats across the three production systems. The medium ranked constraints to production considered were theft of stock, lack of watering sources, labour, lack of veterinary drugs and limited capital for expansion. Poor housing, quality of the breeds, harsh weather conditions, predators and marketing challenges were also mentioned by the farmers, but these generally ranked low as constraints to production. 


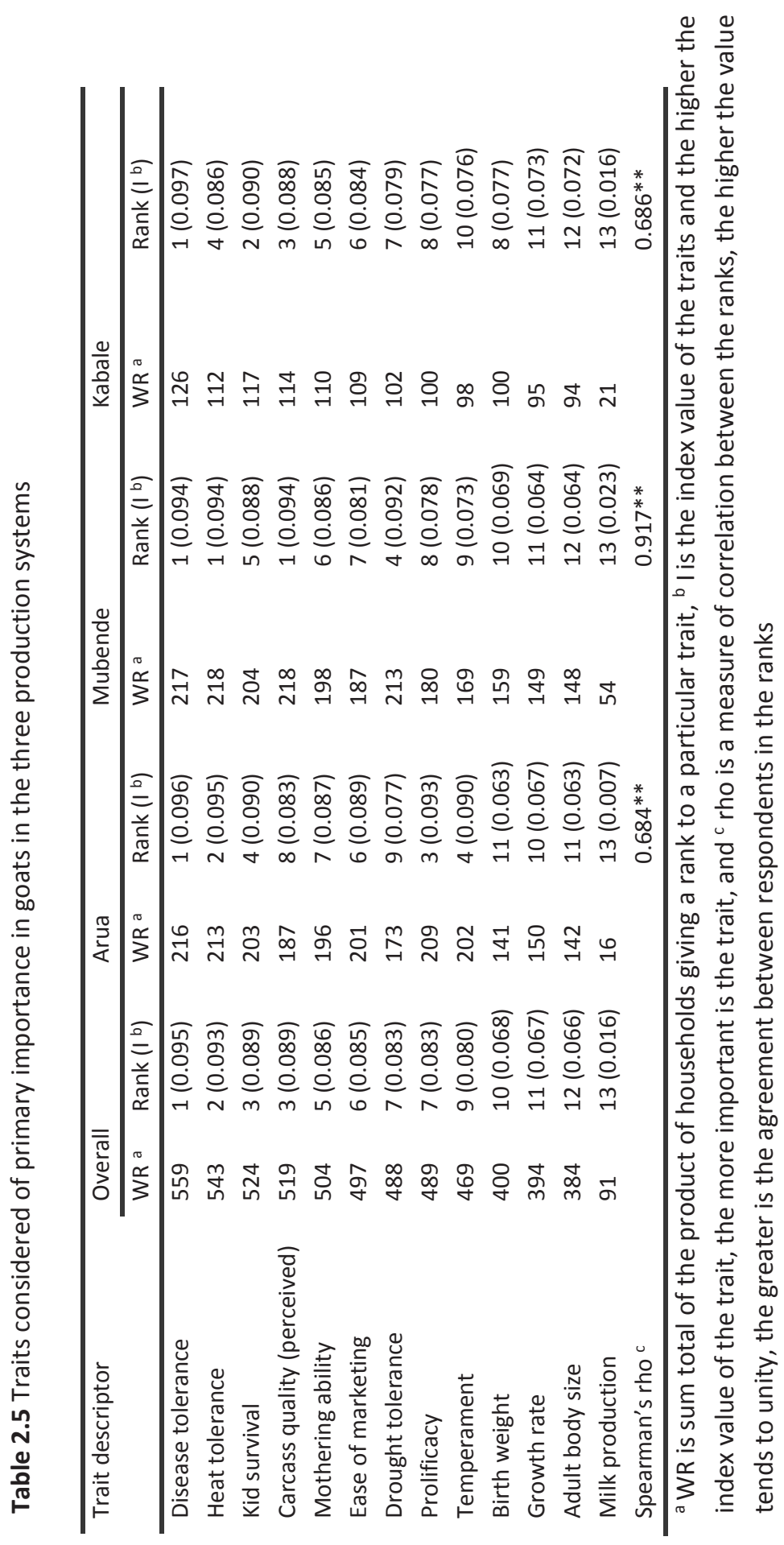




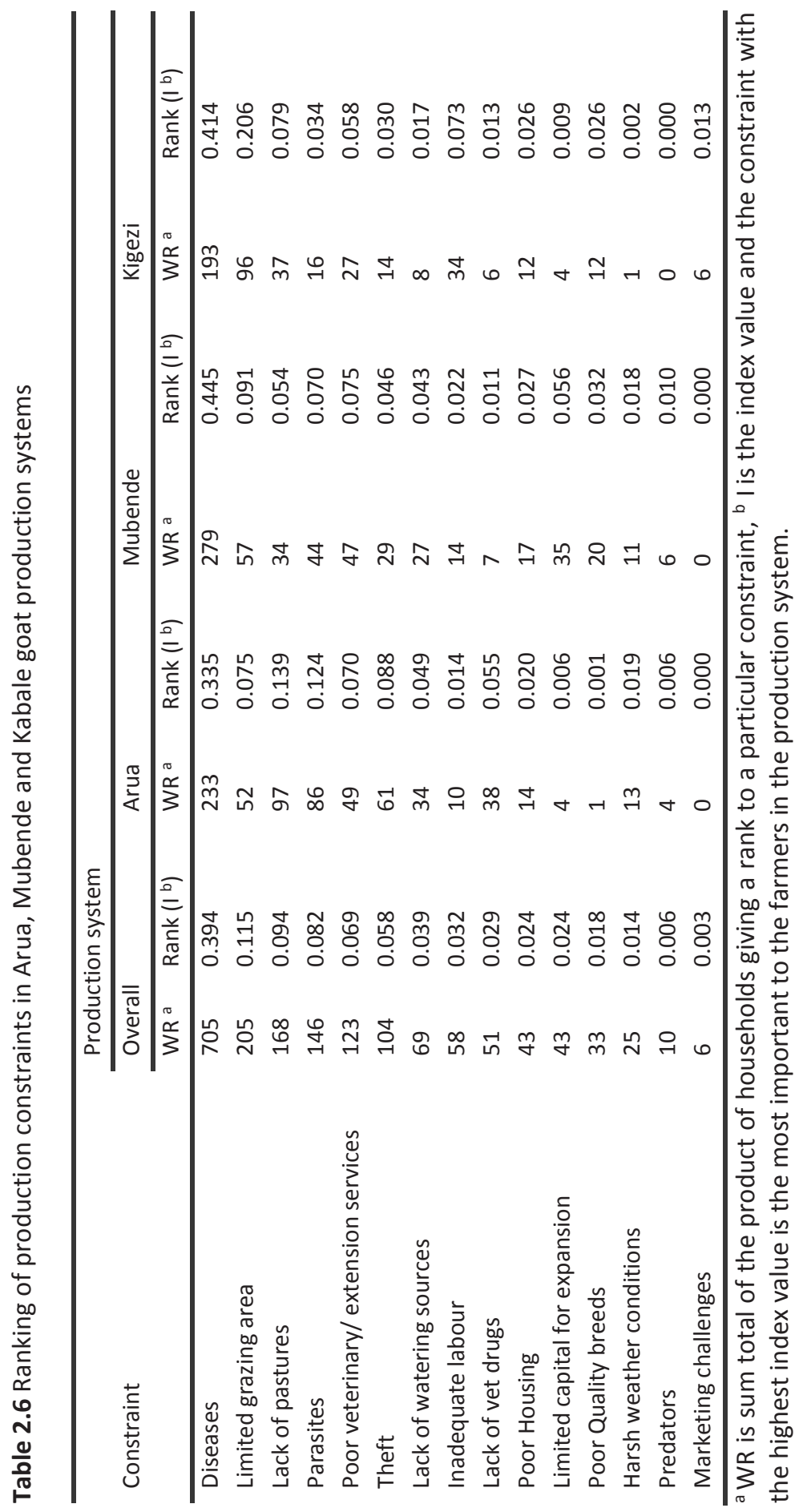




\subsection{Discussion}

The need to understand the production environment in which indigenous goats must produce cannot be over emphasized. In designing a holistic and sustainable breed improvement program, it is of paramount importance to unravel the characteristics of the production environment. Various approaches have been proposed, however the use of participatory approaches involving farmers has been successful in characterization of livestock production systems in Africa. The present study was therefore designed on the model of participatory approaches in assessing the production system characteristics and trait preferences for breed improvement programs for indigenous goats of Uganda.

\subsubsection{Farm and farmer characteristics}

Crop and livestock production constitutes the main livelihood activities of the households that participated in this study. This dependency of rural livelihoods on crop and livestock production is widespread in developing countries (Okeno et al., 2011; Osei-Amponsah et al., 2011). Despite the wide spread production of livestock, it is not considered the main livelihood activity of most of the smallholder farmers in the present study. Among reasons advanced for the low consideration of livestock as a main livelihood activity include small land holdings and land fragmentation. For example, only $17.2 \%$ of farmers interviewed in Kabale engaged in livestock production for livelihood.

The low-income level and the subsistence nature of the smallholder farmers in this study, may have influenced the choice of a primary livelihood activity. Livestock production is considered income intensive activity beyond the reach of most of the smallholder farmers. This may have further influenced the choice of livelihood activities. The results of this study sharply contrast with those in smallholder and pastoral areas of Kenya and Ethiopia, where livestock was considered a primary activity (Kosgey et al., 2008; Abegaz, 2014).

While in the medium to low potential areas of Mubende commonly referred to as the cattle corridor, livestock production was mainly undertaken by few prosperous farmers who owned large farms. The average land holdings were significantly larger in Mubende compared to Arua and Kabale. These differences have implications for developing suitable breeding programs. The cattle corridor region of Uganda, where Mubende goats are found, is predominantly covered by savanna vegetation characterized by shrubs of Acacia hockii whose leaves are rich in crude protein (Ondiek et al., 2010). This area is seen as a high potential area for ranching due to 
abundance of grazing area for livestock. Grazing of livestock is mainly carried out on communal areas, although there is a shift to private ownership in locations that are becoming commercially oriented. The shift in the farmers' production objective towards generating income other than subsistence may have partly contributed to land ownership patterns being observed in Mubende, while in Arua where the overriding reason for keeping goats was socio-cultural, the farms were predominantly communal in nature. The high average land holding in Mubende makes sense for commercial livestock production, thus influencing the farm types that have developed.

Goats were considered a primary livestock across the three production systems (Table 2.3). They are easier to manage by smallholder farmers and are thus preferred over cattle in the production systems under study. Goats require less input in feeds and general management and yet provide an important source of liquid cash due to their small size, which makes them easier to dispose for tangible and intangible benefits. The perception of smallholder farmers is that goats can easily adapt to adverse environmental conditions and are less prone to disease outbreaks, therefore considered less risky to keep than cattle. The importance attached to goats in this study is consistent with the findings of Hassen and Tesfaye (2014) who found that goats were highly ranked in pastoral and agro-pastoral areas of Ethiopia. However, it is important to note that sheep was perceived to be a sacred animal and thus not considered for primary livestock production.

The average herd size for cattle and goats was significantly larger $(P<0.05)$ in Mubende compared to Arua and Kabale. The high average herd size in Mubende may be attributed to the availability of land and the importance attached to cattle and goats to feed the urban population in Kampala and surrounding districts. The availability of urban markets and large suitable grazing areas has implications for the type of breeding programs to be developed.

\subsubsection{Reasons for keeping goats}

Across the production systems studied, indigenous goats played a multifaceted role with the farmers. The multifunctional role is considered vital to maximize benefits derived from the goats under the stressful environment in which they have to produce (Gizaw et al., 2010; Edea et al., 2012). Although goats played a multipurpose role across the three production systems, income generation was considered the overriding goal of keeping goats. This was realized mainly through the sale of live animals. This finding concurs with other studies in developing countries that 
underscore the importance of livestock in generating income for the farmers (Kosgey et al., 2008; Semakula et al., 2010a; Semakula et al., 2010b; Kugonza et al., 2011; Okeno et al., 2011). The income derived from goats was used for accessing education, health and other basic needs of the households.

However, there was a marked difference in the purpose of keeping goats between the production systems with the predominantly subsistence communities, prioritizing non-tangible benefits like cultural values other than income generation. Income generation function was predominant in the Mubende and Kabale production systems compared to Arua production system, where the cultural value of goats was overriding. For a successful implementation of any meaningful breed improvement programs, consideration of socio-cultural roles of goats with the farmers will be very crucial in the short to medium term (Verbeek et al., 2007; Kosgey et al., 2008).

Milk production from goats is considered an inferior reason although the role of goat milk in the nutrition security of pregnant mothers, malnourished children and sick people has been underscored (Haenlein, 2004). The consumption of goat's milk is generally considered a cultural taboo and was unpopular among the farmers. This agrees with findings from a study on two indigenous goat breeds in Ethiopia (Abegaz, 2014). However, this finding contradicts with a study with pastoral communities in Ethiopia and Kenya where milk was considered the primary objective for keeping small ruminants, since the milk was considered a stable diet for the pastoralists (Kosgey et al., 2008; Hassen and Tesfaye, 2014).

Manure production was considered an important reason in the Kigezi goat production system of south western highlands. Similarly, earlier studies with smallholder farmers have also ranked manure highly (Kosgey et al., 2008). Goats manure is generally considered useful in enhancing soil fertility for vegetable production. Mineralization of goats manure results in organic nitrogen and phosphorous, and is therefore a cheap source of organic fertilizer for vegetable production (Nziku et al., 2016). The importance of manure has also been highlighted in production of cash crops under sheep-barley production system in Ethiopia (Gizaw et al., 2010; Tadesse et al., 2013).

It is noteworthy to recognize that the socio-economic and cultural role of goats in the present study is not unique, but confirms findings from similar studies with sheep and goats in Ethiopia (Gizaw et al., 2010; Abegaz, 2014), small ruminants in Kenya (Kosgey et al., 2008) and in Ankole cattle in Uganda (Wurzinger et al., 2006). 


\subsubsection{Farmer preferred trait ranking}

The involvement of farmers in assessing breeding objectives and designing breeding programs is crucial for success of livestock improvement programs (Mueller et al., 2015). The use of preferences based on weightings or indices has become a powerful tool for farmers to rank their own animals in a rather objective and accurate manner. Various studies have employed this participatory approach to provide information for developing breeding objectives for goats in Ethiopia (Gebreyesus et al., 2013), dairy goats (Bett et al., 2009a; Bett et al., 2009b) and red Maasai sheep in Kenya (Zonabend König et al., 2015) and recently for Nile tilapia (Omasaki et al., 2016).

Adaptation traits (resistance/ tolerance to diseases, heat tolerance, drought tolerance) in goats was considered very important by farmers compared to production traits (growth rate, birth weight, adult body weight, milk yield) across the three regions. Small holder farmers in the current study tended to be risk averse and the need for survival of the goats was considered critical. In a recent study with West African Dwarf goats, disease resistance was similarly considered an important preference criterion (Ogah, 2016). Across the three production systems, there was generally a higher preference for adaptation traits in Arua and Kabale compared to Mubende which is seemingly more market oriented due to presence of an urban market in the capital city Kampala. Adaptation traits have particularly been considered important in resource driven production systems of smallholders (Roessler et al., 2008). The current study underscores the importance of adaptation traits like disease resistance and recognises that these traits are equally or more important than production traits. The findings from this study are in line with those of previous studies in Ethiopia by Gizaw et al. (2010) and recently in Somalia by Marshall et al. (2016). It is therefore important to note that a critical understanding of the adaptation traits and including them in the breeding goal is vital for developing sustainable improvement programs. However, selection for adaptation traits may be more complicated, unless if they are considered as composite traits correlated with production performance of the animals.

Although, highly adapted animals were desired, the farmers were cognizant of the need for income from sales of live animals. Therefore, an increased body size and growth rate were substantially ranked by the farmers. Similarly in a recent study, small ruminant farmers in Nyando basin in Kenya expressed the desire for large and resilient animals (Ojango et al., 2016). Large animals were particularly desired for the market-oriented farmers in Mubende, since they were easily sold and fetched better prices. Production traits, particularly body size and growth rate, were also substantially ranked in an earlier study with goats in Uganda (Semakula et al., 
2010b). However, in low input smallholder production systems like in Arua in this study, the use of agro-inputs and access to professional veterinary/ agricultural extension services was often limiting. The farmers tended to rely heavily on robust animals that are adapted to environmental stresses like disease, drought, heat and poor-quality feeds. Generally, indigenous goat breeds were perceived to be superior over their exotic counterparts in survival traits and economic performance. These findings are consistent with those of Ayalew et al. (2003) and Onzima et al. (2014) who found that indigenous goat breeds performed better than their exotic counterparts under tropical environments. Similarly, these findings further support the ideas of Philipsson et al. (2006) and Kugonza et al. (2011), who suggest that the ability to utilise low quality feed resources and, resist diseases and environmental stress explains why indigenous livestock breeds outperform exotic breeds in economic performance.

\subsubsection{Constraints to goat production}

Diseases were considered a very important constraint affecting goat production. Limitation to productivity of goats is presented by diseases caused by gastrointestinal (GI) nematodes, mainly Haemonchus contortus. This parasite is most prevalent and devastating in Uganda and the rest of sub-Saharan Africa (Nsereko et al., 2015). The need for effective control of infection is of paramount importance. Unfortunately, smallholders are resource constrained and an animal that is adapted to the challenge by GI nematodes is highly desired. Limited grazing area in the highly dense regions was another important constraint mentioned by the farmers. This study has similarly shows that feeds, diseases and water scarcity are important constraints to goat production, which agrees with earlier findings in Ethiopia (Gizaw et al., 2010; Tadesse et al., 2013) and Uganda (Semakula et al., 2010a). It is therefore important that these constraints are taken into consideration when developing a breed improvement program.

\subsection{Conclusion}

This study has brought out the characteristics of three production systems for goat production in Uganda. Participatory approaches may be useful in identifying key farmer preferences for traits crucial for sustainable breed improvement programs for indigenous goats. This study has highlighted the main reasons for keeping goats by smallholder farmers and major constraints to consider in the design and implementation of effective breed improvement programs for goats in Uganda. The study has shown the importance of adaptation traits, particularly related to disease resistance and environmental stresses, for consideration alongside key production 
objectives, if a successful and sustainable breeding program is to be developed for improving indigenous goat breeds of Uganda.

Finally, it is important that the farmer preferences identified in this study are included in breeding objectives and selection criteria for goats in the production systems.

\subsection{Acknowledgements}

This study was conducted under the auspices of Animal Breeding and Genomics Centre, Graduate School Wageningen Institute of Animal Science (WIAS), Wageningen University and Research. We are grateful for funding from National Agricultural Research Organization (NARO) through world bank supported project, Agricultural Technology and Agribusiness Advisory Services (ATAAS) (P109224). The authors are grateful to Denis Asizua, Robert Mukiibi and Katali K. Benda from NARO for assistance in data collection and editing, and the administrative staff for the logistical support. We greatly acknowledge field enumerators and government extension staff at the sub-counties visited for data collection. The smallholder farmers who allowed their farms to be used for the study are greatly honoured.

\section{References}

Abegaz, S.G., 2014. Design of community based breeding programs for two indigenous goat breeds in Ethiopia, Ph.D. Thesis. BOKU University of Natural Resources and Life Sciences, Austria, $100 \mathrm{pp}$.

Ayalew, W., Rischkowsky, B., King, J.M., Bruns, E., 2003. Crossbreds did not generate more net benefits than indigenous goats in Ethiopian smallholdings. Agricultural Systems 76, 1137-1156.

Bett, R.C., Bett, H.K., Kahi, A.K., Peters, K.J., 2009a. Evaluation and effectiveness of breeding and production services for dairy goat farmers in Kenya. Ecological Economics 68, 2451-2460.

Bett, R.C., Kosgey, I.S., Kahi, A.K., Peters, K.J., 2009b. Analysis of production objectives and breeding practices of dairy goats in Kenya. Tropical Animal Health and Production 41, 307-320.

Duguma G, Mirkena T, Haile A, Iñiguez L, Okeyo A M, Tibbo M, Rischkowsky B, Sölkner J and Wurzinger M 2010: Participatory approaches to investigate breeding objectives of livestock keepers. Livestock Research for Rural Development. Volume 22, Article \#64. Retrieved January 16, 2017, from http://www.Irrd.org/Irrd22/4/dugu22064.htm. 
Edea, Z., Haile, A., Tibbo, M., Sharma, A.K., Solkner, J., Wurzinger, M., 2012. Sheep production systems and breeding practices of smallholders in western and south-western Ethiopia: Implications for designing community-based breeding strategies. Livestock Research for Rural Development 24, Article \#117. Retrieved August 11, 2016, from http://www.Irrd.org/ Irrd2024/2017/edea24117.htm.

Ensminger, M.E., Parker, R.O., 1986. Sheep and Goat Science. The Interstate Printers and Publishers Inc., Danville, Illinois.

Food and Agriculture Organization (FAO), 2004. Secondary guidelines for development of national farm animal genetic resources management plans Measurement of Domestic Animal Diversity (MoDAD): Recommended microsatellite markers. Rome, Italy.

Food and Agriculture Organization (FAO), 2009. Status and trends report on animal genetic resources 2008., Commission on Genetic Resources for Food and Agriculture. Rome, Italy.

Food and Agriculture Organization (FAO), 2011. Draft guidelines on developing the institutional framework for the management of animal genetic resources., Commission on Genetic Resources for Food and Agriculture. FAO, Rome.

Food and Agriculture Organization (FAO), 2015. The Second Report on the State of the World's Animal Genetic Resources for Food and Agriculture. In: Scherf, B.D., Pilling, D. (Eds.), FAO Commission on Genetic Resources for Food and Agriculture Assessments. Rome, Italy.

Food and Agriculture Organization Statistics (FAOSTAT), 2014. Food and Agriculture Organization Statistics. Rome, Italy. faostat3.fao.org/home/E (retrieved on 9th May 2016).

Gebreyesus, G., Haile, A., Dessie, T., 2013. Breeding scheme based on communitybased participatory analysis of local breeding practices, objectives and constraints for goats around Dire Dawa, Ethiopia. Livestock Research for Rural Development 25, Article \#48. Retrieved April 29, 2016, from http:// www.Irrd.org/Irrd2025/2013/grum25048.htm.

Gizaw, S., Komen, H., van Arendonk, J.A.M., 2010. Participatory definition of breeding objectives and selection indexes for sheep breeding in traditional systems. Livestock Science 128, 67-74.

Haenlein, G.F.W., 2004. Goat milk in human nutrition. Small Ruminant Research 51, 155-163.

Hassen, A.S., Tesfaye, Y., 2014. Sheep and goat production objectives in pastoral and agro-pastoral production systems in Chifra district of Afar, Ethiopia. Tropical Animal Health and Production 46, 1467-1474. 
Kahi, A.K., Rewe, T.O., Kosgey, I.S., 2005. Sustainable community-based organizations for the genetic improvement of livestock in developing countries. Outlook on Agriculture 34, 261-270.

Kosgey, I.S., 2004. Breeding objectives and breeding strategies for small ruminants in the tropics, Ph.D. Thesis. Wageningen University, The Netherlands. 272 pp.

Kosgey, I.S., Baker, R.L., Udo, H.M.J., Van Arendonk, J.A.M., 2006. Successes and failures of small ruminant breeding programmes in the tropics: A review. Small Ruminant Research 61, 13-28.

Kosgey, I.S., Rowlands, G.J., van Arendonk, J.A.M., Baker, R.L., 2008. Small ruminant production in smallholder and pastoral/extensive farming systems in Kenya. Small Ruminant Research 77, 11-24.

Kugonza, D.R., Bareeba, F.B., Kirembe, G., 2001. Characterization of meat goat management systems in three districts of central Uganda. MUARIK Bulletin, Kampala, Uganda, pp. 26 - 29.

Kugonza, D.R., Nabasirye, M., Hanotte, O., Mpairwe, D., Okeyo, A.M., 2011. Pastoralists' indigenous selection criteria and other breeding practices of the long-horned Ankole cattle in Uganda. Tropical Animal Health and Production 44, 557-565.

MAAIF, 2010. Agricultural Sector Development Strategy and Investment Plan (DSIP) 2010/11-2014/15. Ministry of Agriculture Animal Industry and Fisheries (MAAIF), Entebbe, Uganda.

MAAIF, 2011. Statistical Abstract. Ministry of Agriculture Animal Industry and Fisheries (MAAIF), Entebbe, Uganda.

Marshall, K., Mtimet, N., Wanyoike, F., Ndiwa, N., Ghebremariam, H., Mugunieri, L., Costagli, R., 2016. Traditional livestock breeding practices of men and women Somali pastoralists: trait preferences and selection of breeding animals. Journal of Animal Breeding and Genetics, 133, 534-547.

Mason, I.L., Maule, J.P., 1960. The Indigenous livestock of eastern and southern Africa. Commonwealth bureau of animal breeding and genetics. $C A B$ (Commonwealth Agricultural Bureaux), UK.

Mbuthia, J.M., Rewe, T.O., Kahi, A.K., 2014. Evaluation of pig production practices, constraints and opportunities for improvement in smallholder production systems in Kenya. Tropical Animal Health and Production 47, 369-376.

Mirkena, T., Duguma, G., Willam, A., Wurzinger, M., Haile, A., Rischkowsky, B., Okeyo, A.M., Tibbo, M., Solkner, J., 2012. Community-based alternative breeding plans for indigenous sheep breeds in four agro-ecological zones of Ethiopia. Journal of Animal Breeding and Genetics 129, 244-253. 
Mueller, J.P., Rischkowsky, B., Haile, A., Philipsson, J., Mwai, O., Besbes, B., Valle Zárate, A., Tibbo, M., Mirkena, T., Duguma, G., Sölkner, J., Wurzinger, M., 2015. Community-based livestock breeding programmes: essentials and examples. Journal of Animal Breeding and Genetics 132, 155-168.

Nsereko, G., Emudong, P., Mulindwa, H., Okwee-Acai, J., 2015. Prevalence of common gastro-intestinal nematode infections in commercial goat farms in Central Uganda. Uganda Journal of Agricultural Sciences 16, 99-106.

Nsubuga, H.S.K., 1996. Small Ruminant: Goats and Sheep in Uganda:. In: Lebbie S.H.B and Kagwini, E. (Ed.), Small Ruminant Research and Development in Africa. Third Biennial Conference of the African Small Ruminant Research Network. ILRI (International Livestock Research Institute) Nairobi, Kenya, UICC, Kampala Uganda 5 - 6th December,1994, pp. 326.

Nziku, Z.C., Kifaro, G.C., Eik, L.O., Steine, T., Ådnøy, T., 2017. Reasons for keeping dairy goats in Tanzania, and possible goals for a sustainable breeding program. Animal Production Science 57, 338-346.

Ogah, D.M., 2016. Breeding strategies for indigenous goat genetic resources among smallholder farmers in north-central Nigeria. Livestock Research for Rural Development. 28, Article \#60. Retrieved April 29, 2016, from http:// www.Irrd.org/Irrd2028/2014/ogah28060.html

Ojango, J.M.K., Audho, J., Oyieng, E., Recha, J., Okeyo, A.M., Kinyangi, J., Muigai, A.W.T., 2016. System characteristics and management practices for small ruminant production in "Climate Smart Villages" of Kenya. Animal Genetic Resources 58, 101-110.

Okeno, T.O., Kahi, A.K., Peters, K.J., 2011. Characterization of indigenous chicken production systems in Kenya. Tropical Animal Health and Production 44, 601608.

Omasaki, S.K., van Arendonk, J.A.M., Kahi, A.K., Komen, H., 2016. Defining a breeding objective for Nile tilapia that takes into account the diversity of smallholder production systems. Journal of Animal Breeding and Genetics, 133, 404- 413.

Ondiek, J.O., Abdulrazak, S.A., Njoka, E.N., 2010. Chemical and mineral composition, in-vitro gas production, in-sacco degradation of selected indigenous Kenyan browses. Livestock Research for Rural Development. 22. Article \#25 Retrieved April 21, 2016, from http://www.Irrd.org/Irrd2022/2012/ondi22025.html

Osei-Amponsah, R., Kayang, B.B., Naazie, A., Arthur, P.F., Barchia, I.M., 2011. Characterisation of local Ghanaian chickens: growth performance evaluation based on Richards growth model and genetic size scaling. Tropical Animal Health and Production 43, 1195-1201. 
Philipsson, J., Rege, J.E.O., Okeyo, A.M., 2006. ILRI-SLU Animal Genetics Training Resource, CD Version 2. ILRI (International Livestock Research Institute, Nairobi, Kenya, and SLU (Swedish University of Agricultural Sciences), Uppsala, Sweden.

Roessler, R., Drucker, A.G., Scarpa, R., Markemann, A., Lemke, U., Thuy, L.T., Valle Zárate, A., 2008. Using choice experiments to assess smallholder farmers' preferences for pig breeding traits in different production systems in NorthWest Vietnam. Ecological Economics 66, 184-192.

Semakula, J., Mutetikka, D., Kugonza, D.R., Mpairwe, D., 2010a. Comparison of Breeding Systems by Smallholder Goat Keepers in the Humid, Sub-Humid and Semi Arid Ecological Zones of Uganda. Agricultural Journal 5, 89-97.

Semakula, J., Mutetikka, D., Kugonza, R.D., Mpairwe, D., 2010b. Smallholder goat breeding systems in humid, sub-humid and semi arid agro-ecological zones of Uganda. Global Veterinaria 4, 283-291.

SPSS, 2015. IBM Corp. Released 2015. IBM SPSS Statistics for Windows, Version 23.0. Armonk, NY: IBM Corp.

Tadesse, D., Urge, M., Animut, G., Mekasha, Y., 2013. Perceptions of households on purpose of keeping, trait preference, and production constraints for selected goat types in Ethiopia. Tropical Animal Health and Production 46, 363-370.

UBOS, 2015. Statistical Abstract, Uganda Bureau of Statistics. Kampala, Uganda.

UBOS and MAAIF, 2009. National Livestock Census Report, Ministry of Agriculture Animal Industry and Fisheries (MAAIF) and Uganda Bureau of Statistics.

Verbeek, E., Kanis, E., Bett, R.C., Kosgey, I.S., 2007. Socio-Economic factors affecting small ruminant breeding in Kenya. Livestock Research for Rural Development 19, Article \#77 Retrieved August 7, 2016, from http://www.Irrd.org/ Irrd2019/2016/verb19077.html

Wurzinger, M., Ndumu, D., Baumung, R., Drucker, A., Okeyo, A.M., Semambo, D.K., Byamungu, N., Sölkner, J., 2006. Comparison of production systems and selection criteria of Ankole cattle by breeders in Burundi, Rwanda, Tanzania and Uganda. Tropical Animal Health and Production 38, 571-581.

Wurzinger, M., Sölkner, J., Iñiguez, L., 2011. Important aspects and limitations in considering community-based breeding programs for low-input smallholder livestock systems. Small Ruminant Research 98, 170-175.

Zonabend König, E., Mirkena, T., Strandberg, E., Audho, J., Ojango, J., Malmfors, B., Okeyo, A.M., Philipsson, J., 2015. Participatory definition of breeding objectives for sheep breeds under pastoral systems - the case of Red Maasai and Dorper sheep in Kenya. Tropical Animal Health and Production 48, 9-20. 


\section{Between-breed variations in resistance/ resilience to gastrointestinal nematodes among indigenous goat breeds in Uganda}

R. B. Onzima ${ }^{1,2}$, R. Mukiibi ${ }^{3}$ A. Ampaire ${ }^{2}$, K. K. Benda ${ }^{2}$, E. Kanis ${ }^{1}$

${ }^{1}$ Wageningen University \& Research - Animal Breeding and Genomics, P. O. Box 338, 6700AH Wageningen, The Netherlands; ${ }^{2}$ National Agricultural Research Organization (NARO), P. O. Box 295, Entebbe, Uganda; ${ }^{3}$ Department of Agriculture,

Food and Nutritional Sciences (AFNS), Faculty of Agriculture, Life and Environmental Sciences, University of Alberta, 1416 College Plaza, T6G 2C8 Alberta, Canada

Tropical Animal Health and Production (2017) 49:1763-1769

DOI 10.1007/s11250-017-1390-9 


\section{Abstract}

Gastrointestinal nematodes (GINs), Haemonchus contortus, are a major health problem in goat production. Resistance to $H$. contortus, the most prevalent GIN in Uganda, was studied among three indigenous goat breeds to assess their differences. Twelve male goats of each breed approximately 7 months old of small East African (SEA), Mubende, and Kigezi goats from smallholder farmers in Arua, Mubende, and Kabale were assembled for the study.

At the station, they were dewormed with a combination therapy of the broadspectrum dewormers closantel and albendazole to free the goats of gastrointestinal parasites.

During experimentation, the goats were kept indoors and adlibitum fed on clean banana peels and Napier grass. On attainment of zero-worm-egg status, the goats were artificially infected with 18,000 third-stage (L3) larvae of $H$. contortus prepared according to Baermann's procedure. Data were collected on faecal egg count (FEC), packed cell volume (PCV), and body weight (BW) on a 2-week basis until 12 weeks post infection and carcass weight and total worm count (WC) in the abomasum at termination of the experiment. The data on FEC, PCV, and BW were subjected to repeated-measure analysis of variance and the others by one-way analysis of variance. FEC between breeds was only significantly different at 12 weeks post infection $(p=0.04)$. Generally, higher FEC was recorded in Kigezi compared to SEA and Mubende goats.

Carcass weight was significantly different among breeds $(p<0.05)$, with Mubende having the highest carcass weight, followed by Kigezi and SEA. PCV and daily weight gains were significantly different between breeds $(p<0.05)$. WC was not significantly different between the breeds. FEC and PCV were weakly significant at later stages of the experiment with higher parasite burden suggesting potential variation in resistance to $H$. contortus. These differences could be exploited in designing breeding programs with disease resistance in indigenous goat breeds.

Key words: Haemonchus contortus, Small East African goat, Mubende goat, Kigezi goat, dewormer, Breeding programs 


\subsection{Introduction}

The gastrointestinal nematode (GIN) Haemonchus contortus is a major health problem, causing immense economic losses in goat production (Baker et al., 1998; Bambou et al., 2013; Campos et al., 2009; Mandonnet et al., 2001). In Australia the annual losses due to GIN is estimated at over AUD 400 million (McLeod, 1995; Sacket et al., 2006). It is similarly estimated that the costs of diseases generally may be as high as $35 \%-50 \%$ of turnover within the livestock sector in developing countries (Bishop, 2012). In French West Indies losses in goat farm profit of up to $81 \%$ have been reported (Gunia et al., 2013). The losses have mainly been attributed to significant morbidity and mortality in small ruminants.

Helminthosis (diseases including those caused by nematode parasites) is the most important livestock disease in most tropical countries (Khan et al., 2010; Lapenga and Rubaire-Akiiki, 2009; Perry et al., 2002; Vatta and Lindberg, 2006). The most prevalent of Gl nematodes in Uganda is Haemonchus contortus (Nsereko et al., 2015). GIN particularly Haemonchus contortus has a high fecundity and is a debilitating blood sucking parasite in the abomasum causing significant production losses through severe chronic anaemia, anorexia, loss of condition and eventual death of the affected animals (Notter et al., 2003)

Options for control of GI nematodes include vaccination, chemotherapy, improved management and utilization of host genetic variation. The control of gastrointestinal parasites in many livestock production systems has been mainly through the use of anthelminthics. However, the development of resistance to major anthelminthics (Kaplan, 2004; Zajac and Gipson, 2000) and increasing consumer health concerns over occurrence of drug residues in food have further complicated control of nematodes. The decreasing efficacy of anthelminthics coupled with the desire for less chemical use in production systems has stimulated search for alternatives for sustainable control of parasites. Genetic resistance against GI nematodes is well described within and between sheep breeds and to a lesser extent in some goat breeds (Bishop and Stear, 2003; Fakae et al., 2004; Gruner et al., 2004; Mandonnet et al., 2001). The use of relatively resistant animals improves growth and there is less contamination of pastures, thus minimizing the need for anthelmintics and the development of anthelmintic resistance (Matika et al., 2003).

Resistance in animals is the ability of breeds to suppress establishment and subsequent development of infection (Albers et al., 1987), while resilience or tolerance refers to the ability of the host/animal surviving and remaining productive despite parasite challenge (Bishop, 2012). Resistance to GI parasites can be exhibited by a lower faecal egg count (FEC), while resilience is commonly measured with the 
packed cell volume (PCV) (Bisset and Morris, 1996) and increase in body weight (BW) in growing animals. The PCV measures the volume of circulating erythrocytes in the blood compared to the whole blood, making it a suitable cut-off point for anaemia in animals. There is consensus that a ruminant with a PCV of $20-26 \%$ may have a mild anaemia (Tvedten, 2010) and the normal range in goats is estimated to be from 22$38 \%$ (Byers and Kramer, 2010). Thus any animal with a PCV below $20 \%$ can be considered to be anaemic and not resilient to the GI nematode.

Goats are markedly susceptible to GI nematodes. However, there are breeds and individuals which are genetically resistant to nematodes (Behnke et al., 2006; Pralomkarn et al., 1997). These breeds and animals show a low FEC and parasite survival (worm burden). Worm burden is a measure of number of adult worms in an individual host. A positive correlation may exist between faecal egg counts and worm counts/ burden (Cabaret and Gasnier, 1994; Cabaret et al., 1998). Therefore, FEC may be used as an indicator for worm burden. However, there is scepticism over this approach in that, the worms are not randomly distributed in the hosts. Low levels of FEC and worm burdens are closely associated, and are good indicators of resistant animals. It may therefore be possible to select for improved resistance to nematodes in goats (Mandonnet et al., 2001; Mandonnet et al., 2006).

Studies with sheep show a marked susceptibility of male lambs to GI nematodes compared to female lambs, arising from both natural and experimental infections. This may be attributed to sex steroids (androgens vs. oestrogens) which control several aspects of host immunity (Klein, 2000a; Klein, 2000b). Therefore, the use of male animals is envisaged to give a large (and variable) response in challenge studies. Evidence for variation in resistance to GIN, particularly Haemonchus contortus, between breeds has been extensively documented in sheep (Alba-Hurtado et al., 2010; Amarante et al., 2004; Getachew et al., 2015; González et al., 2011; Haile et al., 2002). A few studies confirm the existence of resistance in indigenous goats in Africa, for example the West African Dwarf (WAD) goats (Chiejina and Behnke, 2011) and Kenyan Small East African (SEA) goats (Baker et al., 1998). However, there is no known scientific literature about the variation in resistance/resilience to GIN amongst the indigenous goat breeds of Uganda.

The objective of this study was therefore to evaluate the variation in resistance/resilience in three indigenous goat breeds of Uganda when artificially infected with GIN Haemonchus contortus. 


\subsection{Materials and methods}

\subsubsection{Experimental animals and management}

An on-station challenge experiment was conducted at Kachwekano Zonal Agricultural Research and Development Institute (KAZARDI) in Kabale (1.33 ${ }^{\circ} \mathrm{S}$, $30.00^{\circ} \mathrm{E}, 1864$ metres above sea level (masl)). Twelve male kids each of the three main indigenous goat breeds in Uganda were purchased from smallholder farmers in Kabale $\left(1.33^{\circ} \mathrm{S}, 30.00^{\circ} \mathrm{E}, 1864 \mathrm{masl}\right)$, Mubende $\left(0.59^{\circ} \mathrm{N}, 31.36^{\circ} \mathrm{E}\right.$ and $\left.1324 \mathrm{masl}\right)$ and Arua $\left(3.03^{\circ} \mathrm{N}, 30.91^{\circ} \mathrm{E}\right.$ and $\left.1157 \mathrm{masl}\right)$; where Kigezi (KIG), Mubende (MUB) and Small East African (SEA) goats, respectively, were predominantly found. Only male kids were used to eliminate a possible sex effect and, moreover, male goats were easily accessible across all production systems in Uganda. The goats used in this experiment were approximately 7 months of age at time of purchase and selected from different parental lines in widely distributed locations to ensure that they were not related to each other. Goats at this age were commonly believed to be immunologically immature (Hoste et al., 2010) and the males are generally considered more susceptible than females and were therefore suitable for the study. The management at the farms was similar where the kids were raised together with the does and grazed together on natural grass. While on-station, the animals were subjected to the same management (feeding and housing) prior to experimentation. They were initially drenched with a combination therapy of nilzan plus albendazole $10 \%$, followed by a closantel treatment where the parasite was not cleared by nilzan plus - albendazole combination therapy. The goats were then allowed to adjust to the prevailing husbandry conditions for a period of $4-6$ weeks. Briefly, on arrival at the station the animals were kept in isolation and sprayed against ectoparasites, particularly ticks, and treated against enterotoxaemia according to approved standard procedures. During the quarantine period their health was closely monitored and any ailment that may have an adverse effect on the goats was treated promptly. To avoid secondary infection, the experiment was performed under a cut and carry system of feeding. The goats were fed on clean banana peels and Napier grass (Pennisetum purpureum) as the basal diet and supplemented with legumes, mainly Lablab (Lablab purpureus) and Calliandra (Calliandra calothyrsus) forage, throughout the experimental period. The fodder was obtained from established pastures not previously grazed by animals but mainly used for cut and carry feeding. Mineral blocks rich in essential minerals were availed in each pen to meet their mineral requirements. Water was provided to the goats ad libtum and each pen with goats was kept clean at all times to minimize secondary infection. Experimental 
management and data collection were performed using approved ethical standards of Uganda National Council of Science and Technology (UNCST)(SBLS/REC/15/131).

\subsubsection{Worm cultures and inoculation}

Grazing goats are usually infected by third stage larvae (L3) of Haemonchus contortus (Hoste et al., 2010). However, worm infections tend to occur as mixed proportions of helminths. To obtain pure cultures of Haemonchus contortus goats were sampled from several herds and two goats with over $90 \%$ infection by Haemonchus contortus were recruited as source for developing pure Haemonchus contortus cultures. Briefly, faecal samples were obtained from the donors and female fully engorged Haemochus contortus were isolated and incubated in sterile faecal material at a temperature of $27^{\circ} \mathrm{C}$ for 14 days before harvesting the L3 larvae using Baermann's technique (Hansen and Perry, 1994). The technique works on the principle of active migration of the larvae, allowing them to move into the water and sink into the bottom of the Baermann's apparatus to be collected, while the faecal particles remain suspended in water (Fig 1). The larval cultures (Plate 1) were stored at $10^{\circ} \mathrm{C}$ in fridge until used. The viability of the larvae was ascertained before administering to the goats to ensure that sufficient living larvae were fed to the experimental goats. 10-14 days prior to artificially infecting the goats with L3 larvae, a thorough faecal examination is undertaken to ensure that the experimental goats were free of nematode eggs.

Twelve goats of each breed were assigned to three different breed groups (KIG, MUB, SEA) in different pens. Prior to infection of the goats, the viability of the L3 larvae was ascertained microscopically and the number of living larvae was counted for every doing. 18,000 infective L3 was administered to the goats orally using a syringe.

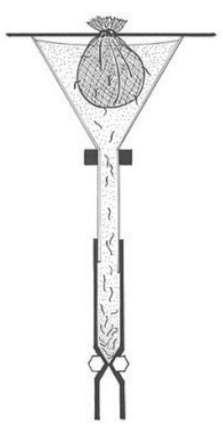

Figure 3.1: Baermann apparatus (Adapted from Hansen and Perry, 1994) 


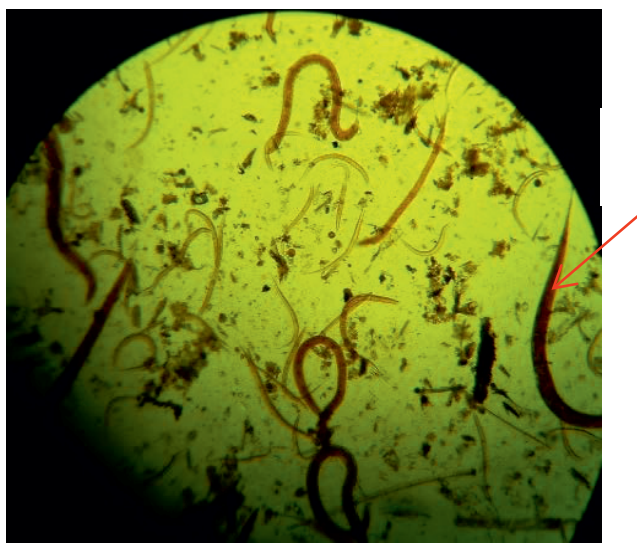

Haemonchus contortus

Plate 1: Haemonchus contortus larvae as seen under the microscope (100X)

\subsubsection{Data}

Data collection commenced from week 3 post-infection and continued for 10 weeks. During experimentation FEC, PCV and BW for each animal were measured once every week. For FEC, fresh faecal samples were taken thrice weekly in the morning hours, directly from the rectum of the experimental animals by rectal palpitation by a trained and skilled technician to minimize soft tissue damage. During the experimentation period, the physiological status of animals was closely.

\subsubsection{Parasitological data}

FEC was determined for each individual faeces sample and averaged per animal per week. The data were expressed as average number of eggs per gram faeces (epg) (Fakae et al., 1999). To obtain FEC, $20 \mathrm{~g}$ of fresh faecal samples were collected directly from the rectum of each animal and processed individually with modified McMaster technique (MAFF, 1986) using standard operating procedures. With the procedure, three grams of faeces were put into a container and a saturated $\mathrm{NaCl}$ solution was added. The resultant suspension was thoroughly homogenised and strained through a sieve to remove large debris. The strained faecal samples were then examined for worm eggs on a McMaster slide under a light microscope using a 100X magnification (Cringoli et al., 2004). Meanwhile BW was determined on a weekly basis using a sensitive scale.

At termination of the experiment (D84), all animals were slaughtered and WC determined by the number of adult worms recovered from the abomasum (Hoste et al., 2010). Briefly, the abomasum was separated, opened and contents were emptied 
into a volumetric flask. The lining mucosa was then thoroughly washed with warm $0.9 \% \mathrm{NaCl}$ to detach any adherent nematodes and added to the respective abomasal contents. An aliquot of the washings and contents were assessed for nematode worms to establish the WC.

\subsubsection{Haematology}

PCV was measured using a haematocrit reader according to the procedure of (Dacie and Lewis, 1995). PCV measurements were taken at the start of the experiment (D0) and subsequently on weekly basis up to week 12 (D84) post-infection. Blood samples for PCV determination were collected from the jugular vein into an ethylenediamine tetra-acetic acid (EDTA) coated vacutainer tube. The freshly collected blood samples were subjected to haematocrit analysis to obtain the PCV values.

\subsubsection{Data analysis}

Data on the effect of breed on CW, FEC, WC, PCV and BW at different time periods were tested using linear mixed model implemented by the R package $\mathrm{n} / \mathrm{me}$ ( $\mathrm{R}$ Core Team, 2016) with goat identification(goat-id) as random factor accounting for spatial correlation of the measurements in the same goat. Data for FEC and WC were first log transformed to normalize the data before statistical analysis. The model used included fixed effects of breed, week of measurement and breed $\times$ week interactions and a random (repeated) effect of the goat-id.

$$
Y_{i j k}=\mu+\tau_{i}+\beta_{j}+\tau_{i} \beta_{j}+\varepsilon_{i j k}
$$

Where $Y_{i j k}$ is the measurement (FEC or BW or BW) on the $k^{\text {th }}$ individual within the $i^{\text {th }}$ breed and the $j^{\text {th }}$ week, $\mu$ is the overall mean, $\tau_{i}$ the effect of breed $\mathrm{i}, \beta_{j}$ the effect of week $\mathrm{j}, \tau_{i} \beta_{j}$ is effect of the interaction between $i^{\text {th }}$ breed and $j^{\text {th }}$ week and $\varepsilon_{i j k}$ is the error term. One-way analysis of variance (ANOVA) in R was used to test for breed differences in carcass weight (CW) and WC.

$$
Y_{i j}=\mu+\tau_{i}+\varepsilon_{i j}
$$

Where $Y_{i j}$ is the individual measure of $\mathrm{CW}$ or WC for the $\mathrm{j}^{\text {th }}$ goat from the $\mathrm{i}^{\text {th }}$ breed, $\tau_{i}$ is the effect of the $i^{\text {th }}$ breed. $r$. 


\subsection{Results}

The overall variation in FEC (logEPG), PCV and Total Worm count between the breeds is represented in Table 3.1. Log transformed eggs per gram (LEPG) was not significantly different between the breeds, although the numerical values were higher in KIG, followed by SEA and lowest in MUB. The PCV in SEA was significantly lower compared to KIG and MUB. Total worm count was not significantly different between breeds $(P>0.05)$. However, there was a higher number of adult worms in KIG compared to MUB and SEA goats.

Table 3.1 Least square means \pm standard error of log FEC, packed cell volume and total worm count of Haemonchus contortus infected goats.

\begin{tabular}{llll}
\hline Breed & LFEC(logEPG) & PCV & Total Worm count \\
\hline Kigezi & $1.917^{\mathrm{a}} \pm 0.040$ & $29.682^{\mathrm{a}} \pm 1.096$ & $25.364^{\mathrm{a}} \pm 6.052$ \\
Mubende & $1.792^{\mathrm{a}} \pm 0.042$ & $30.350^{\mathrm{a}} \pm 1.150$ & $16.800^{\mathrm{a}} \pm 6.348$ \\
Small East African (SEA) & $1.847^{\mathrm{a}} \pm 0.044$ & $25.750^{\mathrm{b}} \pm 1.212$ & $16.000^{\mathrm{a}} \pm 6.691$ \\
\hline
\end{tabular}

$a, b, c$ Means within the same column with differing superscripts differ significantly $(\mathrm{P}<0.05)$

The variation in the faecal egg counts is shown in the different breeds during the period of challenge is shown in Table 3.2. Faecal egg counts (FEC) were similar among the three indigenous breeds. Although, FEC differed numerically, they were not statistically significant $(P>0.05)$ at the initial stages of the experiment. However, at week 12 , FEC was marginally significant $(P=0.04)$ with the highest value recorded in KIG goats. The differences between SEA and MUB goats remained similar statistically throughout the experiment. FEC data was recorded after 8 weeks post infection (PI) as shown in Figure 3.2.

The live body weight (BW), carcass weight and average daily gains is shown in Table 3.3. The average live body weight and carcass weights were significantly different among the breeds $(P<0.05)$. The highest body weight was found in Mubende, followed by Kigezi and SEA respectively. generally higher in Mubende. There was a general reduction in average body weight PI with L3 larvae of Haemonchus contortus (Figure 3.3). Daily weigh gain (DWG) was significantly $(P<0.05)$ different in MUB compared to SEA and KIG. The highest weight loss was recorded in KIG followed by SEA with MUB respectively. 
Table 3.2 Log transformed faecal egg counts (LEPG) in three different indigenous goat breeds

\begin{tabular}{llll}
\hline Weeks (post infection) & \multicolumn{3}{l}{ Log Faecal Egg Counts (Mean \pm S.D) } \\
\cline { 2 - 4 } & Kigezi & Mubende & Small East African (SEA) \\
\hline 2 & $1.699^{\mathrm{a}} \pm 0.000$ & $1.699^{\mathrm{a}} \pm 0.000 \pm$ & $1.699^{\mathrm{a}} \pm 0.000$ \\
4 & $1.699^{\mathrm{a}} \pm 0.000$ & $1.699^{\mathrm{a}} \pm 0.000$ & $1.699^{\mathrm{a}} \pm .000$ \\
8 & $1.726^{\mathrm{a}} \pm 0.908$ & $1.729^{\mathrm{a}} \pm 0.952$ & $1.732^{\mathrm{a}} \pm 0.100$ \\
12 & $2.545^{\mathrm{a}} \pm 0.522$ & $2.054^{\mathrm{bc}} \pm 0.472$ & $2.256^{\mathrm{ac}} \pm 0.546$ \\
\hline
\end{tabular}

$\mathrm{a}, \mathrm{b}, \mathrm{c}$ Means within the same row with differing superscripts differ significantly $(P<0.05)$

Table 3.3 Least square means and standard error for live body weight, carcass weight and daily weight gain

\begin{tabular}{lccl}
\hline Breed & $\begin{array}{c}\text { Body Weight } \\
(\mathrm{Kg})\end{array}$ & $\begin{array}{c}\text { Carcass Weight } \\
(\mathrm{Kg})\end{array}$ & $\begin{array}{l}\text { Daily } \\
\text { Gain }\end{array}$ \\
\hline Kigezi & $14.614^{\mathrm{a}} \pm 0.565$ & $5.818^{\mathrm{a}} \pm 0.302$ & $-0.030^{\mathrm{a}} \pm 0.005$ \\
Mubende & $18.575^{\mathrm{b}} \pm 0.593$ & $7.650^{\mathrm{b}} \pm 0.317$ & $-0.007^{\mathrm{b}} \pm 0.005$ \\
Small East African (SEA) & $11.167^{\mathrm{c}} \pm 0.625$ & $4.389^{\mathrm{c}} \pm 0.334$ & $-0.016^{\mathrm{a}} \pm 0.006$ \\
\hline
\end{tabular}

$\mathrm{a}, \mathrm{b}, \mathrm{c}$ Means within the same column with differing superscripts differ significantly $(P<0.05)$

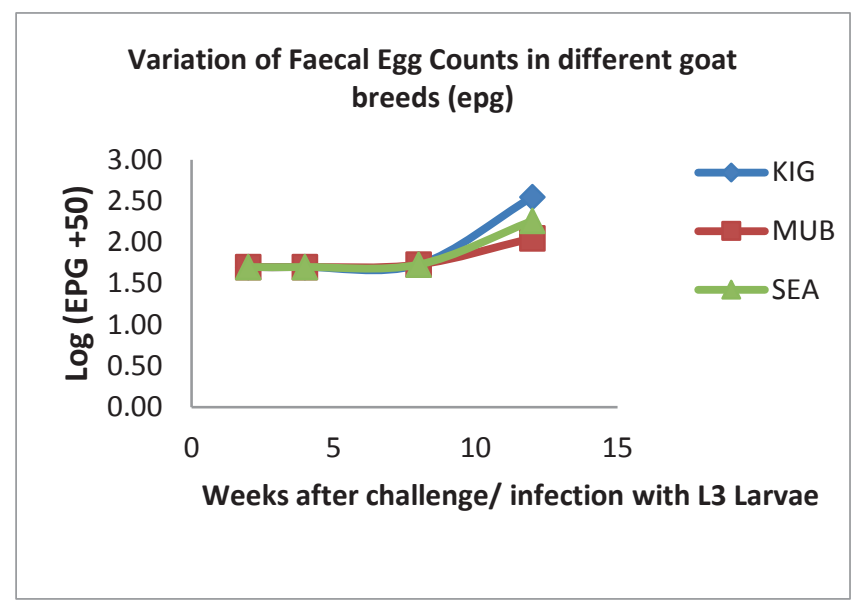

Figure 3.2 Change in FEC over time in Kigezi, Mubende and Small East African (SEA) goats 


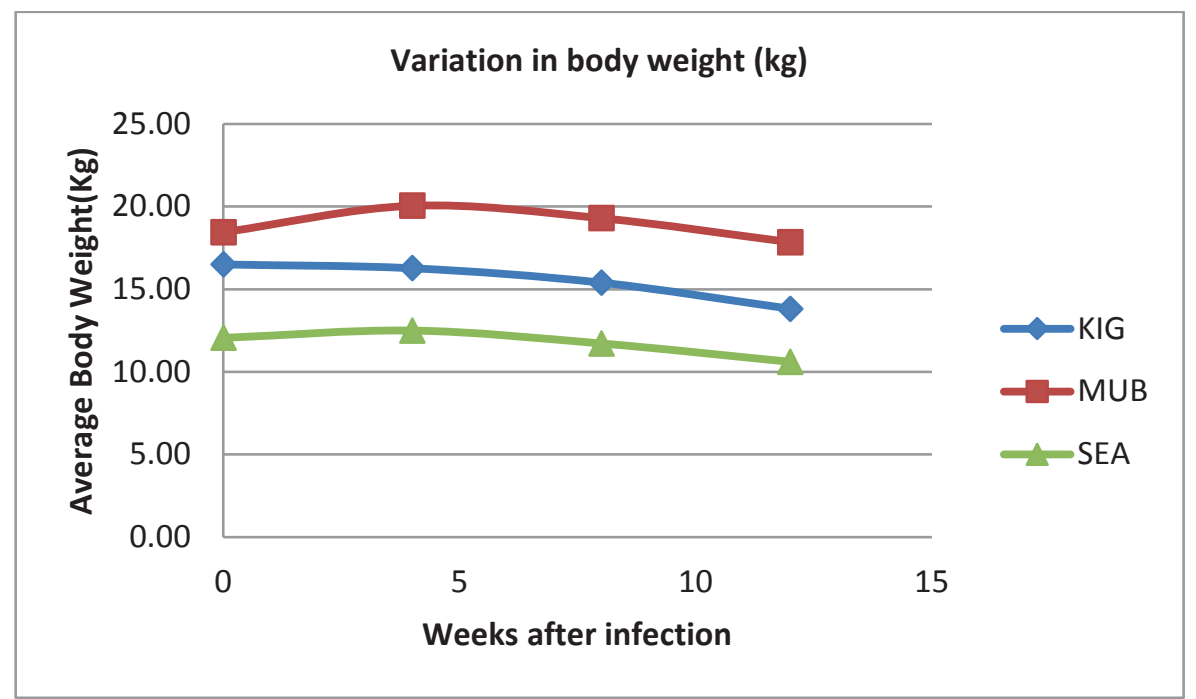

Figure 3.3 Variation in average live body weight of breeds post infection (PI) with L3 larvae of Haemochus contortus. $\mathrm{KIG}=$ Kigezi, $\mathrm{MUB}=$ Mubende, $\mathrm{SEA}=$ Small East African

\subsection{Discussion}

Difference between breeds to resistance to gastrointestinal parasites are always limited by the small numbers of experimental animals per breed or genotypes being compared. This often affects the ability to draw meaningful conclusions from such studies (Marume et al., 2011). In the present study, we did not find a significant difference in FEC between the breeds, although PCV in SEA was significantly lower than for KIG and Mubende (Table 3.1). The findings in the current study agree with findings of Costa et al. (2000) working with three goat breeds in Brazil, who found similar FEC but significantly different PCV values between breeds. PCV is a good indicator for resilience when the GIN is a blood sucking parasite like $H$. contortus (Baker et al., 2001). In this regard, MUB with the highest PCV showed a relatively high degree of resilience to GIN particularly Haemonchus contortus and the lowest resilience was found with SEA which showed the lowest PCV. Overly, PCV across the breeds was within the $22-38 \%$ range recognised as the normal range in goats by Byers and Kramer (2010). This may have been due to the low levels of infection recorded as the parasite established itself in the host as indicated by the gradual rise in FEC (Table 3.2). In the present study, FEC was not significant, however it is noteworthy here that there is a close correlation between aneamia and PCV in 
Haemonchus contortus infection in both sheep (Albers et al., 1987) and goats (Baker et al., 1998). We conclude from this finding that MUB may probably present as the more resistant of the three breeds under study. Further, a plot of LEPG over time (Fig.2), shows invariably lower values in MUB compared to KIG and SEA. The differences in FEC and PCV could be attributed to breed genetic differences. Genetic differences in resistance/ resilience in goats have been previously reported in West African Dwarf goats (Chiejina and Behnke, 2011) and SEA goats in Kenya by (Baker and Gray, 2004; Baker et al., 1998). The differences reported in this study; if under genetic control offer an opportunity to include the resistance traits in breed improvement programs for these indigenous goats.

Body and carcass weight were all significantly different from each other and there was a general loss in weight experienced with all the breeds (Fig 3). However the daily body weight loss found in MUB was significantly lower $(\mathrm{P}<0.05)$ than in SEA and KIG. This implies that MUB was able to maintain a relatively stable weight despite the worm challenge as compared to KIG and SEA. The initial loss in weight during the acclimatization could be attributed to change in feeding system, however in the long run, other factors may have possibly come into play including the genetic differences.

\subsection{Conclusions and recommendation}

There was a significant variation in daily weight gain between the breeds suggesting some variation in the effect of the parasite on the different goat breeds.

FEC and PCV were weakly significant at later stage of the experiment when the parasite burden was increased suggesting variation in a difference in genetic predisposition which could be exploited.

There is need for long term study with more recorded individuals to validate the findings from this experiment.

Development of selection population with genomic selection in the long run could become a useful tool in goat breed improvement programs in the tropics. 


\section{Acknowledgements}

This work was supported by Agricultural Technology and Agribusiness Advisory Services Project (ATAAS) (Project P109224) under National Agricultural Research Organization (NARO) with funding from International Development Association (IDA) of World Bank and Government of Uganda. It was coordinated by Animal Breeding and Genomics Centre, Wageningen University, the Netherlands where the first author is a student. We are grateful to the management of Kachwekano Zonal Agricultural Research and Development Institute (KAZARDI) where the experiments were conducted and the smallholder farmers of Uganda.

\section{References}

Alba-Hurtado, F., Romero-Escobedo, E., Muñoz-Guzmán, M.A., Torres-Hernández, G., Becerril-Pérez, C.M., 2010. Comparison of parasitological and productive traits of Criollo lambs native to the central Mexican Plateau and Suffolk lambs experimentally infected with Haemonchus contortus. Veterinary Parasitology 172, 277-282.

Albers, G.A.A., Gray, G.D., Piper, L.R., Barker, J.S.F., Jambre, L.F.L., Barger, I.A., 1987. The genetics of resistance and resilience to Haemonchus contortus infection in young merino sheep. International Journal for Parasitology 17, 13551363.

Amarante, A.F.T., Bricarello, P.A., Rocha, R.A., Gennari, S.M., 2004. Resistance of Santa Ines, Suffolk and lle de France sheep to naturally acquired gastrointestinal nematode infections. Veterinary Parasitology 120, 91-106.

Baker, R., Audho, J., Aduda, E., Thorpe, W., 2001. Genetic resistance to gastrointestinal nematode parasites in Galla and Small East African goats in the sub-humid tropics. Animal Science-GLASGOW- 73, 61-70.

Baker, R., Gray, G., 2004. Appropriate breeds and breeding schemes for sheep and goats in the tropics. Worm control for small ruminants in tropical Asia, 63.

Baker, R.L., Mwamachi, D.M., Audho, J.O., Aduda, E.O., Thorpe, W., 1998. Resistance of Galla and Small East African goats in the sub-humid tropics to gastrointestinal nematode infections and the peri-parturient rise in faecal egg counts. Veterinary Parasitology 79, 53-64.

Bambou, J.C., Cei, W., Camous, S., Archimède, H., Decherf, A., Philibert, L., Barbier, C., Mandonnet, N., González-García, E., 2013. Effects of single or trickle Haemonchus contortus experimental infection on digestibility and host responses of naïve Creole kids reared indoor. Veterinary Parasitology 191, 284-292. 
Behnke, J.M., Chiejina, S.N., Musongong, G.A., Fakae, B.B., Ezeokonkwo, R.C., Nnadi, P.A., Ngongeh, L.A., Jean, E.N., Wakelin, D., 2006. Naturally occurring variability in some phenotypic markers and correlates of haemonchotolerance in West African Dwarf goats in a subhumid zone of Nigeria. Veterinary Parasitology 141, 107-121.

Bishop, S.C., 2012. Possibilities to breed for resistance to nematode parasite infections in small ruminants in tropical production systems. animal 6, 741747.

Bishop, S.C., Stear, M.J., 2003. Modeling of host genetics and resistance to infectious diseases: understanding and controlling nematode infections. Veterinary Parasitology 115, 147-166.

Bisset, S.A., Morris, C.A., 1996. Feasibility and implications of breeding sheep for resilience to nematode challenge. International Journal for Parasitology 26, 857-868.

Byers, S.R., Kramer, J.W., 2010. Normal hematology of sheep and goats, 6th Edn Edition. Blackwell Publishing Ltd, Ames, 836 - 842 pp.

Cabaret, J., Gasnier, N., 1994. Farm history and breeding management influences on the intensity and specific diversity of nematode infection of dairy goats. Veterinary Parasitology 53, 219-232.

Cabaret, J., Gasnier, N., Jacquiet, P., 1998. Faecal egg counts are representative of digestive-tract strongyle worm burdens in sheep and goats. Parasite 5, 137142.

Campos, A.K., Araújo, J.V., Guimarães, M.P., Dias, A.S., 2009. Resistance of different fungal structures of Duddingtonia flagrans to the digestive process and predatory ability on larvae of Haemonchus contortus and Strongyloides papillosus in goat feces. Parasitology Research 105, 913-919.

Chiejina, S.N., Behnke, J.M., 2011. The unique resistance and resilience of the Nigerian West African Dwarf goat to gastrointestinal nematode infections. Parasites \& Vectors 4.

Costa, C., Vieira, L.d.S., Berne, M., Silva, M., Guidoni, A., Figueiredo, E., 2000. Variability of resistance in goats infected with Haemonchus contortus in Brazil. Veterinary Parasitology 88, 153-158.

Cringoli, G., Rinaldi, L., Veneziano, V., Capelli, G., Scala, A., 2004. The influence of flotation solution, sample dilution and the choice of McMaster slide area (volume) on the reliability of the McMaster technique in estimating the faecal egg counts of gastrointestinal strongyles and Dicrocoelium dendriticum in sheep. Veterinary Parasitology 123, 121-131. 
Dacie, J.V., Lewis, S.M., 1995. Practical Hematology, 8th Ed Edition Churchhill Livingstone.

Fakae, B.B., Chiejina, S.N., Behnke, J.M., Ezeokonkwo, R.C., Nnadi, P.A., Onyenwe, W.I., Gilbert, F.S., Wakelin, D., 1999. The response of Nigerian West African Dwarf goats to experimental infections with Haemonchus contortus. Research in Veterinary Science 66, 147-158.

Fakae, B.B., Musongong, G.A., Chiejina, S.N., Behnke, J.M., Ngongeh, L.A., Wakelin, D., 2004. Variability in the resistance of the Nigerian West African Dwarf goat to abbreviated escalating trickle and challenge infections with Haemonchus contortus. Veterinary Parasitology 122, 51-65.

Getachew, T., Alemu, B., Sölkner, J., Gizaw, S., Haile, A., Gosheme, S., Notter, D.R., 2015. Relative resistance of Menz and Washera sheep breeds to artificial infection with Haemonchus contortus in the highlands of Ethiopia. Tropical Animal Health and Production 47, 961-968.

González, J.F., Hernández, Á., Meeusen, E.N.T., Rodríguez, F., Molina, J.M., Jaber, J.R., Raadsma, H.W., Piedrafita, D., 2011. Fecundity in adult Haemonchus contortus parasites is correlated with abomasal tissue eosinophils and $\gamma \delta \mathrm{T}$ cells in resistant Canaria Hair Breed sheep. Veterinary Parasitology 178, 286292.

Gruner, L., Bouix, J., Khang, J., Mandonnet, N., Eychenne, F., Cortet, J., Sauve, C., Limouzin, C., 2004. A short-term divergent selection for resistance to Teladorsagia circumcincta in Romanov sheep using natural or artificial challenge. Genetics Selection Evolution 36, 217 - 242.

Gunia, M., Mandonnet, N., Arquet, R., Alexandre, G., Gourdine, J.-L., Naves, M., Angeon, V., Phocas, F., 2013. Economic values of body weight, reproduction and parasite resistance traits for a Creole goat breeding goal. animal 7, 2233.

Haile, A., Tembely, S., Anindo, D.O., Mukasa-Mugerwa, E., Rege, J.E.O., Yami, A., Baker, R.L., 2002. Effects of breed and dietary protein supplementation on the responses to gastrointestinal nematode infections in Ethiopian sheep. Small Ruminant Research 44, 247-261.

Hansen, J., Perry, B., 1994. The Epidemiology, Diagnosis and Control of Helminth Parasites of Ruminants. Nairobi, Kenya.

Hoste, H., Sotiraki, S., Landau, S.Y., Jackson, F., Beveridge, I., 2010. Goat-Nematode interactions: think differently. Trends in parasitology 26, 376-381.

Kaplan, R.M., 2004. Drug resistance in nematodes of veterinary importance: a status report. Trends in Parasitology 20, 477-481. 
Khan, M.N., Sajid, M.S., Khan, M.K., Iqbal, Z., Hussain, A., 2010. Gastrointestinal helminthiasis: prevalence and associated determinants in domestic ruminants of district Toba Tek Singh, Punjab, Pakistan. Parasitology Research 107, 787-794.

Klein, S.L., 2000a. Hormones and mating system affect sex and species differences in immune function among vertebrates. Behavioural Processes 51, 149-166.

Klein, S.L., 2000b. The effects of hormones on sex differences in infection: from genes to behavior. Neuroscience \& Biobehavioral Reviews 24, 627-638.

Lapenga, O., Kenneth., Rubaire-Akiiki, C., 2009. The Effect of Helminthiasis on Weight Gains and Carcass Values of Young Indigenous Goats in Uganda. Journal of Animal and Veterinary Advances, 8: 1993-1998. 8, 1993 - 1998.

MAFF, 1986. Fisheries and Food, Reference Book, Manual of Veterinary Parasitological Laboratory Techniques.London, UK.

Mandonnet, N., Aumont, G., Fleury, J., Arquet, R., Varo, H., Gruner, L., Bouix, J., Khang, J.V.T., 2001. Assessment of genetic variability of resistance to gastrointestinal nematode parasites in Creole goats in the humid tropics. Journal of Animal Science 79, 1706-1712.

Mandonnet, N., Menendez-Buxadera, A., Arquet, R., Mahieu, M., Bachand, M., Aumont, G., 2006. Genetic variability in resistance to gastro-intestinal strongyles during early lactation in Creole goats. Animal Science 82, 283287.

Marume, U., Chimonyo, M., Dzama, K., 2011. A preliminary study on the responses to experimental Haemonchus contortus infection in indigenous goat genotypes. Small Ruminant Research 95, 70-74.

Matika, O., Nyoni, S., van Wyk, J.B., Erasmus, G.J., Baker, R.L., 2003. Resistance of Sabi and Dorper ewes to gastro-intestinal nematode infections in an African semi-arid environment. Small Ruminant Research 47, 95-102.

McLeod, R.S., 1995. Costs of major parasites to the Australian livestock industries. International Journal for Parasitology 25, 1363-1367.

Notter, D.R., Andrew, S.A., Zajac, A.M., 2003. Responses of hair and wool sheep to a single fixed dose of infective larvae of Haemonchus contortus. Small Ruminant Research 47, 221-225.

Nsereko, G., Emudong, P., Mulindwa, H., Okwee-Acai, J., 2015. Prevalence of common gastro-intestinal nematode infections in commercial goat farms in Central Uganda. Uganda Journal of Agricultural Sciences 16, 99-106.

Perry, B.D., McDermott, J.J., Randolf, T.F., Sones, K.R., Thornton, P.K. 2002. Investing in animal health research to alleviate poverty. (Nairobi, Kenya, International Livestock Research Institute (ILRI)). 
Pralomkarn, W., Pandey, V.S., Ngampongsai, W., Choldumrongkul, S., Saithanoo, S., Rattaanachon, L., Verhulst, A., 1997. Genetic resistance of three genotypes of goats to experimental infection with Haemonchus contortus. Veterinary Parasitology 68, 79-90.

Sacket, D., Holmes, P., Abbott, K., Jephcott, S., Barber, M. 2006. Assessing the economic cost of endemic diseases on profitability of the Australian beef cattle and sheep producers. Final Report, Meat and Livestock Australia. (Sydney,).

R Core Team. 2016. R: A language and environment for statistical computing ( $R$ Foundation for Statistical Computing, Vienna, Austria.).

Tvedten, H., 2010. Laboratory and Clinical diagnosis of anemia. Blackwell Publishing Ltd, Ames.

Vatta, A.F., Lindberg, A.L.E., 2006. Managing anthelmintic resistance in small ruminant livestock of resource-poor farmers in South Africa : review article. Journal of the South African Veterinary Association; Vol 77, No 1 (2006).

Zajac, A.M., Gipson, T.A., 2000. Multiple anthelmintic resistance in a goat herd. Vet Parasitol 87, 163-172. 


\section{4}

\section{Genome-wide population structure and admixture analysis reveals weak differentiation among Ugandan goat breeds}

R. B. Onzima ${ }^{1,2}$, M. R. Upadhyay ${ }^{1,3}$, R. Mukiibi ${ }^{4}$, E. Kanis ${ }^{1}$, M. A. M. Groenen ${ }^{1}$, R. P. M. A. Crooijmans ${ }^{1}$

${ }^{1}$ Wageningen University and Research Animal Breeding and Genomics, P. O. Box 338, 6700AH Wageningen, The Netherlands; ${ }^{2}$ National Agricultural Research Organization (NARO), P. O. Box 295, Entebbe, Uganda; ${ }^{3}$ Department of Animal Breeding and Genetics, Swedish University of Agricultural Sciences, Uppsala, Sweden; ${ }^{4}$ Department of Agriculture, Food and Nutritional Sciences (AFNS), Faculty of Agriculture, Life and Environmental Sciences, University of Alberta, 1416 College Plaza Edmonton, Alberta, Canada T6G 2C8 


\section{Abstract}

Uganda has a large population of goats from predominantly indigenous breeds reared in diverse production systems, whose existence is threatened by crossbreeding with exotic Boer goats. Knowledge about the genetic characteristics and relationships among these Ugandan goat breeds and the potential admixture with Boer goats is still limited. Using a medium density single nucleotide polymorphism (SNP) panel, we assessed the genetic diversity, population structure and admixture in six goat breeds in Uganda: Boer, Karamojong, Kigezi, Mubende, Small East African and Sebei. All the animals had genotypes for about 46,105 SNPs after quality control. We found high proportions of polymorphic SNPs ranging from 0.885 (Kigezi) to 0.928 (Sebei). The overall mean observed $\left(H_{O}\right)$ and expected $\left(H_{E}\right)$ heterozygosity across breeds was $0.355 \pm 0.147$ and $0.384 \pm 0.143$ respectively. Principle components, genetic distances and ADMIXTURE analyses revealed weak population sub-structuring among the breeds. Principle components separate Kigezi and weakly Small East African from other indigenous goats. Sebei and Karamojong are tightly entangled together while Mubende occupies a more central position with high admixture from all other local breeds. The Boer breed showed a unique cluster from the Ugandan indigenous goat breeds. The results reflect common ancestry but also some level of geographical differentiation. ADMIXTURE and $f_{4}$ - statistics revealed gene-flow from Boer and varying levels of genetic admixture among the breeds. Generally, moderate to high levels of genetic variability were observed. Our findings provide useful insights to maintain genetic diversity and design appropriate breeding programs to exploit within breed diversity and heterozygote advantage in cross-breeding schemes.

Key words: breed composition, breed diversity, Capra hircus, heterozygosity, indigenous goats, population genetics 


\subsection{Introduction}

According to archaeo-zoological evidence, goats were among the first ungulates to be domesticated, about 10,000 years ago near the fertile crescent that spans from Eastern Anatolia to the Zagros Mountains in Northern Iran (Zeder \& Hesse 2000; Naderi et al. 2008). From the centre of domestication, archaeological evidence suggests the rapid spread of goats to Eurasia and Africa following human migrations and trade routes. Migration of goats into Africa occurred through three main entry routes, one along the Mediterranean coast, a second via the Red Sea hills region, and a third through the Nile Valley via the Sinai peninsula and Nile delta (Taberlet et al. 2008; Pereira et al. 2009; Gifford-Gonzalez \& Hanotte 2011). Other movements have also been reported from the Near East into the Ethiopian highlands and central Sahara (Clutton-Brock 2000).

Today, goats are amongst the most important livestock species in developing countries. They are of significant socio-economic, nutritional and cultural importance in smallholder farming systems. Uganda has three major indigenous goat breeds (Mubende, Kigezi and Small East African goats) that are geographically isolated and are raised in diverse production systems (Mason \& Maule 1960; Nsubuga 1996; MAAIF \& UBOS 2009). Besides these three indigenous breeds, several indistinct ecotypes of Ugandan indigenous goat breeds exist, including Karamojong and Sebei. In the early 1990's, cross-breeding with introduced Boer goats from South Africa was initiated to improve the production characteristics of the Ugandan indigenous goats (Nsubuga 1996). Boer goats are widely used as a source of breeding stock to cross with the indigenous goats (Onzima et al. 2014). The choice of Boer goats was premised on the fact that they have a fast growth rate and exhibit better disease resistance than other exotic goat breeds (Casey \& Van Niekerk 1988). However, with uncoordinated breeding management, indiscriminate crossing may occur increasing the risk of the disappearance of resilient and well adapted indigenous breeds. The existence of the various breeds presents an enormous source of diversity in the current goat populations that needs to be characterized, conserved and utilized in a sustainable manner under the existing production systems. Genetic diversity in populations is important since it provides the basis for natural as well as artificial selection (Qanbari \& Simianer 2014).

In order to study diversity, molecular tools are essential as a valuable complement to the evaluation of phenotypes and production systems, and sometimes as a proxy for phenotypic diversity of local breeds (Ajmone-Marsan et al. 2014). However, compared to other livestock species, African goats remain poorly studied especially at the molecular level. Earlier studies in Africa, using mitochondrial and 
microsatellite DNA markers, indicate a lack of phylogeographic structure amongst the goat breeds (Alemu 2004; Chenyambuga et al. 2004; Okpeku et al. 2011; Hassen et al. 2012; Benjelloun et al. 2015). These studies were mainly geared towards assessing genetic diversity to monitor genetic erosion and to identify conservation priorities. In Uganda, earlier genetic characterization of the indigenous goats was carried out using a limited number of microsatellites (Chenyambuga et al. 2004; Muema et al. 2009). A drawback of microsatellite analysis is that it is difficult to integrate data across laboratories, mainly due to the inherent poor reproducibility of allele-calling (FAO 2011). Therefore, a comparison of results from different studies that used microsatellites is complicated. However, the advent of the GoatSNP50 BeadChip in 2014 (Tosser-Klopp et al. 2014) has changed the landscape and depth of genomic research in goats (Tosser-Klopp 2015) due to its robustness, low genotyping costs, automatic allele calling and ability to interrogate the goat genome at high resolution (Ajmone-Marsan et al. 2014). The illumina GoatSNP50 BeadChip that features 53,347 Single Nucleotide Polymorphisms (SNPs) was developed from SNP loci detected by whole genome sequencing of six goat breeds (Tosser-Klopp et al. 2014; Tosser-Klopp 2015). The SNP chip has been used to study genetic diversity and population structure of goats in various countries with indigenous goat breeds such as Italy (Nicoloso et al. 2015), Spain (Manunza et al. 2016), South Africa (Lashmar et al. 2016; Mdladla et al. 2016; Visser et al. 2016), Ethiopia (Abegaz 2014; Mekuriaw 2016) and Australia (Kijas et al. 2013). Therefore, the objective of the current study was to: (i) assess the degree of genetic diversity in Ugandan goat breeds using SNPs, (ii) infer population structure and breed relationships; and (iii) investigate admixture among breeds, namely the influence of the commercial Boer breed in Ugandan goats. The information generated from this study can be used in management and conservation of Ugandan goat genetic resources and makes it possible to design effective strategies for breed improvement.

\subsection{Material and methods}

\subsubsection{Animal resources and sampling}

A total of 144 animals from six goat breeds were included in this study. Five indigenous goat breeds (Mubende, Kigezi, Small East African, Karamojong and Sebei) were sampled from 79 smallholder farms/herds, while the exotic Boer goats were sampled from a commercial multiplication centre (Ssembeguya Estates) and a government breeding centre (Rubona Stock farm) that are sources of breeding stock for goat improvement in Uganda. 
Sampling was carried out at selected geographical locations (Figure 4.1) according to livestock statistics from the Livestock Census Report 2008 (MAAIF \& UBOS 2009). The goat populations sampled originated from the following five agro-ecological zones of Uganda: Mubende goats from Mubende district in the mid altitude farmlands and central wooded savanna; Kigezi from Kabale and Kisoro districts in the south western highlands; Small East African from Arua district in the short savanna grasslands; Karamojong from Moroto district in the north eastern semi-arid region; Sebei from Sironko in the eastern highlands; and Boer goats from Ssembabule and Kabarole district in the mid altitude zone. Sampling was done to cover a wide distribution of individual animals across the selected production locations. Within a herd we relied on the farmers' pedigree knowledge to select as much as possible unrelated individuals.

Ear punch tissue was collected from the 144 goats at smallholder farms for the indigenous breeds Mubende $(n=29)$, Kigezi $(n=29)$, Small East African $(n=29)$, Karamojong $(n=15)$ and Sebei $(n=29)$, and at a commercial and a government breeding centre for Boer $(n=13)$. The ear tissue samples were collected into vials containing a desiccant and stored within 12 hours in a freezer at $-4^{\circ} \mathrm{C}$.

The study was approved by the ethics committee of Uganda National Council of Science and Technology (UNCST)(SBLS/REC/15/131).

\subsubsection{DNA Extraction}

Genomic DNA was extracted using the DNeasy blood and tissue kit (Qiagen ${ }^{\bullet}$, Hilden, Germany). Twenty DNA samples were randomly selected and analyzed on a $1 \%$ agarose gel for a preliminary estimate of the DNA quality and quantity. The final DNA quality and quantity were validated using Qubit ${ }^{\circledR}$ dsDNA BR (Broad-Range) Assay Kit on the Qubit 2.0 fluorimeter (Invitrogen, Germany), prior to genotypying.

\subsubsection{Genotyping and quality control}

DNA samples were genotyped with the Illumina GoatSNP50 bead chip (Illumina Inc., San Diego, CA 92122 USA). The bead chip, developed by the International Goat Genome Consortium (IGGC), features 53,347 SNPs across the whole goat genome with inter SNP spacing of approximately $40 \mathrm{~kb}$ (Tosser-Klopp et al. 2014). Data were analyzed with Genome Studio ${ }^{\text {TM }}$ software v1.1 (Illumina Inc.). Genomic locations of the SNPS and cluster files were provided by IGGC. Standard SNP genotype quality control procedures were performed using PLINK v1.07 (Purcell et al. 2007). Individuals with missing genotype call rate of more than or equal to $10 \%$ were excluded from further analysis using the --mind function in PLINK. The remaining 
individuals were then subjected to SNP quality control. The SNPs with call rate of less than 0.95 , minor allele frequency (MAF) of 0.05 or less and SNPs whose genotypes were not in Hardy Weinberg Equilibrium (HWE) $\mathrm{P}<0.001$ were excluded from downstream analysis. The dataset of SNPs used in the analysis are available from https://www.animalgenome.org/repository/pub/WAGNL2017.1002/.

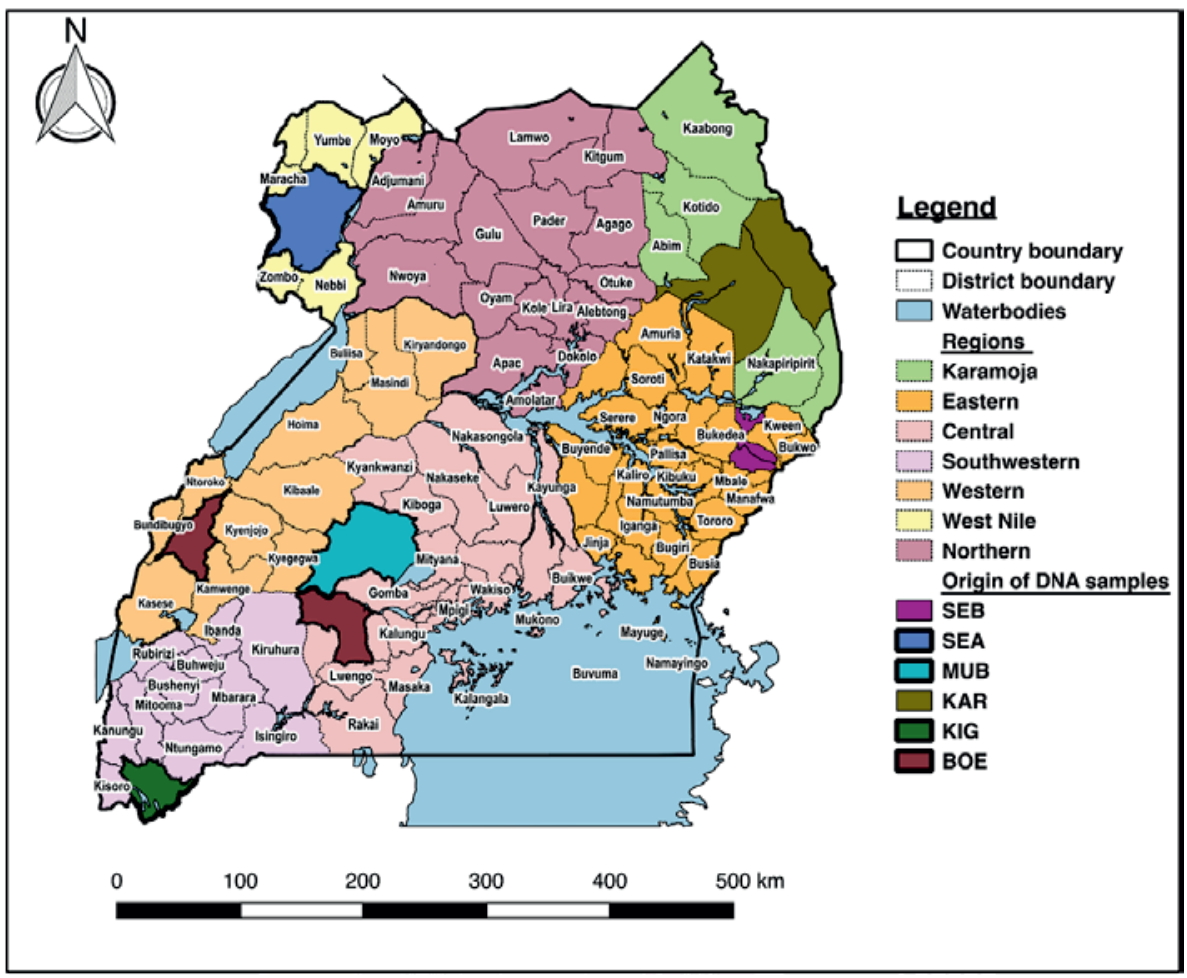

Figure 4.1 Map of Uganda showing geographical origin of the goat DNA samples analysed. Breed acronyms are defined as follows: BOE, Boer; KAR, Karamojong; KIG, Kigezi; MUB, Mubende; SEA, Small East African; SEB, Sebei. 


\subsubsection{Data analysis}

The observed $\left(H_{0}\right)$ and expected $\left(H_{E}\right)$ heterozygosity's for the respective populations were calculated using PLINK (Purcell et al. 2007). The population structuring and relatedness were estimated from the SNP genotypes using principal component analysis (PCA) available from the R package SNPrelate (Zheng et al. 2012).

Additionally, population structure analyses were performed to infer the most likely number of ancestral populations using ADMIXTURE software version 1.23 (Alexander et al. 2009; Alexander \& Lange 2011). To estimate the individual ancestry within the population, ADMIXTURE employs prior defined $K$-values corresponding to the assumed number of ancestral populations. The procedure involves the use of maximum likelihood estimates on data from multiple loci to estimate individual ancestry within the population being considered. To determine the most optimal population structure, a cross validation procedure was undertaken with hypothetical ADMIXTURE runs from $K=2$ to 7 . Optimal partitioning of the population was achieved at the lowest cross-validation error.

Phylogenetic relationships between the goat breeds were inferred using the Neighbour-Net procedure in the SPLITSTREE 4 software (Huson \& Bryant 2006) based on Reynold's genetic distances, while individual relationships across all breeds were calculated using Identity by state (IBS) distances.

To further investigate admixture in Ugandan goat breeds, we performed three population $\left(f_{3}\right)$ test (Reich et al. 2009; Patterson et al. 2012) and four population $\left(f_{4}\right)$ test (Keinan et al. 2007; Patterson et al. 2012) implemented in TreeMix (Pickrell \& Pritchard 2012). These statistics are used to explain admixture history of the populations being investigated particularly where correlations in allele frequencies do not conform to population evolution with split tree (Reich et al. 2009; Patterson et al. 2012). To provide support for past admixture events between the populations, the THREEPOP program from TreeMix was used to calculate $f_{3}(\mathrm{~A} ; \mathrm{B}, \mathrm{C})$ statistics for all possible combinations of three populations. Generally, if a population $A$ is a result of an admixture between two other populations B and C, the calculated z-score for each tested combination of three populations would have a significant negative value. A positive z-score may either indicate absence of admixture or substantial post-admixture drift resulting from the alleles in the population. Meanwhile, the FOURPOP program from TreeMix was used to calculate $f_{4}(A, B ; C, D)$ statistics for subsets of the population. The four population test $f_{4}(A, B ; C, D)$ (Keinan et al. 2007; 
Patterson et al. 2012) was used to test if (A,B) and (C,D) are genetically distinct groups (clades) in the population tree. A significant non-zero z-score indicates geneflow between $(A, B)$ and $(C, D)$ in the population tree (Keinan et al. 2007; Patterson et al. 2012; Makina et al. 2016). Larger values indicate strong evidence of gene-flow in the tree.

\subsection{Results}

\subsubsection{Level of SNP polymorphism within breeds}

After quality control procedures on the 53,347 SNPs included in the SNP chip, 7,242 SNPs were excluded (Table 4.1) which resulted in 46,105 loci available for downstream analysis. Of the SNPs excluded, 2,093 showed SNP call rate $<0.95,3,500$ had MAF $<0.05$ and 2,817 significantly deviated from HWE $(p<0.001)$. The highest number of SNPs that showed a MAF $<0.05$ was found in Small East African $(n=7,818)$ while Sebei showed the lowest number of SNPs excluded $(n=6,826)$. All animals passed the quality criteria and were used in the analysis.

Table 4.1 Number of animals and SNPs excluded and remaining after quality control procedures on genotype data

\begin{tabular}{lllllll}
\hline & & \multicolumn{2}{c}{$\begin{array}{l}\text { Excluded SNPs } \\
\text { Breed }\end{array}$} & MAF & & \multicolumn{2}{l}{ Remaining } \\
SNP CR $<0.95$ & $<0.05$ & HWE & Total & SNPs \\
\hline Boer & 13 & 2,577 & 5,280 & 208 & 7,323 & 46,024 \\
Karamojong & 15 & 2,640 & 5,687 & 358 & 7,803 & 45,544 \\
Kigezi & 29 & 1,977 & 6,139 & 543 & 7,793 & 45,554 \\
Mubende & 29 & 2,260 & 4,922 & 767 & 7,034 & 46,313 \\
Small East African & 29 & 2,523 & 5,669 & 589 & 7,818 & 45,529 \\
Sebei & 29 & 2,429 & 4,824 & 469 & 6,826 & 46,521 \\
Merged & 144 & 2,093 & 3,500 & 2,817 & 7,242 & 46,105 \\
\hline
\end{tabular}

${ }^{1}$ Some SNPs were excluded due to more than a single criterion. $\mathrm{N}$ is number of animals; $\mathrm{CR}$ call rate; MAF minor allele frequency; HWE chi square test for Hardy-Weinberg equilibrium ( $p$-value $<0.001$ ).

loci $(\mathrm{MAF}=0)$ was similar across the breeds, ranging from Karamojong (0.06) to Mubende (0.04). Despite only Boer being represented in the group of goat breeds used to develop this SNP array, $93.4 \%$ of the SNP markers across the six goat breeds was polymorphic (MAF $\geq 0.05$ ) (Table 4.2). The highest proportion of polymorphic 
loci (PN) was found in Sebei (0.928) and the lowest in Kigezi (0.885); however, the differences in $P_{N}$ were negligible across all the breeds.

\subsubsection{Breed genetic diversity}

Genetic diversity was assessed within each breed (Table 4.2). The results indicate small differences in genetic diversity between the breeds. The lowest observed heterozygosity was found in Kigezi $\left(\mathrm{H}_{\mathrm{O}}=0.340 \pm 0.181\right)$ and the highest in Boer ( $\mathrm{H}_{\mathrm{O}}=$ $0.377 \pm 0.193$ ), indicating higher diversity in Boer compared to Kigezi. Also, the MAFs across all loci were lowest in Kigezi (0.257) and highest in Boer (0.280). In general, the observed heterozygosity was slightly lower.

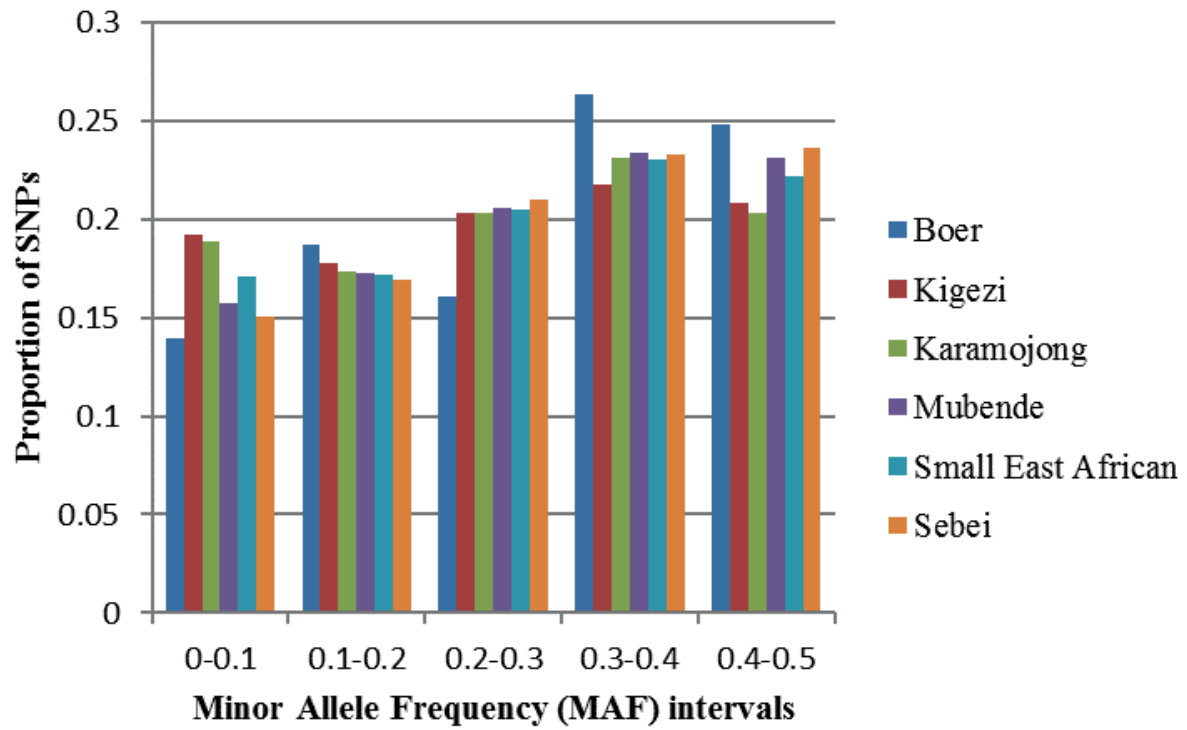

Figure 4.2 Distribution of SNPs by MAF intervals in each breed. 
Table 4.2 Population characteristics showing proportion of polymorphic SNPs ( $\left.P_{N}\right)$, mean minor allele frequency (MAF), expected $\left(H_{E}\right)$ and observed $\left(H_{0}\right)$ heterozygosity for the six goat populations

\begin{tabular}{llllll}
\hline Breed & $\mathrm{N}$ & $\mathrm{P}_{\mathrm{N}}$ & $\mathrm{MAF}$ & $\mathrm{H}_{\mathrm{E}} \pm \mathrm{SD}$ & $\mathrm{H}_{\mathrm{O}} \pm \mathrm{SD}$ \\
\hline Boer & 13 & 0.901 & 0.280 & $0.408 \pm 0.178$ & $0.377 \pm 0.193$ \\
Karamojong & 15 & 0.893 & 0.271 & $0.410 \pm 0.192$ & $0.357 \pm 0.192$ \\
Kigezi & 29 & 0.885 & 0.257 & $0.377 \pm 0.189$ & $0.340 \pm 0.181$ \\
Mubende & 29 & 0.908 & 0.272 & $0.391 \pm 0.179$ & $0.355 \pm 0.178$ \\
Small East African & 29 & 0.894 & 0.266 & $0.393 \pm 0.189$ & $0.349 \pm 0.180$ \\
Sebei & 29 & 0.928 & 0.274 & $0.395 \pm 0.178$ & $0.365 \pm 0.176$ \\
Merged & 144 & 0.934 & 0.289 & $0.384 \pm 0.143$ & $0.355 \pm 0.147$ \\
\hline
\end{tabular}

\subsubsection{Population structure analysis}

The first principle component, eigen vector 1 (EV1) in Figure 4.3A separates the Boer from the Ugandan indigenous goat breeds and accounts for $10.7 \%$ of the total variance. The second principle component (EV2) accounts for $3.2 \%$ of the total variance and divides the Ugandan indigenous goat breeds into two clusters: a distinct cluster comprising of Kigezi and Mubende breeds and a combined breed cluster consisting of Sebei, Karamojong and Small East African breeds (Figure 4.3). A more detailed analysis in which the first principle component (EV1) explained $3.6 \%$ and second principle component (EV2) accounted for $2.9 \%$ of total variance in the Ugandan indigenous goat breeds showed a similar clustering pattern for all breeds except the Small East African goats which formed a separate cluster (Figure 4.3B). Mubende clusters between all other breeds indicating possible admixture with the other goats.

Breed relationships were also assessed by computing genetic distances between each pair of individuals from the number of loci for which they differ. Based on the estimated genetic distances, a Neighbour-Net graph was computed to depict breed clustering (Figure 4.4). The Ugandan indigenous breeds show short branching suggesting low differentiation between the breeds, while the exotic Boer goat breed shows a long branch suggesting a well-differentiated and distinctive clade. Individuals belonging to the same breed mostly clustered together as inferred by the IBS distance-based Neighbour Joining tree (Fig.4.S1). Some individuals of Sebei and Karamojong appear to be entangled (or admixed), whereas Mubende is sub-divided into two groups. The remaining breeds (i.e. Small East African, Kigezi and Boer) all form tight groups. 


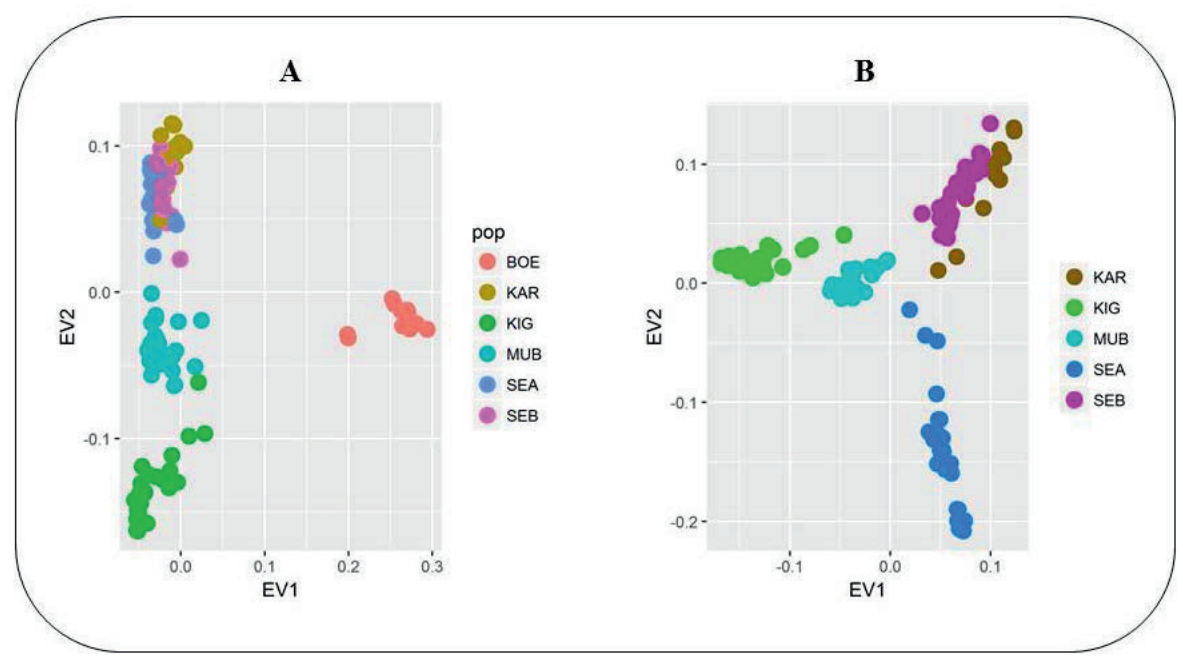

Figure 4.3 Principle components analyses plot based on SNP array data. A 5 Ugandan indigenous goats and Boer breeds and B 5 Ugandan indigenous goat breeds only: Goat populations analysed: $\mathrm{BOE}=$ Boer, $\mathrm{KAR}=$ Karamojong, $\mathrm{KIG}=$ Kigezi, MUB=Mubende, $\mathrm{SEA}=$ Small East African and SEB=Sebei

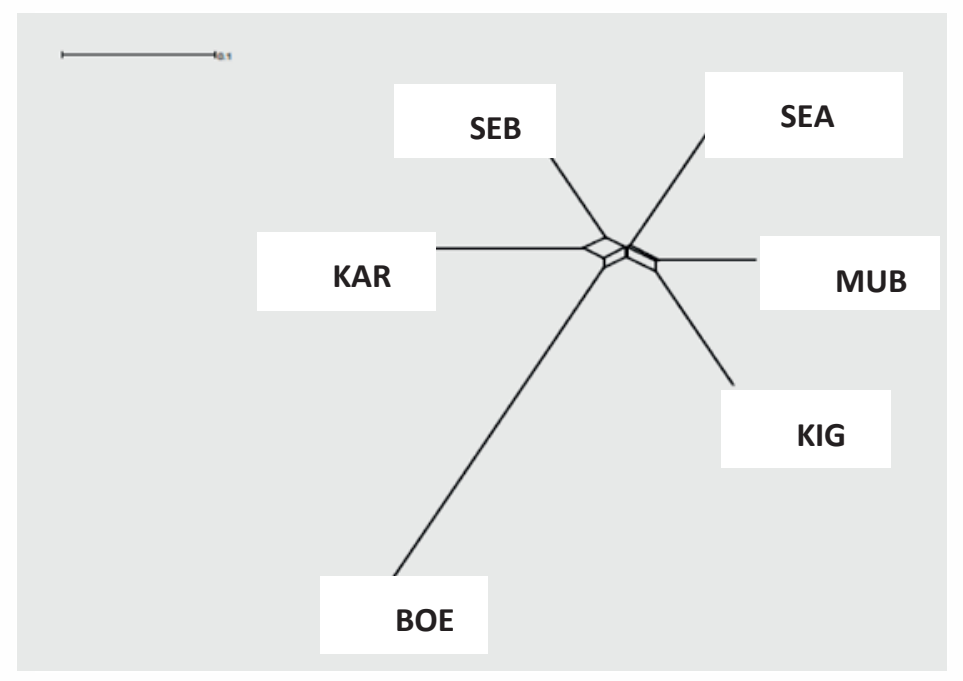

Figure 4.4 Neighbour-Net graph based on Reynolds genetic distances depicting breed relationships among five Ugandan indigenous goat populations and one commercial goat breed. BOE=Boer, KAR=Karamojong, $\mathrm{KIG}=$ Kigezi, MUB=Mubende, SEA = Small East African and SEB=Sebei. 


\subsubsection{Genetic admixture}

Similar to the results from PCA, ADMIXTURE analysis at $K=2$ separates the Ugandan indigenous goats from the commercial Boer goats (Fig.4.5). Additionally, at $K=3$ the analysis separates the populations into three subpopulations: Boer; Kigezi and Mubende; and Small East African, Karamojong and Sebei. It also indicates a considerable component of Boer and Kigezi in the subpopulations. Based on the least

cross-validation error (Figure 4. S2), $K=4$ was identified as the optimal number of ancestral populations and indicates a Boer component in all the five Ugandan indigenous goats. On average, around 3,5,5,1 and $1 \%$ of the Boer goat genome was shared with Karamojong, Kigezi, Mubende, Small East African and Sebei goats, respectively (Table 4.3). It also revealed a finer resolution of the Ugandan indigenous breeds at which Kigezi and Small East African goats emerged as a distinct group. Karamojong and Sebei remained tightly clustered together and Mubende breed appears to be the more admixed population comprising of Kigezi, Small East African and Karamojong/Sebei breeds (50, 20 and 25\% respectively). ADMIXTURE runs from $=2$ to $K=4$ revealed considerable admixture between the breeds and gene-flow from Boer was observed in all the indigenous Ugandan goat breeds.

To further confirm admixture between the goat breeds, we calculated $f_{3}$ statistics for all possible three population groups for all the six breeds, and $f_{4}$ statistics for all possible sub-populations for sister and opposing sister groups. With the Ugandan goats in this study, we found only four significant $f_{3}$ tests that all involved the Mubende breed (Table 4.4). This suggests admixture between Mubende and the other goat breeds. 

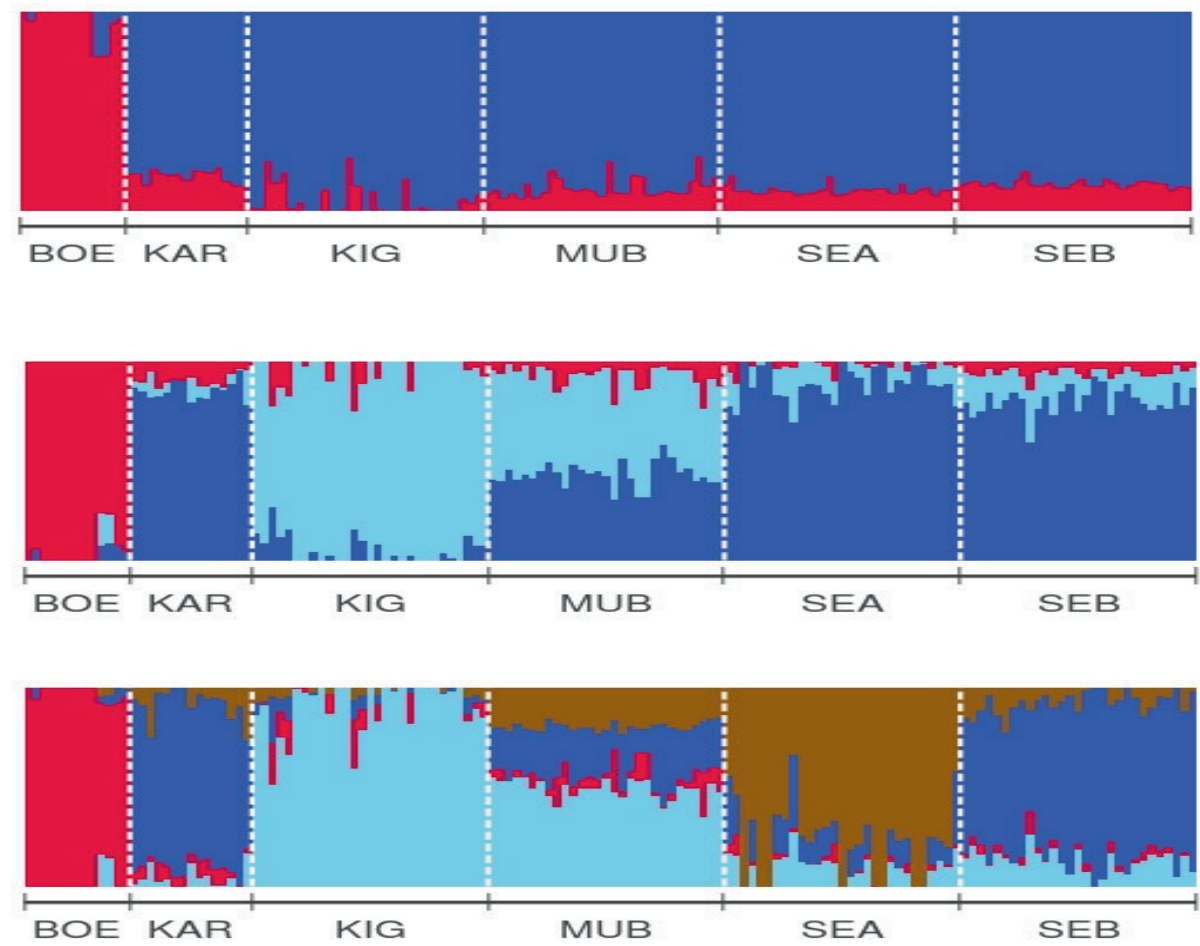

Figure 4.5 Population structure plots showing proportions of ancestral populations for

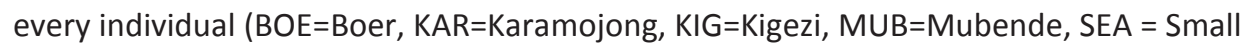
East African and SEB=Sebei) for $K=2$ to 4 
Table 4.3 Average breed composition of 6 goat populations given 4 clusters estimated by ADMIXTURE software

\begin{tabular}{lllllll}
\hline Breed & $N$ & $\begin{array}{l}\text { Cluster } \\
(\mathrm{SEA})\end{array}$ & $\begin{array}{l}\text { Cluster } \\
(\mathrm{KAR} / \mathrm{SEB})\end{array}$ & $\begin{array}{l}\text { Cluster } \\
(\mathrm{BOE})\end{array}$ & $\begin{array}{l}\text { Cluster } \\
(\mathrm{KIG})\end{array}$ \\
\hline Boer & 13 & $0.008 \pm 0.017$ & $0.018 \pm 0.027$ & $0.950 \pm 0.084$ & $0.024 \pm 0.055$ \\
Karamojong & 15 & $0.091 \pm 0.079$ & $0.840 \pm 0.120$ & $0.031 \pm 0.025$ & $0.038 \pm 0.056$ \\
Kigezi & 29 & $0.022 \pm 0.027$ & $0.027 \pm 0.046$ & $0.045 \pm 0.070$ & $0.905 \pm 0.129$ \\
Mubende & 29 & $0.202 \pm 0.022$ & $0.245 \pm 0.066$ & $0.049 \pm 0.053$ & $0.503 \pm 0.055$ \\
Small East African & 29 & $0.776 \pm 0.178$ & $0.123 \pm 0.107$ & $0.009 \pm 0.023$ & $0.091 \pm 0.070$ \\
Sebei & 29 & $0.077 \pm 0.059$ & $0.784 \pm 0.121$ & $0.012 \pm 0.021$ & $0.127 \pm 0.058$ \\
\hline
\end{tabular}

$\mathrm{BOE}=$ Boer, $\mathrm{KAR}=$ Karamojong, $\mathrm{KIG}=$ Kigezi, $\mathrm{MUB}=$ Mubende, $\mathrm{SEA}=$ Small East African and SEB=Sebei goats

Table 4.4 Summary of three population tests with significant $f_{3}$ statistics showing admixture in Ugandan goats with Kigezi as one of the source populations

\begin{tabular}{lllllll}
\hline $\begin{array}{l}\text { Population } \\
\text { (Admixed) }\end{array}$ & A & $\begin{array}{l}\text { Population } \\
\text { (Source) }\end{array}$ & $\begin{array}{l}\text { Population } \\
\text { (Source) }\end{array}$ & $\begin{array}{l}\text { C } \\
\text { (S Statistic }\end{array}$ & SE & Z-score \\
\hline MUB & BOE & KIG & -0.0017 & 0.0002 & $-7.1891^{* *}$ \\
MUB & KIG & SEB & -0.0012 & 0.0001 & $-13.7787^{* *}$ \\
MUB & KAR & KIG & -0.0016 & 0.0001 & $-16.0069^{* *}$ \\
MUB & KIG & SEA & -0.0016 & 0.0001 & $-19.4077^{* *}$ \\
\hline
\end{tabular}

$\mathrm{BOE}=$ Boer, $\mathrm{KAR}=$ Karamojong, $\mathrm{KIG}=$ Kigezi, $\mathrm{MUB}=$ Mubende, SEA=Small East African and $\mathrm{SEB}=$ Sebei goats. ${ }^{* *}$ significant $f_{3}$ statistics.

Based on the $f_{4}$ test statistic, combining Boer with any of the Ugandan indigenous goats resulted into the most significant values (Table 4.5). This suggests gene-flow from Boer into Ugandan indigenous breeds. Similarly, the significant $f_{4}$ statistics for subpopulations involving Karamojong and Kigezi goats with the other Ugandan indigenous goats suggest gene-flow from these breeds (Table 4. S1). 
Table 4.5 Significant $f_{4}$ statistics for Ugandan indigenous goats with Boer goat breed

\begin{tabular}{|c|c|c|c|c|c|c|}
\hline Pop 1 & Pop 2 & Pop 3 & Pop 4 & f4 statistic & Std error (se) & Z Score \\
\hline BOE & KIG & KAR & MUB & 0.0050 & 0.0002 & $20.5959 * *$ \\
\hline BOE & MUB & KAR & KIG & 0.0051 & 0.0003 & $20.4125^{* *}$ \\
\hline BOE & KAR & MUB & SEB & 0.0034 & 0.0002 & $16.4090 * *$ \\
\hline BOE & KIG & KAR & SEB & 0.0022 & 0.0002 & $14.3987 * *$ \\
\hline BOE & KAR & KIG & SEB & 0.0033 & 0.0003 & $12.5043^{* *}$ \\
\hline BOE & MUB & KAR & SEB & 0.0018 & 0.0002 & $12.1647^{* *}$ \\
\hline BOE & MUB & KAR & SEA & 0.0027 & 0.0003 & $10.8053^{* *}$ \\
\hline BOE & KIG & KAR & SEA & 0.0027 & 0.0003 & $10.2101 * *$ \\
\hline BOE & KAR & SEA & SEB & 0.0020 & 0.0002 & $9.2824 * *$ \\
\hline BOE & SEA & KAR & SEB & 0.0014 & 0.0002 & $8.2888^{* *}$ \\
\hline BOE & KAR & MUB & SEA & 0.0014 & 0.0002 & $6.0396 * *$ \\
\hline BOE & SEA & KAR & MUB & 0.0013 & 0.0002 & $5.6349 * *$ \\
\hline BOE & SEA & KAR & KIG & 0.0014 & 0.0003 & $5.0805^{* *}$ \\
\hline BOE & SEB & MUB & SEA & 0.0010 & 0.0002 & $4.4690 * *$ \\
\hline BOE & KAR & KIG & SEA & 0.0013 & 0.0003 & $4.4078 * *$ \\
\hline BOE & SEB & KAR & KIG & -0.0011 & 0.0003 & $-4.0038^{* *}$ \\
\hline BOE & MUB & SEA & SEB & -0.0009 & 0.0002 & $-4.1880 * *$ \\
\hline BOE & SEB & KAR & MUB & -0.0016 & 0.0002 & $-6.4749 * *$ \\
\hline BOE & KIG & MUB & SEA & -0.0023 & 0.0002 & $-9.8169 * *$ \\
\hline BOE & MUB & KIG & SEA & -0.0024 & 0.0003 & $-9.4555^{* *}$ \\
\hline BOE & KIG & MUB & SEB & -0.0028 & 0.0002 & $-12.9529 * *$ \\
\hline $\mathrm{BOE}$ & MUB & KIG & SEB & -0.0033 & 0.0002 & $-14.3171 * *$ \\
\hline
\end{tabular}

$\mathrm{BOE}=$ Boer, $\mathrm{KAR}=$ Karamojong, $\mathrm{KIG}=$ Kigezi, $\mathrm{MUB}=$ Mubende, SEA=Small East African and $\mathrm{SEB}=$ Sebei goats. ${ }^{* *}$ significant $f_{4}$ statistics indicating presence of gene-flow. 


\subsection{Discussion}

In this study, we assessed genetic diversity, population structure and admixture in Ugandan indigenous goat breeds at a genome-wide scale using a moderately dense SNP panel. We further assessed the presence of admixture of an exotic goat breed (Boer) into the Ugandan breeds.

\subsubsection{Genotypic data and level of polymorphism}

The first objective of the study was to assess the level of polymorphism in Ugandan goat breeds with the GoatSNP50 BeadChip. Our results show that the proportion of polymorphic loci within Ugandan goat breeds ranges from 0.885 in Kigezi goats to 0.928 in Sebei (Table 4.2). This high level of genetic polymorphism indicates that most of the SNPs are segregating in the breeds under investigation. The level of polymorphism observed in this study is similar to those observed during SNP discovery and validation within breeds with similar numbers of animals genotyped (Tosser-Klopp et al. 2014). The GoatSNP50 BeadChip was developed using dairy and mixed breeds (Alpine, Saanen and Creole) and meat type breeds (Boer, Katjang and Savanna). The chip was validated with 10 breeds from different backgrounds. The SNPs were segregating at $>78 \%$ in seven of the breeds, including Angora and Skopelos that were not used during SNP discovery (Tosser-Klopp et al. 2014). Similar levels of polymorphism in goat breeds have been reported elsewhere (Kijas et al. 2013; Nicoloso et al. 2015; Lashmar et al. 2016; Mdladla et al. 2016; Mekuriaw 2016). For example, Mdladla et al. (2016) reported levels of polymorphism ranging from $84.2 \%$ to $97.6 \%$ in nine South African indigenous goats, $96.8 \%$ to $99.7 \%$ in Italian goats (Nicoloso et al. 2015) and greater than $97 \%$ in Australian goat breeds (Kijas et al. 2013). The success of the chip can be attributed to the use of six goat breeds from different types, origins and production environments for SNP discovery. Therefore, similar high levels of polymorphism were envisaged across other breeds that were not used during the design of the SNP chip.

\subsubsection{Breed genetic diversity}

The Ugandan indigenous goats and the Boer breeds show a high degree of genetic diversity as determined by the high heterozygosity values detected in this study. Our results revealed that the expected and observed heterozygosity's ranged from $0.377 \pm 0.189$ (Kigezi) to $0.410 \pm 0.192$ (Karamojong) and $0.340 \pm 0.181$ (Kigezi) to $0.377 \pm 0.193$ (Boer), respectively (Table 4.2). The heterozygosity values obtained in this study are comparable with those reported for indigenous goats in Ethiopia (Mekuriaw 2016), South Africa (Mdladla et al. 2016), Egypt (Kim et al. 2016), Spain 
(Manunza et al. 2016) and Italy (Nicoloso et al. 2015), as well as for commercial goats from Canada and Australia (Brito et al. 2017), South Africa (Lashmar et al. 2016) and a variety of Angora goat populations in Argentina, France and South Africa (Visser et al. 2016).

The expected and observed heterozygosity for Boer $(0.408 \pm 0.178$ and $0.377 \pm 0.193$ ) were slightly higher than those reported for Boer populations in Canada ( $H_{E}=0.357$ and $H_{O}=0.363$ ) (Brito et al. 2017) and Australia $\left(H_{E}=0.355\right.$ and $H_{O}=0.363$ ) (Kijas et al. 2013). These differences may be attributed to differences in effective population sizes, duration of isolation and selection practices in the different production systems.

We obtained the highest expected heterozygosity in Karamojong goats, which could be due to the pastoral production system used. Under communal production systems practiced by pastoral and smallholder farmers, there is absence of structured artificial selection programs, with random mating and high admixing between populations and herds probably occurring. This favours an increase in genetic variability and reduction in inbreeding, which is a decisive factor in the success for conservation programs. A similar trend of genetic diversity was also reported for indigenous goat breeds in South Africa (Mdladla et al. 2016) and local goat breeds in Brazil (da Rocha et al. 2016). Similarly, a study investigating breed composition of Creole goats from 10 American countries found a moderate to high heterozygosity values (Ginja et al. 2017).

The difference between the observed and expected heterozygosity was small and within a fraction of one standard error. As a general trend, the observed heterozygosity was lower than the expected heterozygosity $\left(H_{O}<H_{E}\right)$ within all breeds. Thus, these differences may be due to a Wahlund effect rather than inbreeding.

\subsubsection{Population structure and admixture}

The results of the population structure and admixture analyses indicate that the five Ugandan goat breeds are weakly differentiated. This may be due to the recent establishment of these breeds from probably the same founder population or related populations, but to confirm this, an in-depth analysis of the breed history will be required. Another possible explanation for the low degree of differentiation could be continuous gene-flow between the indigenous breeds.

The results of our population structure and admixture analyses agree. The three methods used separate the breeds into clusters. The first principle component separates the Boer from the Ugandan indigenous goat breeds (Figure 4.3). 
Furthermore, the presence of a distinct branching of Boer in the Neighbour Joining (NJ) tree suggests a differentiated gene-pool (Figure 4.4).

At $K=2$, the ADMIXTURE analysis separates the breeds into two distinct clusters, the Boer and the Ugandan indigenous goats (Figure 4.5). This observation agrees with the PCA results that show the same two major clusters. The optimal clustering is observed at $K=4$ where the cross-validation error is lowest (Fig. S2). At this optimal $K$-value, ADMIXTURE analysis differentiates Ugandan indigenous goat breeds into distinct clusters of Small East African and Kigezi, and Karamojong \& Sebei tightly grouped together, while Mubende is admixed showing influences from the 3 groups. The differentiation of Kigezi and Small East African goats could be attributed to genetic drift but could have resulted from selection and/ or adaptation pressures.

The three $\left(f_{3}\right)$ and four $\left(f_{4}\right)$ population tests (Reich et al. 2009; Patterson et al. 2012; Keinan et al. 2007) were used to further qualify admixture and gene-flow. Using the three-population test statistic, we found strong evidence of admixture in only four comparisons, all involving the Mubende goats as the admixed breed. The most significant z-score (-19.408) was found with Mubende $f_{3}$ (Mubende; Kigezi, Small East African). All the significant $f_{3}$ statistics were observed when Kigezi was one of the source populations indicating that Kigezi might be contributing to the gene pool either through ancestral generations or crossbreeding with Mubende. The $f_{4}$ statistics showed the most significant scores for the Boer and the Ugandan indigenous goats (Table 4. S1). This is supported by the results of the Admixture analysis as soon by breed composition of individual goats studied (Table 4. S2). However, determining the extent of the admixture in the Ugandan goat populations requires further studies involving larger sample sizes and more ecotypes and breeds.

The indigenous Ugandan goat breeds showed a clear differentiation according to their geographical regions. The results show a clear differentiation of Kigezi and Small East Africa, while Karamojong and Sebei remained tightly clustered together, which may be attributed to the contiguous territory of the breeds (Figure 4.1). Mubende is centrally located and prone to admixture with Kigezi, Karamojong/Sebei and Small East African. The lack of differentiation in some of the indigenous breeds is also confirmed by the presence of short branches in the NJ tree (Figure 4.4), suggesting a high level of genetic similarity and low divergence, which may be attributed to local admixture between the breeds. The lack of differentiation in geographically diverse populations may also indicate common ancestry, short domestication history, lack of selection pressure and mobility of the goats may play a role. The Boer goat breed was introduced into Uganda for improving growth 
characteristics of the indigenous goats for meat production. The breed originates from South Africa, where it has been extensively selected for faster growth (Casey \& Van Niekerk 1988).

Our results support admixture between all the breeds, although the highest admixture was observed in Mubende goats. This may be due to the fact that the breed is widely used across production systems as a preferred breed by the farmers due to its large live body weight (Onzima et al. 2016, 2017). ADMIXTURE analysis further revealed admixing between the Boer and the indigenous goats, however, the results suggest there is limited gene-flow from Boer to the Ugandan indigenous goat populations due to cross-breeding.

\subsection{Conclusion}

Overall, the results described in this study indicate a high genetic variability of the Ugandan goat populations and sufficient genetic potential for further improvement of the breeds for heritable economic traits. The Ugandan indigenous goats are weakly differentiated consisting of two breeds forming more uniform clusters (Kigezi and Small East African), two breeds clearly cross-bred (Karamojong and Sebei) and Mubende showing signs of gene-flow from all these goat populations. Nonetheless, there is rather limited Boer admixture in the Ugandan goat population. This knowledge can be exploited to devise strategies for sustainable utilization and maintenance of genetic diversity.

\section{Acknowledgements}

We would like to acknowledge Bert Dibbits from Wageningen University \& Research, Animal Breeding and Genomics for performing the quality and quantity measurements on the genomic DNA samples. We acknowledge Paul Kashaija from the National Livestock Resources Research Institute and Benda Katali from Kachwekano Zonal Agricultural Research and Development Institute for support in DNA extraction and field sampling respectively. We are grateful for funding from National Agricultural Research Organization (NARO) through a world bank supported project, Agricultural Technology and Agribusiness Advisory Services (ATAAS) (P109224). The smallholder farmers who allowed their animals to be sampled for the study are greatly honoured. 


\section{References}

Abegaz S.G. (2014) Design of community based breeding programs for two indigenous goat breeds in Ethiopia. p. 100. PhD Thesis - Department of Sustainable Agricultural Systems, BOKU-University of Natural Resources and Life Sciences, Vienna - Austria, 100pp.

Ajmone-Marsan P., Colli L., Han J.L., Achilli A., Lancioni H., Joost S., Crepaldi P., Pilla F., Stella A., Taberlet P., Boettcher P., Negrini R. \& Lenstra J.A. (2014) The characterization of goat genetic diversity: Towards a genomic approach. Small Ruminant Research 121, 58-72.

Alemu T. (2004) Genetic characterization of indigenous goat populations of Ethiopia using microsatellite DNA markers. National Dairy Research Institute, Deemed University.

Alexander D.H. \& Lange K. (2011) Enhancements to the ADMIXTURE algorithm for individual ancestry estimation. BMC Bioinformatics 12:246.

Alexander D.H., Novembre J. \& Lange K. (2009) Fast model-based estimation of ancestry in unrelated individuals. Genome Res 19:1655-1664. doi:10.1101/gr.094052.109.

Benjelloun B., Alberto F.J., Streeter I., Boyer F., Coissac E., Stucki S., BenBati M., Ibnelbachyr M., Chentouf M., Bechchari A., Leempoel K., Alberti A., Engelen S., Chikhi A., Clarke L., Flicek P., Joost S., Taberlet P. \& Pompanon F. (2015) Characterizing neutral genomic diversity and selection signatures in indigenous populations of Moroccan goats (Capra hircus) using WGS data. Frontiers in Genetics 6:107. doi:10.3389/fgene.2015.00107

Brito L., Jafarikia M., Grossi D., Kijas J., Porto-Neto L., Ventura R., Salgorzaei M. \& Schenkel F. (2015) Characterization of linkage disequilibrium, consistency of gametic phase and admixture in Australian and Canadian goats. BMC Genetics 16, 1-15.

Brito L.F., Kijas J.W., Ventura R.V., Sargolzaei M., Porto-Neto L.R., Cánovas A., Feng Z., Jafarikia M. \& Schenkel F.S. (2017) Genetic diversity and signatures of selection in various goat breeds revealed by genome-wide SNP markers. BMC Genomics 18, 229.

Casey N.H. \& Van Niekerk W.A. (1988) The boer goat. I. Origin, adaptability, performance testing, reproduction and milk production. Small Ruminant Research 1, 291-302.

Chenyambuga S.W., Hanotte O., Hirbo J., Watts P.C., Kemp S.J., Kifaro G.C., Gwakisa P.S., Petersen P.H. \& Rege J.E.O. (2004) Genetic characterization of 
indigenous goats of sub-Saharan Africa using microsatellite DNA markers. Asian-Australasian Journal of Animal Sciences 17, 445-52.

Clutton-Brock J. (2000) Cattle, sheep, and goats south of the Sahara: an archaeozoological perspective. The Origins and Development of African Livestock-Archaeology, Genetics, Linguistics and Ethnography, 30-7.

da Rocha L.L., Filho E.C.P., Filho M.A.G., Delgado J.V., Martínez A.M. \& Ribeiro M.N. (2016) Impact of foreign goat breeds on the genetic structure of Brazilian indigenous goats and consequences to intra-breed genetic diversity. Small Ruminant Research 134, 28-33.

FAO (2011) Molecular genetic Characterization of animal genetic resources. In: FAO Animal Health Production and Health Guidelines. FAO, Rome.

Garrick D. (2011) The nature, scope and impact of genomic prediction in beef cattle in the United States. Genetics Selection Evolution 43:17.

Gifford-Gonzalez D. \& Hanotte O. (2011) Domesticating Animals in Africa: Implications of Genetic and Archaeological Findings. Journal of World Prehistory 24, 1-23. Doi: https://doi.org/10.1007/s10963-010-9042-2

Ginja C., Gama L.T., Martínez A., Sevane N., Martin-Burriel I., Lanari M.R., Revidatti M.A., Aranguren-Méndez J.A., Bedotti D.O., Ribeiro M.N., Sponenberg P., Aguirre E.L., Alvarez-Franco L.A., Menezes M.P.C., Chacón E., Galarza A., Gómez-Urviola N., Martínez-López O.R., Pimenta-Filho E.C., da Rocha L.L., Stemmer A., Landi V. \& Delgado-Bermejo J.V. (2017) Genetic diversity and patterns of population structure in Creole goats from the Americas. Animal Genetics 48, 315-29.

Hassen H., Lababidi S., Rischkowsky B., Baum M. \& Tibbo M. (2012) Molecular characterization of Ethiopian indigenous goat populations. Tropical Animal Health and Production 44, 1239-46. doi: https://doi.org/10.1007/s11250011-0064-2.

Huson D.H. \& Bryant D. (2006) Application of phylogenetic networks in evolutionary studies. Mol Biol Evol 23. (2): 254-267.

Keinan A., Mullikin J.C., Patterson N. \& Reich D. (2007) Measurement of the human allele frequency spectrum demonstrates greater genetic drift in East Asians than in Europeans. Nature Genetics 39, $1251-1255$

Kijas J.W., Ortiz J.S., McCulloch R., James A., Brice B., Swain B., Tosser-Klopp G. \& the International Goat Genome C. (2013) Genetic diversity and investigation of polledness in divergent goat populations using 52088 SNPs. Animal Genetics 44, 325-35. Doi: https://doi.org/10.1111/age.12011. 
Kim E.S., Elbeltagy A.R., Aboul-Naga A.M., Rischkowsky B., Sayre B., Mwacharo J.M. \& Rothschild M.F. (2016) Multiple genomic signatures of selection in goats and sheep indigenous to a hot arid environment. Heredity 116, 255-64. doi: https://doi.org/10.1038/hdy.2015.94.

Lashmar S.F., Visser C. \& Marle-Köster E.v. (2016) SNP-based genetic diversity of South African commercial dairy and fiber goat breeds. Small Ruminant Research 136, 65-71.

MAAIF \& UBOS (2009) The National Livestock Census Report 2008. Ministry of Agriculture, Animal Industry and Fisheries (MAAIF), Entebbe/Uganda Bureau of Statistics, Kampala, Uganda.

Makina S.O., Whitacre L.K., Decker J.E., Taylor J.F., MacNeil M.D., Scholtz M.M., van Marle-Köster E., Muchadeyi F.C., Makgahlela M.L. \& Maiwashe A. (2016) Insight into the genetic composition of South African Sanga cattle using SNP data from cattle breeds worldwide. Gen. Sel. Evol. 48:88. doi: https://doi.org/10.1186/s12711-016-0266-1.

Manunza A., Noce A., Serradilla J.M., Goyache F., Martínez A., Capote J., Delgado J.V., Jordana J., Muñoz E., Molina A., Landi V., Pons A., Balteanu V., Traoré A., Vidilla M., Sánchez-Rodríguez M., Sànchez A., Cardoso T.F. \& Amills M. (2016) A genome-wide perspective about the diversity and demographic history of seven Spanish goat breeds. Genetics Selection Evolution 48:52. doi: https://doi.org/10.1186/s12711-016-0229-6

Mason I.L. \& Maule J.P. (1960) The Indigenous livestock of eastern and southern Africa. In: Commonwealth bureau of animal breeding and genetics. CAB (Commonwealth Agricultural Bureaux), UK.

Mdladla K., Dzomba E.F., Huson H.J. \& Muchadeyi F.C. (2016) Population genomic structure and linkage disequilibrium analysis of South African goat breeds using genome-wide SNP data. Animal Genetics 47, 471-82. Doi: https://doi.org/10.1111/age.12442

Mekuriaw G. (2016) Molecular characterization of Ethiopian indigenous goat populations: Genetic diversity and structure, demographic dynamics and assessment of the kisspeptin gene polymorphism. Addis Ababa University.

Muema E., Wakhungu J., Hanotte O. \& Jianlin H. (2009) Genetic diversity and relationship of indigenous goats of Sub-saharan Africa using microsatellite DNA markers. Livest Res Rural Dev 21:28. https://www.Irrd.org//rrd21/2/ muem21028.htm

Naderi S., Rezaei H.R., Pompanon F., Blum M.G.B., Negrini R. \& Naghash H.R. (2008) The goat domestication process inferred from large-scale mitochondrial 
DNA analysis of wild and domestic individuals. Proc Natl Acad Sci U S A 105:17659-17664, https://doi.org/10.1073/pnas.0804782105

Nicoloso L., Bomba L., Colli L., Negrini R., Milanesi M., Mazza R., Sechi T., Frattini S., Talenti A., Coizet B., Chessa S., Marletta D., D’Andrea M., Bordonaro S., Ptak G., Carta A., Pagnacco G., Valentini A., Pilla F., Ajmone-Marsan P. \& Crepaldi P. (2015) Genetic diversity of Italian goat breeds assessed with a mediumdensity SNP chip. Genetics Selection Evolution 47:62. doi: https://doi.org/ 10.1186/s12711-015-0140-6

Nsubuga H.S.K. (1996) Small Ruminant: Goats and Sheep in Uganda:. p. 326. ILRI (International Livestock Research Institute) Nairobi, Kenya, UICC, Kampala Uganda $5^{\text {th }}-6^{\text {th }}$ December,1994.

Okpeku M., Peters S.O., Ozoje M.O., Adebambo O.A., Agaviezor B.O., O'Neill M.J. \& Imumorin I.G. (2011) Preliminary analysis of microsatellite-based genetic diversity of goats in southern Nigeria. Animal Genetic Resources 49, 33-41.

Onzima R.B., Gizaw S.,Kugonza D.R., van Arendonk J.A.M. \& Kanis E. (2018) Production system and participatory identification of breeding objective traits for indigenous goat breeds of Uganda. Small Ruminant Research. In Press. DOI:https://doi.org/10.1016/j.smallrumres.2017.07.007

Onzima R.B., Mukiibi R., Benda K.K., van Arendonk J.A.M., Komen H. \& Kanis E. (2016) Participatory definition of breeding objectives and trait preferences by smallholder farmers for indigenous goats in Uganda. In: Book of Abstracts of the 12th International Conference on Goats "ICG 2016", pp. 107-, Antalya, Turkey.

Onzima R.B., Aheisibwe A.R., Benda K.K., Kanis E. \& van Arendonk J.A.M. (2014) Economic analysis of cross breeding programs for indigenous goat breeds in Uganda. In: 10th World Congress on Genetics Applied to Livestock Production (WCGALP). Vancouver, BC, Canada.

Patterson N., Moorjani P., Luo Y., Mallick S., Rohland N. \& Zhan Y. (2012) Ancient admixture in human history. Genetics 192 (3): 1065-1093; https://doi.org/ $\underline{10.1534 / \text { genetics.112.145037 }}$

Pereira F., Queirós S., Gusmão L., Nijman I.J., Cuppen E. \& Lenstra J.A. (2009) Tracing the history of goat pastoralism: new clues from mitochondrial and $Y$ chromosome DNA in North Africa. Mol Biol Evol 26 (12): 2765-2773 DOI: https://doi.org/10.1093/molbev/msp200

Pickrell J.K. \& Pritchard J.K. (2012) Inference of Population Splits and Mixtures from Genome-Wide Allele Frequency Data. PLOS Genetics 8, e1002967. https://doi.org/10.1371/journal.pgen.1002967 
Purcell S., Neale B., Todd-Brown K., Thomas L., Ferreira M.A., Bender D., Maller J., Sklar P., Bakker P.I. \& Daly M.J. (2007) PLINK: a tool set for whole-genome association and population-based linkage analyses. Am J Hum Genet 81(3) 559-575 https://doi.org/10.1086/519795

Qanbari S. \& Simianer H. (2014) Mapping signatures of positive selection in the genome of livestock. Livestock Science 166, 133-43. DOI: https://doi.org/ 10.1016/j.livsci.2014.05.003

Reich D., Thangaraj K., Patterson N., Price A.L. \& Singh L. (2009) Reconstructing Indian population history. Nature 461, 489-494. https://doi.org/ doi:10.1038/nature08365

Taberlet P., Valentini A., Rezaei H.R., Naderi S., Pompanon F. \& Negrini R. (2008) Are cattle, sheep, and goats endangered species? Mol Ecol 17, 275-284. DOI: https://doi.org/10.1111/i.1365-294X.2007.03475.x

Tosser-Klopp G. (2015) Update on the International Goat Genome Consortium Projects. In: Plant and Animal Genome XXIII Conference. Plant and Animal Genome.

Tosser-Klopp G., Bardou P., Bouchez O., Cabau C., Crooijmans R., Dong Y., Donnadieu-Tonon C., Eggen A., Heuven H.C., Jamli S., Jiken A.J., Klopp C., Lawley C.T., McEwan J., Martin P., Moreno C.R., Mulsant P., Nabihoudine I., Pailhoux E., Palhiere I., Rupp R., Sarry J., Sayre B.L., Tircazes A., Jun W., Wang W. \& Zhang W. (2014) Design and Characterization of a 52K SNP Chip for Goats. PLoS One 9 (1), https://doi.org/10.1371/journal.pone.0086227

Visser C., Lashmar S.F., Van Marle-Köster E., Poli M.A. \& Allain D. (2016) Genetic Diversity and Population Structure in South African, French and Argentinian Angora Goats from Genome-Wide SNP Data. PLoS ONE 11 (5), e0154353. doi: https://doi.org/10.1371/journal.pone.0154353

Zeder M.A. \& Hesse B. (2000) The Initial Domestication of Goats (Capra hircus) in the Zagros Mountains 10,000 Years Ago. Science 287, 2254-7. DOI: https://doi.org/10.1126/science.287.5461.2254

Zheng X., Levine D., Shen J., Gogarten S.M., Laurie C. \& Weir B.S. (2012) A highperformance computing toolset for relatedness and principal component analysis of SNP data. Bioinformatics 28, 3326-8. DOI: https://doi.org/ $\underline{10.1093 / \text { bioinformatics/bts606 }}$ 


\section{Supplementary materials}

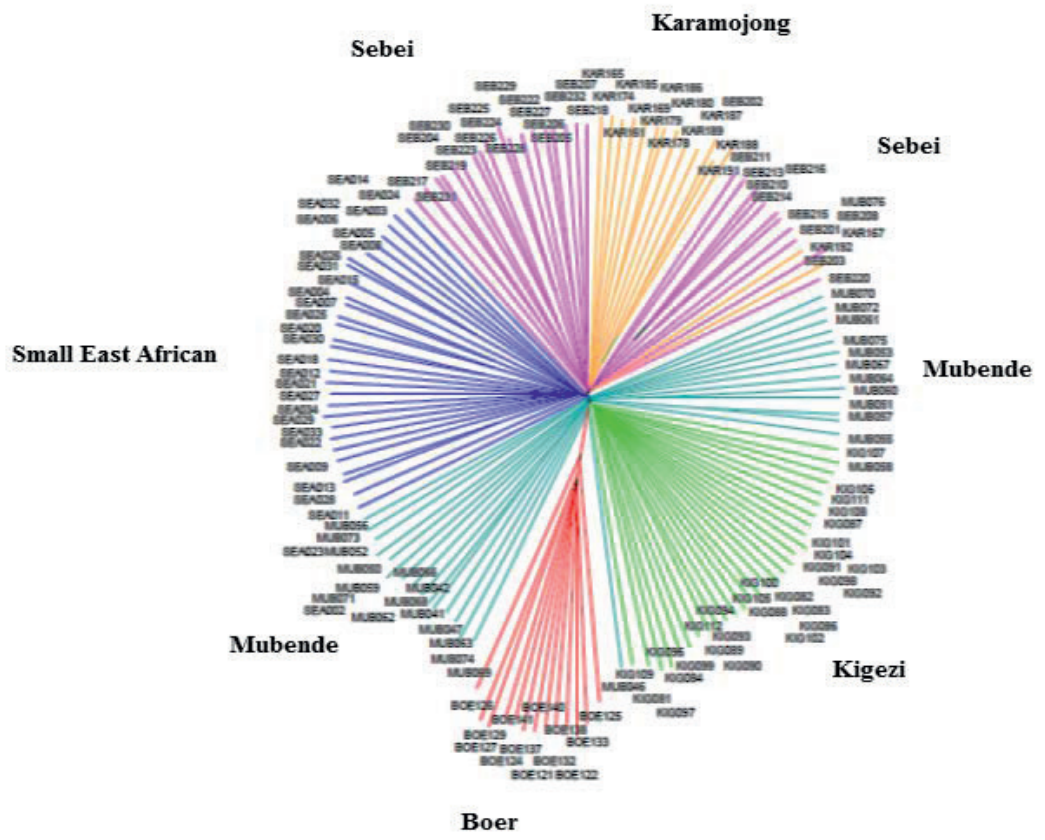

Figure 4. S1 Genetic relationships among five Ugandan indigenous goat breeds and one commercial goat breed; constructed using neighbour - joining tree from identity by state (IBS) distances derived from 46105 SNPs 


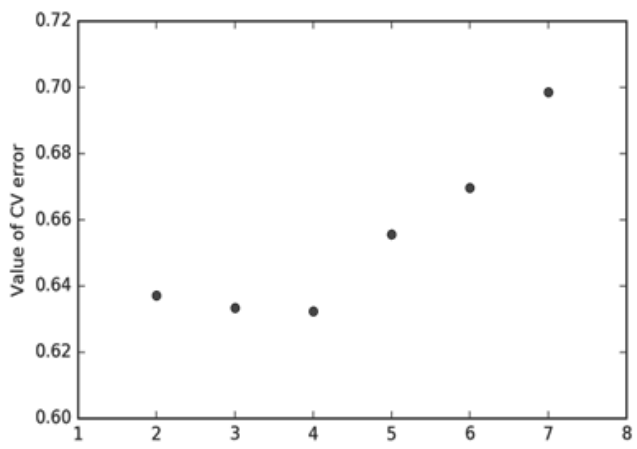

Figure 4. S2 Cross - validation error plot indicating the choice of the appropriate K-value

Table 4. S1: Significant $f_{4}$ statistics for Ugandan goats indicating gene-flow in the populations.

\begin{tabular}{|c|c|c|c|c|c|c|}
\hline Pop 1 & Pop 2 & Pop 3 & Pop 4 & f4 statistic & Std error & Z Score \\
\hline BOE & KIG & KAR & MUB & 0.0050 & 0.0002 & 20.5959 \\
\hline BOE & MUB & KAR & KIG & 0.0051 & 0.0003 & 20.4125 \\
\hline BOE & KIG & KAR & SEA & 0.0027 & 0.0003 & 10.2101 \\
\hline $\mathrm{BOE}$ & KAR & KIG & SEB & 0.0033 & 0.0003 & 12.5043 \\
\hline BOE & $\mathrm{KIG}$ & KAR & SEB & 0.0022 & 0.0002 & 14.3987 \\
\hline BOE & MUB & KAR & SEA & 0.0027 & 0.0003 & 10.8053 \\
\hline BOE & KAR & MUB & SEB & 0.0034 & 0.0002 & 16.4090 \\
\hline BOE & MUB & KAR & SEB & 0.0018 & 0.0002 & 12.1647 \\
\hline $\mathrm{BOE}$ & KAR & SEA & SEB & 0.0020 & 0.0002 & 9.2824 \\
\hline $\mathrm{BOE}$ & SEA & KAR & SEB & 0.0014 & 0.0002 & 8.2888 \\
\hline $\mathrm{BOE}$ & KAR & MUB & SEA & 0.0014 & 0.0002 & 6.0396 \\
\hline $\mathrm{BOE}$ & SEA & KAR & MUB & 0.0013 & 0.0002 & 5.6349 \\
\hline BOE & SEA & KAR & KIG & 0.0014 & 0.0003 & 5.0805 \\
\hline BOE & SEB & MUB & SEA & 0.0010 & 0.0002 & 4.4690 \\
\hline BOE & KAR & KIG & SEA & 0.0013 & 0.0003 & 4.4078 \\
\hline BOE & SEB & KAR & KIG & -0.0011 & 0.0003 & -4.0038 \\
\hline BOE & MUB & SEA & SEB & -0.0009 & 0.0002 & -4.1880 \\
\hline
\end{tabular}




\begin{tabular}{|c|c|c|c|c|c|c|}
\hline BOE & SEB & KAR & MUB & -0.0016 & 0.0002 & -6.4749 \\
\hline $\mathrm{BOE}$ & KIG & MUB & SEA & -0.0023 & 0.0002 & -9.8169 \\
\hline $\mathrm{BOE}$ & MUB & KIG & SEA & -0.0024 & 0.0003 & -9.4555 \\
\hline $\mathrm{BOE}$ & KIG & MUB & SEB & -0.0028 & 0.0002 & -12.9529 \\
\hline BOE & MUB & KIG & SEB & -0.0033 & 0.0002 & -14.3171 \\
\hline \multicolumn{7}{|c|}{ Karamojong } \\
\hline KAR & SEB & MUB & SEA & -0.0004 & 0.0001 & -4.5315 \\
\hline KAR & SEB & KIG & MUB & -0.0004 & 0.0001 & -5.4680 \\
\hline KAR & SEB & KIG & SEA & -0.0008 & 0.0001 & -7.0525 \\
\hline KAR & KIG & MUB & SEA & -0.0037 & 0.0001 & -29.0164 \\
\hline KAR & MUB & KIG & SEA & -0.0037 & 0.0001 & -27.2518 \\
\hline KAR & KIG & MUB & SEB & -0.0062 & 0.0001 & -47.4086 \\
\hline KAR & MUB & KIG & SEB & -0.0066 & 0.0001 & -47.1151 \\
\hline KAR & KIG & SEA & SEB & -0.0025 & 0.0001 & -18.3191 \\
\hline KAR & SEA & KIG & SEB & -0.0033 & 0.0001 & -22.1784 \\
\hline KAR & MUB & SEA & SEB & -0.0029 & 0.0001 & -23.6741 \\
\hline KAR & SEA & MUB & SEB & -0.0033 & 0.0001 & -23.2563 \\
\hline \multicolumn{7}{|c|}{ Kigezi } \\
\hline KIG & SEA & MUB & SEB & 0.0029 & 0.0001 & 23.4857 \\
\hline KIG & SEB & MUB & SEA & 0.0033 & 0.0001 & 28.0769 \\
\hline KIG & MUB & SEA & SEB & -0.0004 & 0.0001 & -4.3254 \\
\hline
\end{tabular}

MUB=Mubende, $\mathrm{BOE}=$ Boer, KAR=Karamojong, KIG=Kigezi, SEA=Small East African and $\mathrm{SEB}=$ Sebei goats. All Z-scores are significant indicating presence of gene-flow 
Table 4. S2 Breed composition of cluster 1, 2, 3 and 4, interpreted as representative of Small East African (SEA), Karamojong (KAR)/Sebei (SEB), Boer (BOE) and Kigezi (KIG) ancestries, respectively, and admixed Mubende (MUB) estimated for each individual belonging to goat populations from Uganda.

\begin{tabular}{|c|c|c|c|c|c|}
\hline Animal & breed & Cluster 1 (SEA) & Cluster 2 (KAR/SEB) & Cluster 3 (BOE) & Cluster 4(KIG) \\
\hline BOE132 & $\mathrm{BOE}$ & 0.0000 & 0.0000 & 1.0000 & 0.0000 \\
\hline BOE133 & $\mathrm{BOE}$ & 0.0006 & 0.0676 & 0.9318 & 0.0000 \\
\hline BOE137 & BOE & 0.0000 & 0.0000 & 1.0000 & 0.0000 \\
\hline BOE138 & $\mathrm{BOE}$ & 0.0000 & 0.0000 & 1.0000 & 0.0000 \\
\hline BOE140 & $\mathrm{BOE}$ & 0.0000 & 0.0000 & 1.0000 & 0.0000 \\
\hline BOE141 & BOE & 0.0000 & 0.0000 & 1.0000 & 0.0000 \\
\hline BOE121 & BOE & 0.0000 & 0.0000 & 1.0000 & 0.0000 \\
\hline BOE122 & $\mathrm{BOE}$ & 0.0000 & 0.0000 & 1.0000 & 0.0000 \\
\hline BOE124 & BOE & 0.0000 & 0.0000 & 1.0000 & 0.0000 \\
\hline BOE125 & BOE & 0.0529 & 0.0179 & 0.7707 & 0.1586 \\
\hline BOE126 & $\mathrm{BOE}$ & 0.0426 & 0.0521 & 0.7572 & 0.1482 \\
\hline BOE127 & $\mathrm{BOE}$ & 0.0057 & 0.0723 & 0.9221 & 0.0000 \\
\hline BOE129 & BOE & 0.0028 & 0.0256 & 0.9715 & 0.0000 \\
\hline KAR161 & KAR & 0.0581 & 0.9079 & 0.0340 & 0.0000 \\
\hline KAR165 & KAR & 0.0941 & 0.8443 & 0.0465 & 0.0151 \\
\hline KAR167 & KAR & 0.2576 & 0.6264 & 0.0000 & 0.1159 \\
\hline KAR169 & KAR & 0.0450 & 0.8917 & 0.0575 & 0.0059 \\
\hline KAR174 & KAR & 0.0399 & 0.9026 & 0.0494 & 0.0081 \\
\hline KAR178 & KAR & 0.0000 & 0.9996 & 0.0004 & 0.0000 \\
\hline KAR179 & KAR & 0.0000 & 0.9833 & 0.0167 & 0.0000 \\
\hline KAR180 & KAR & 0.1140 & 0.7552 & 0.0167 & 0.1141 \\
\hline KAR185 & KAR & 0.0609 & 0.8804 & 0.0582 & 0.0005 \\
\hline KAR186 & KAR & 0.0564 & 0.8332 & 0.0465 & 0.0639 \\
\hline KAR187 & KAR & 0.0574 & 0.8779 & 0.0534 & 0.0112 \\
\hline KAR188 & KAR & 0.0495 & 0.8749 & 0.0756 & 0.0000 \\
\hline KAR189 & KAR & 0.1613 & 0.7839 & 0.0025 & 0.0522 \\
\hline KAR191 & KAR & 0.1011 & 0.8989 & 0.0000 & 0.0000 \\
\hline KAR192 & KAR & 0.2715 & 0.5331 & 0.0078 & 0.1876 \\
\hline
\end{tabular}




\begin{tabular}{|c|c|c|c|c|c|}
\hline KIG106 & KIG & 0.0666 & 0.0576 & 0.0000 & 0.8758 \\
\hline KIG108 & KIG & 0.0713 & 0.0000 & 0.0000 & 0.9286 \\
\hline KIG109 & KIG & 0.0661 & 0.2067 & 0.2001 & 0.5272 \\
\hline KIG107 & KIG & 0.0734 & 0.0377 & 0.1186 & 0.7702 \\
\hline KIG081 & KIG & 0.0608 & 0.1029 & 0.1766 & 0.6598 \\
\hline KIG088 & KIG & 0.0000 & 0.0000 & 0.0000 & 1.0000 \\
\hline KIG089 & KIG & 0.0000 & 0.0000 & 0.0250 & 0.9750 \\
\hline KIG090 & KIG & 0.0071 & 0.0000 & 0.0000 & 0.9929 \\
\hline KIG091 & KIG & 0.0000 & 0.0000 & 0.0000 & 1.0000 \\
\hline KIG092 & KIG & 0.0230 & 0.0000 & 0.1125 & 0.8645 \\
\hline KIG093 & KIG & 0.0000 & 0.0000 & 0.0000 & 1.0000 \\
\hline KIG094 & KIG & 0.0000 & 0.0000 & 0.0000 & 1.0000 \\
\hline KIG096 & KIG & 0.0613 & 0.0910 & 0.2393 & 0.6083 \\
\hline KIG097 & KIG & 0.0306 & 0.0679 & 0.1169 & 0.7846 \\
\hline KIG098 & KIG & 0.0000 & 0.0000 & 0.0000 & 1.0000 \\
\hline KIG099 & KIG & 0.0323 & 0.0408 & 0.0862 & 0.8407 \\
\hline KIG100 & KIG & 0.0000 & 0.0000 & 0.0000 & 1.0000 \\
\hline KIG101 & KIG & 0.0000 & 0.0000 & 0.0000 & 1.0000 \\
\hline KIG102 & KIG & 0.0000 & 0.0000 & 0.0000 & 1.0000 \\
\hline KIG103 & KIG & 0.0059 & 0.0238 & 0.1415 & 0.8288 \\
\hline KIG104 & KIG & 0.0000 & 0.0000 & 0.0000 & 1.0000 \\
\hline KIG105 & KIG & 0.0000 & 0.0000 & 0.0000 & 1.0000 \\
\hline KIG086 & KIG & 0.0000 & 0.0000 & 0.0000 & 1.0000 \\
\hline KIG087 & KIG & 0.0181 & 0.0000 & 0.0000 & 0.9819 \\
\hline KIG082 & KIG & 0.0000 & 0.0000 & 0.0000 & 1.0000 \\
\hline KIG083 & KIG & 0.0000 & 0.0000 & 0.0000 & 1.0000 \\
\hline KIG084 & KIG & 0.0553 & 0.0701 & 0.0351 & 0.8396 \\
\hline KIG111 & KIG & 0.0227 & 0.0517 & 0.0000 & 0.9256 \\
\hline KIG112 & KIG & 0.0548 & 0.0342 & 0.0557 & 0.8554 \\
\hline MUB051 & MUB & 0.2042 & 0.1914 & 0.0153 & 0.5891 \\
\hline MUB066 & MUB & 0.2156 & 0.1830 & 0.0529 & 0.5485 \\
\hline MUB067 & MUB & 0.2101 & 0.2692 & 0.0053 & 0.5154 \\
\hline MUB055 & MUB & 0.1947 & 0.2184 & 0.0183 & 0.5686 \\
\hline
\end{tabular}




\begin{tabular}{|c|c|c|c|c|c|}
\hline MUB061 & MUB & 0.1934 & 0.2385 & 0.0029 & 0.5652 \\
\hline MUB062 & MUB & 0.2301 & 0.1935 & 0.0624 & 0.5140 \\
\hline MUB068 & MUB & 0.2229 & 0.2407 & 0.0000 & 0.5364 \\
\hline MUB073 & MUB & 0.1814 & 0.3554 & 0.0149 & 0.4483 \\
\hline MUB074 & MUB & 0.1886 & 0.2921 & 0.1060 & 0.4133 \\
\hline MUB060 & MUB & 0.1979 & 0.1679 & 0.0989 & 0.5353 \\
\hline MUB053 & MUB & 0.2245 & 0.2429 & 0.0353 & 0.4973 \\
\hline MUB059 & MUB & 0.2020 & 0.2655 & 0.0274 & 0.5052 \\
\hline MUB052 & MUB & 0.2145 & 0.2636 & 0.0268 & 0.4951 \\
\hline MUB056 & MUB & 0.2468 & 0.2301 & 0.0192 & 0.5038 \\
\hline MUB064 & MUB & 0.2337 & 0.2147 & 0.0000 & 0.5516 \\
\hline MUB046 & MUB & 0.1721 & 0.1557 & 0.1850 & 0.4872 \\
\hline MUB047 & MUB & 0.2398 & 0.3022 & 0.0000 & 0.4580 \\
\hline MUB050 & MUB & 0.2129 & 0.2390 & 0.0060 & 0.5421 \\
\hline MUB057 & MUB & 0.1826 & 0.1349 & 0.1117 & 0.5708 \\
\hline MUB058 & MUB & 0.1902 & 0.1265 & 0.1078 & 0.5755 \\
\hline MUB070 & MUB & 0.1804 & 0.3547 & 0.0198 & 0.4451 \\
\hline MUB071 & MUB & 0.1879 & 0.4201 & 0.0000 & 0.3920 \\
\hline MUB072 & MUB & 0.2020 & 0.3417 & 0.0205 & 0.4357 \\
\hline MUB075 & MUB & 0.2241 & 0.2255 & 0.0230 & 0.5275 \\
\hline MUB076 & MUB & 0.2201 & 0.2717 & 0.0194 & 0.4888 \\
\hline MUB063 & MUB & 0.1852 & 0.2138 & 0.0935 & 0.5075 \\
\hline MUB069 & MUB & 0.1770 & 0.2619 & 0.1954 & 0.3657 \\
\hline MUB041 & MUB & 0.1666 & 0.2536 & 0.0635 & 0.5162 \\
\hline MUB042 & MUB & 0.1687 & 0.2501 & 0.1035 & 0.4778 \\
\hline SEA002 & SEA & 0.4465 & 0.3744 & 0.0121 & 0.1669 \\
\hline SEA003 & SEA & 0.5727 & 0.1914 & 0.0919 & 0.1440 \\
\hline SEA004 & SEA & 1.0000 & 0.0000 & 0.0000 & 0.0000 \\
\hline SEA005 & SEA & 0.6671 & 0.2003 & 0.0000 & 0.1326 \\
\hline SEA006 & SEA & 1.0000 & 0.0000 & 0.0000 & 0.0000 \\
\hline SEA007 & SEA & 1.0000 & 0.0000 & 0.0000 & 0.0000 \\
\hline SEA008 & SEA & 0.6615 & 0.1935 & 0.0168 & 0.1282 \\
\hline SEA009 & SEA & 0.6849 & 0.1517 & 0.0000 & 0.1634 \\
\hline
\end{tabular}




\begin{tabular}{|c|c|c|c|c|c|}
\hline SEA011 & SEA & 0.3394 & 0.3817 & 0.0000 & 0.2789 \\
\hline SEA012 & SEA & 0.7611 & 0.1270 & 0.0000 & 0.1118 \\
\hline SEA013 & SEA & 0.7908 & 0.1032 & 0.0000 & 0.1060 \\
\hline SEA014 & SEA & 0.7312 & 0.1663 & 0.0000 & 0.1025 \\
\hline SEA015 & SEA & 0.7088 & 0.1508 & 0.0038 & 0.1367 \\
\hline SEA018 & SEA & 0.6786 & 0.0999 & 0.0885 & 0.1330 \\
\hline SEA020 & SEA & 1.0000 & 0.0000 & 0.0000 & 0.0000 \\
\hline SEA021 & SEA & 0.8327 & 0.1116 & 0.0000 & 0.0557 \\
\hline SEA022 & SEA & 0.8111 & 0.1245 & 0.0000 & 0.0645 \\
\hline SEA023 & SEA & 0.7242 & 0.1586 & 0.0000 & 0.1172 \\
\hline SEA025 & SEA & 1.0000 & 0.0000 & 0.0000 & 0.0000 \\
\hline SEA026 & SEA & 1.0000 & 0.0000 & 0.0000 & 0.0000 \\
\hline SEA027 & SEA & 0.7184 & 0.1276 & 0.0154 & 0.1386 \\
\hline SEA028 & SEA & 0.8039 & 0.1081 & 0.0000 & 0.0880 \\
\hline SEA029 & SEA & 0.7834 & 0.1160 & 0.0282 & 0.0724 \\
\hline SEA030 & SEA & 1.0000 & 0.0000 & 0.0000 & 0.0000 \\
\hline SEA031 & SEA & 1.0000 & 0.0000 & 0.0000 & 0.0000 \\
\hline SEA032 & SEA & 0.7619 & 0.1319 & 0.0131 & 0.0932 \\
\hline SEA033 & SEA & 0.7943 & 0.0876 & 0.0000 & 0.1181 \\
\hline SEA034 & SEA & 0.8092 & 0.1026 & 0.0000 & 0.0882 \\
\hline SEA024 & SEA & 0.4307 & 0.3623 & 0.0000 & 0.2070 \\
\hline SEB232 & SEB & 0.1520 & 0.6956 & 0.0001 & 0.1523 \\
\hline SEB217 & SEB & 0.1825 & 0.5895 & 0.0373 & 0.1907 \\
\hline SEB218 & SEB & 0.1095 & 0.7059 & 0.0132 & 0.1714 \\
\hline SEB219 & SEB & 0.0220 & 0.8817 & 0.0000 & 0.0963 \\
\hline SEB207 & SEB & 0.1635 & 0.6530 & 0.0131 & 0.1703 \\
\hline SEB208 & SEB & 0.1980 & 0.6346 & 0.0012 & 0.1662 \\
\hline SEB228 & SEB & 0.1006 & 0.7817 & 0.0000 & 0.1178 \\
\hline SEB229 & SEB & 0.0585 & 0.8038 & 0.0320 & 0.1058 \\
\hline SEB220 & SEB & 0.0971 & 0.5467 & 0.0921 & 0.2641 \\
\hline SEB222 & SEB & 0.0779 & 0.7473 & 0.0100 & 0.1649 \\
\hline SEB223 & SEB & 0.0143 & 0.8756 & 0.0000 & 0.1101 \\
\hline SEB204 & SEB & 0.1373 & 0.6515 & 0.0114 & 0.1998 \\
\hline
\end{tabular}




\begin{tabular}{|c|c|c|c|c|c|}
\hline SEB230 & SEB & 0.0620 & 0.8328 & 0.0000 & 0.1052 \\
\hline SEB231 & SEB & 0.0275 & 0.9218 & 0.0000 & 0.0506 \\
\hline SEB203 & SEB & 0.1062 & 0.6934 & 0.0000 & 0.2003 \\
\hline SEB224 & SEB & 0.0245 & 0.8714 & 0.0403 & 0.0637 \\
\hline SEB225 & SEB & 0.0000 & 1.0000 & 0.0000 & 0.0000 \\
\hline SEB226 & SEB & 0.0000 & 0.9577 & 0.0000 & 0.0423 \\
\hline SEB227 & SEB & 0.0976 & 0.6782 & 0.0494 & 0.1749 \\
\hline SEB216 & SEB & 0.0403 & 0.8693 & 0.0020 & 0.0884 \\
\hline SEB214 & SEB & 0.0000 & 0.9485 & 0.0000 & 0.0515 \\
\hline SEB215 & SEB & 0.0271 & 0.8571 & 0.0000 & 0.1158 \\
\hline SEB201 & SEB & 0.1551 & 0.6791 & 0.0063 & 0.1594 \\
\hline SEB202 & SEB & 0.1196 & 0.6878 & 0.0238 & 0.1688 \\
\hline SEB205 & SEB & 0.0465 & 0.8083 & 0.0000 & 0.1452 \\
\hline SEB206 & SEB & 0.0645 & 0.7941 & 0.0000 & 0.1414 \\
\hline SEB210 & SEB & 0.0000 & 0.9473 & 0.0000 & 0.0527 \\
\hline SEB211 & SEB & 0.1247 & 0.7089 & 0.0146 & 0.1518 \\
\hline SEB213 & SEB & 0.0120 & 0.9199 & 0.0000 & 0.0682 \\
\hline
\end{tabular}

$\mathrm{BOE}=$ Boer, $\mathrm{KAR}=$ Karamojong, $\mathrm{KIG}=$ Kigezi, $\mathrm{MUB}=$ Mubende, $\mathrm{SEA}=$ Small East African and $\mathrm{SEB}=$ Sebei goats. 


\section{5 \\ Genome-wide Characterization of Selection Signatures and Runs of Homozygosity in Ugandan Goat Breeds}

R.B. Onzima ${ }^{1,2}$, M. R. Upadhyay ${ }^{1,3}$, H. P. Doekes ${ }^{1}$, L. F. Brito ${ }^{4}$, M. Bosse ${ }^{1}$, E. Kanis ${ }^{1}$, M. A. M. Groenen ${ }^{1}$, R. P. M. A. Crooijmans ${ }^{1}$

${ }^{1}$ Wageningen University \& Research Animal Breeding and Genomics, Wageningen, The Netherlands; ${ }^{2}$ National Agricultural Research Organization (NARO), Entebbe, Uganda; ${ }^{3}$ Swedish University of Agricultural Sciences, Uppsala, Sweden; ${ }^{4}$ Centre for Genetic Improvement of Livestock (CGIL), Department of Animal Biosciences, University of Guelph, Guelph, Ontario, Canada

Frontiers in Genetics, Livestock Genomics, 9: 318

Doi: 10.3389/fgene.2018.00318 


\section{Abstract}

Both natural and artificial selection are among the main driving forces shaping genetic variation across the genome of livestock species. Selection typically leaves signatures in the genome, which are often characterized by high genetic differentiation across breeds and/or a strong reduction in genetic diversity in regions associated with traits under intense selection pressure. In this study, we evaluated selection signatures and genomic inbreeding coefficients, $F_{\mathrm{ROH}}$, based on runs of homozygosity $(\mathrm{ROH})$, in six Ugandan goat breeds: Boer $(n=13)$, and the indigenous breeds Karamojong $(n=15)$, Kigezi $(n=29)$, Mubende $(n=29)$, Small East African ( $n$ $=29$ ) and Sebei $(n=29)$. After genotyping quality control, 45,294 autosomal single nucleotide polymorphisms (SNPs) remained for further analyses. A total of 394 and 6 breed-specific putative selection signatures were identified across all breeds, based on marker-specific fixation index ( $F_{\mathrm{ST}}$-values) and haplotype differentiation (hapFLK), respectively. These regions were enriched with genes involved in signalling pathways associated directly or indirectly with environmental adaptation, such as immune response (e.g. IL1ORB and IL23A), growth and fatty acid composition (e.g. FGF9 and IGF1), and thermo-tolerance (e.g. MTOR and MAPK3). The study revealed little overlap between breeds in genomic regions under selection and generally did not display the typical classic selection signatures as expected due to the complex nature of the traits. In the Boer breed, candidate genes associated with production traits, such as body size and growth (e.g. GJB2 and GJA3) were also identified. Furthermore, analysis of $\mathrm{ROH}$ in indigenous goat breeds showed very low levels of genomic inbreeding (with the mean $F_{\mathrm{ROH}}$ per breed ranging from $0.8 \%$ to $2.4 \%$ ), as compared to higher inbreeding in Boer (mean $F_{\mathrm{ROH}}=13.8 \%$ ). Short $\mathrm{ROH}$ were more frequent than long $\mathrm{ROH}$, except in Karamojong, providing insight in the developmental history of these goat breeds. This study provides insights into the effects of long-term selection in Boer and indigenous Ugandan goat breeds, which are relevant for implementation of breeding programs and conservation of genetic resources, as well as their sustainable use and management.

Key words: Capra hircus, homozygosity, adaptation, genomic inbreeding, genetic diversity, selective sweeps, candidate genes 


\subsection{Introduction}

Goats are amongst the most important livestock species in developing countries, such as Uganda, playing a significant socio-economic, nutritional and cultural role in smallholder production systems (MAAIF, 2011). The total goat population in Uganda is estimated to consist of over14 million animals, predominantly from indigenous breeds (98\%) and a small proportion (2\%) from exotic breeds (MAAIF and UBOS, 2009; UBOS, 2015). Exotic breeds have been artificially selected for production traits over several generations, whereas indigenous breeds have undergone no or less intense artificial selection. While exotic breeds are subjected to more intense artificial selection, it is expected that the effect of natural selection (i.e. adaptation to the specific environment) is more apparent in the indigenous breeds and has played an important role in their development. Based on this hypothesis, it is expected that indigenous breeds will tend to exhibit resistance to gastro-intestinal parasites and local diseases, tolerance to heat, water scarcity and ability to use low quality fodder. Often high order traits like adaptation to environmental stress are influenced by several traits acting in combination. Adaptation is a complex trait that involves many biological processes and quantitative trait loci with each having a small but cumulative effect on the overall expression of the phenotype (Kim et al., 2016; Yang et al., 2016; Mwacharo et al., 2017).

Selection (both natural and artificial) is one of the main driving forces shaping genetic variation across genomes of livestock species. Under strong positive selection pressure, the frequency of favourable alleles will increase over time (Maynard and Haigh, 2007). This may result in genomic regions with high genetic differentiation across breeds and / or specific haplotypes rising to high frequencies. Such regions can thus be selection signatures. Analysis of selection signatures has the goal of identifying genomic regions or loci showing deviations from neutrality. Other forces like migration, admixture events and population bottlenecks may have a profound effect on genomic variability, locally increasing or reducing the genetic variation.

Two well-established methods to detect selection signatures include the fixation index $\left(F_{S T}\right)$ (Wright, 1949; Weir and Cockerham, 1984; Porto-Neto et al., 2013) and haplotype differentiation statistic - hapFLK (Fariello et al., 2013). $F_{S T}$ is one of the most popular methods to detect selection signatures if data is available for multiple populations. The $F_{S T}$-approach measures population differentiation due to locusspecific allele frequencies between populations and can detect highly differentiated alleles undergoing divergent selection among populations (McRae et al., 2014; Zhao et al., 2015). A drawback of the approach is that the $F_{S T}$-statistic assumes that all populations are of similar effective population size and are derived independently 
from the same ancestral population. The hapFLK - statistic measures differences of haplotype frequencies between populations and accounts for the hierarchical structure of the populations (Fariello et al., 2013). The use of a combination of haplotype information and of the hierarchical structure of populations results in greater power for the detection of selection signatures.

Selection signature analyses using genome-wide SNPs have been widely applied in exploring the genomes of livestock species such as sheep (Kijas et al., 2012; Purfield et al., 2017; Rochus et al., 2018), cattle (Porto-Neto et al., 2014; Zhao et al., 2015; Taye et al., 2017) and goats (Burren et al., 2016; Kim et al., 2016; Brito et al., 2017). These studies have identified genes associated with a variety of traits including thermo-tolerance, immune response, reproduction functions, skin and hair structure, feed intake and metabolism.

Ugandan indigenous goat breeds can be phenotypically categorized within three main breeds: Kigezi, Mubende and Small East African (Mason and Maule, 1960). Other indistinct ecotypes of indigenous goat breeds also exist including Karamojong and Sebei (Nsubuga, 1996). These breeds show high genetic diversity, but weak population sub-structuring (Onzima et al., 2018). The result of the weak population structure is low levels of inbreeding and some of the breeds having similar selection signatures (Msalya et al., 2017). The indigenous breeds present a high degree of adaptation to parasites and heat tolerance, and survive on poor quality fodder, while also maintaining good reproductive rates (Mwacharo et al., 2017). However, production levels are much lower compared to specialized breeds. Therefore, Boer goats were introduced in Uganda in the early 1990s to genetically improve the growth rate and body size of the indigenous breeds (Nsubuga, 1996). Because of community-based small ruminant breeding programs and the use of limited Boer breeding males for cross breeding, the increase in inbreeding levels is a major concern to the industry.

The increase in inbreeding in livestock at a genomic level over generations leads to a reduction in genetic diversity. When an offspring is inbred, it may inherit autozygous chromosomal segments from both parents that are identical by descent (IBD) i.e. segments that are derived from a common ancestor (Broman and Weber, 1999). The result is continuous homozygous segments in the genome, also known as runs of homozygosity $(\mathrm{ROH})$. The extent of $\mathrm{ROH}$ can be used to estimate the inbreeding coefficient (Bosse et al., 2012; Marras et al., 2015; Peripolli et al., 2018). $\mathrm{ROH}$ can be used to disclose the genetic relationships among individuals, usually estimating with high accuracy the autozygosity at an individual and/or population

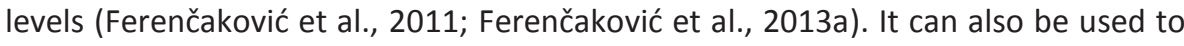
establish the level of selection pressure on the populations (Zhang et al., 2015). 
Length and frequency of ROHs may also be used to distinguish distant from more recent inbreeding, since the length of IBD segments follows an inverse exponential distribution with a mean of $1 / 2 \mathrm{~g}$ Morgans, where $\mathrm{g}$ is the number of generations from a common ancestor (Howrigan et al., 2011).

The objectives of this study were to: 1 ) identify unique selection signatures in the genome and the genes under selection in Ugandan goat breeds, and 2) assess the occurrence and distribution of $\mathrm{ROH}$ and $\mathrm{ROH}$-based genomic inbreeding in Ugandan goat breeds.

\subsection{Materials and Methods}

\subsubsection{Animals and genotype quality control}

The data used in this study were derived from 144 animals from six goat populations and has been described in detail previously (Onzima et al., 2018). The animals were from the five indigenous breeds, Mubende $(n=29)$, Kigezi $(n=29)$, Small East African $(n=29)$, Karamojong $(n=15)$ and Sebei $(n=29)$, and from the exotic Boer breed $(n$ =13). All animals were genotyped with the Illumina GoatSNP50 BeadChip (TosserKlopp et al., 2014), which features 53,347 single nucleotide polymorphisms (SNPs). Genotype quality control (QC) procedures were performed using PLINK v1.90 (Chang et al., 2015). All samples passed the quality criteria (missing genotype call rate $\geq 0.1$ ) and were used in the analysis. The SNPs with a call rate below 0.95, a minor allele frequency (MAF) lower than 0.05, located on non-autosomal chromosomes, or not in Hardy Weinberg Equilibrium (at $\mathrm{P}<0.001$ ) were discarded. After quality control procedures, 46,105 autosomal SNPs remained. For these SNPs, the position on the genome was obtained from the goat reference genome assembly ARS1 release 102 (Bickhart et al., 2017). After removing SNPs with unknown position on the ARS1 genome assembly, 45,294 autosomal SNPs from 144 goats remained in the final dataset.

\subsubsection{Relatedness within and between breeds}

The level of relatedness between individuals (both within and between breeds) was determined using genomic similarities. For each pair of individuals, the genomic similarity $\left(\operatorname{SIM}_{S N P_{i j}}\right)$ was determined according to Malécot. (1948):

$$
\operatorname{SIM}_{S N P_{i j}}=\frac{\sum_{k=1}^{n_{S N P}}\left(I_{11, k}+I_{12, k}+I_{21, k}+I_{22, k}\right)}{4 n_{S N P}}
$$


where $n_{S N P}$ is the total number of markers and $I_{x y, k}$ is an indicator variable that was set to 1 when allele $x$ of individual $i$ and allele $y$ of individual $j$ at marker $k$ were identical by state (IBS), and to 0 otherwise. Note that, as self-similarities were included, the average similarity in a breed was equivalent to the expected homozygosity in that breed.

\subsubsection{Identifying signatures of selections}

To increase the likelihood to detect true selection signatures (i.e., no false positive results), multiple approaches can be used (Simianer, 2014). The methods adapted for analysis of selection signatures need to be robust enough to disentangle selective pressures from other effects on the population such as migration, admixture and population bottlenecks. In this study, we used allele specific population differentiation defined as $F_{S T}$ (Wright, 1949) and a haplotype based differentiation approach, hapFLK (Fariello et al., 2013), which accounts for haplotype structure of populations and for variable effective population sizes.

\subsubsection{Fixation index $\left(F_{S T}\right)$}

Selection signatures for each breed were identified using an $F_{\mathrm{ST}^{-}}$-statistic per SNP that compares the allele frequency in the breed to the allele frequency in a combined population of the remaining breeds, following the unbiased estimator proposed by Weir and Cockerham (1984) and implemented in PLINK (Chang et al., 2015). For example, differences between the exotic Boer breed on the one hand, and the indigenous goat breeds on the other, were investigated by calculating the $F_{\mathrm{ST}}$-values between Boer and a combined population of all the indigenous breeds. We also computed $F_{\mathrm{ST}}$-values for the indigenous breeds while excluding Boer from the analysis. However, as the exclusion of Boer did not influence the results for the indigenous breeds, only results with Boer included are reported in the subsequent sections.

In general, genomic regions showing high $F_{\mathrm{ST}}$-values with moving averages and single SNPs indicate strong breed differentiation or selection, while low $F_{\mathrm{ST}}$-values suggest no or a limited amount of population differentiation. Negative $F_{\mathrm{ST}}$ values were set to zero, as they imply no genetic differentiation between the two groups. To visualize and infer region-specific differences over the erratic pattern of individual SNPs, we computed a moving average of $F_{\mathrm{ST}}\left(m a F_{\mathrm{ST}}\right)$ values for 5 adjacent SNPs. The $m a F_{\text {ST }}$ was computed for 5 adjacent SNPs and plotted against the chromosomal position for all goat autosomes ( $\mathrm{CHI}$ coordinates). The SNPs with a $\mathrm{maF}_{\mathrm{ST}}$ above the $95 \%$ quantile of the empirical distribution of raw $F_{\mathrm{ST}}$ values were considered as putative selection signatures. The moving average (ma) is a simple approach for 
identifying regions of interest in the genome from the erratic pattern of SNPs. This approach has been implemented successfully in analysing systematic differences in response to genetic variation to pedigree and genome-based selection methods in chicken (Heidaritabar et al., 2014) and genome-wide genetic diversity in Dutch dairy cattle (Doekes et al., 2018). By using $\mathrm{maF}_{\mathrm{ST}}$, rather than $F_{\mathrm{ST}}$ for single SNPs, we aimed to reduce the influence of the small sample sizes on the results.

\subsubsection{Haplotype differentiation (hapFLK)}

To account for haplotype structure and varying effective population sizes, we used hapFLK (Fariello et al., 2013) to detect potential selection signatures in the six goat populations. The used procedure has been described in detail by Brito et al. (2017). Briefly, hapFLK was applied to the unphased genotype data to identify putative regions under selection, by estimating the neighbour joining tree and a kinship relationship matrix based on Reynolds' genetic distances between the breeds. The pairwise Reynolds' distances (Reynolds et al., 1983) between populations (including an outgroup) are computed for each SNP and averaged over the genome. Using the genotype data and kinship matrix, and assuming 6 clusters in the fastPHASE model $(-k, 6)$, the program was run and the hapFLK statistic was computed as an average of 20 expectation maximization iterations to fit the Linkage Disequilibrium (LD) model. With hapFLK values generated for each SNP, $p$-values were computed based on a chisquare distribution of the numerical values. The mean and variance of hapFLK distribution were estimated and used to standardize each SNP specific value. This was subsequently followed by computation of $p$-values from a standard normal distribution, and the $(-\log 10)$ of $p$-values was plotted against the genomic positions. To minimize the number of false positives, a q-value threshold of 0.01 was set to control the false discovery rate (FDR) at the $1 \%$ level. Putative selective signatures were defined by the regions with a threshold of $\mathrm{P}<0.005$.

\subsubsection{Identification of candidate genes associated with selection signatures}

Genes within putative selection signature regions were retrieved from $\mathrm{NCBI}$ (www.ncbi.nlm.nih.gov), using the goat reference assembly ARS1. The genes overlapping either partially or fully within the $95 \%$ threshold of the empirical distribution of the raw $F_{\mathrm{ST}}$-values and within the regions with $\mathrm{P}<0.005$ for hapFLK, were putative selection candidate genes.

For each of the breeds, gene enrichment analyses were performed based on the $F_{\mathrm{ST}}$, and hapFLK results with the web-based tool, Database for Annotation, Visualization and Integrated Discovery (DAVID) v6.8 (Huang et al., 2009; Jiao et al., 2012), which 
allows for the investigation of the Kyoto Encyclopaedia of Genes and Genomes (KEGG) pathways (Kanehisa et al., 2012) and Gene Ontology (GO) for biological processes (Ashburner et al., 2000). Fisher's exact test ( $p$-value $=0.05$ ), was applied to identify significantly enriched GO biological and functional processes. More stringent settings, such as Bonferroni correction, FDR and Fold enrichment test were not considered in the detection given the limited scope of the study. Human gene ontologies were used since the goat genome has not been properly annotated. Moreover, the human genome is highly annotated than closely related species like bovine; thereby increasing the probability of retrieving GO terms in the goat genome. Phenotypes known to be affected by the identified candidate genes were compared from literature and using the AnimalQTLdb at: https://www.animalgenome.org/cgi-bin/QTLdb/index.

\subsubsection{Runs of homozygosity (ROH) and genomic inbreeding $\left(\mathrm{F}_{\mathrm{ROH}}\right)$}

For each individual, runs of homozygosity (ROHs) were identified using an in-house script which incorporates a set of criteria for defining regions of homozygosity.

An ROH was called if the following criteria were fulfilled: (i) 20 or more consecutive SNPs were homozygous, (ii) a minimum physical length of $2 \mathrm{Mb}$, (iii) a maximum gap between two consecutive SNPs of $500 \mathrm{~Kb}$ and (iv) maximum of 2 missing genotypes and no heterozygous calls within $\mathrm{ROH}$. The rather stringent criteria were used to minimise incorrect discovery of $\mathrm{ROH}$ (false positives) within regions of low marker density. The minimum expected length of homozygous DNA segments was based on the time frame of approximately twenty-five generations, over which goats are believed to have been characterized in separate breeds in Uganda (Mason and Maule, 1960). The length of $\mathrm{ROH}$ derived from a common ancestor $g$ generations ago follows an inverse exponential distribution with the mean equal to $100 / 2 \mathrm{~g} \mathrm{cM}$ (Fisher, 1954; Thompson, 2013). A genetic distance of approximately $1 \mathrm{cM}$ per Mb is often assumed in cattle (Arias et al., 2009) and assuming a similar relationship for goats, the mean length of $\mathrm{ROH}$ derived from common ancestor from 25 generations ago would be $2 \mathrm{Mb}$.

The proportion of ROH per animal in comparison to the whole genome SNP coverage provides a useful indication of the level of inbreeding. Genomic inbreeding coefficient based on ROHs were computed as the length of the autosome covered by ROHs divided by the overall length of the autosome covered by the SNPS (McQuillan et al., 2008):

$$
F_{R O H, i}=\frac{L_{R O H}}{L_{A U T O}}
$$


where $L_{R O H}$ is the sum of the total length of $\mathrm{ROH}$ in individual $i$ and $L_{A U T O}$ is the total length of the autosomes covered by the SNPs $(2.463 \mathrm{~Gb})$. The number of ROHs and $F_{\mathrm{ROH}}$ were also evaluated for different $\mathrm{ROH}$ length categories. We focused on length classes from $2 \mathrm{Mb}$ to $16 \mathrm{Mb}$ to investigate more ancient inbreeding ( 2 and $16 \mathrm{Mb}$ are the expected lengths of $\mathrm{ROH}$ derived from common ancestors 25 and 3 generations ago, respectively) and $>16 \mathrm{Mb}$ to assess more recent inbreeding (expected length of $\mathrm{ROH}$ derived from ancestors $\leq 3$ generations ago).

The $\mathrm{ROH}$ were estimated in each individual separately and then classified into four length categories: 2 $-4 \mathrm{Mb}, 4-8 \mathrm{Mb}, 8-16 \mathrm{Mb}$ and >16 Mb, following classification used in similar studies (Kirin et al., 2010; Ferenčaković et al., 201 BMar,ras et al., 2015), specified from now on as $\mathrm{ROH}_{2-4} \mathrm{Mb}, \mathrm{ROH}_{4-8} \mathrm{mb}, \mathrm{ROH}_{8-16} \mathrm{Mb}$ and $\mathrm{ROH}_{>16} \mathrm{mb}$, respectively. For each length category in each of the individuals of each breed, we computed the total number of $\mathrm{ROH}$ identified - $\mathrm{nROH}$, mean sum of $\mathrm{ROH}$ coverage $\mathrm{S}_{\mathrm{ROH}}$ in $\mathrm{Mb}$ (defined by sum of all $\mathrm{ROH}$ per individual divided by the number of animals per breed) and average length of $\mathrm{ROH}\left(\mathrm{L}_{\mathrm{ROH}}, \mathrm{Mb}\right)$.

\subsection{Results}

\subsubsection{Relatedness among Ugandan goats}

Mean genomic similarities within and between breeds are shown in Table 5.1. As expected, within breed similarities (diagonal) were higher than between breed similarities (off-diagonal). Within breeds, the highest mean similarity was found in Kigezi (0.643) and the lowest in Sebei (0.623). Between breeds, the indigenous Ugandan goat breeds showed higher genomic similarity with each other than the Boer breed.

Table 5.1 Mean genomic similarity within (diagonal) and between (off-diagonal) six goat breeds

\begin{tabular}{lllllll}
\hline & BOE & KIG & MUB & SEA & KAR & SEB \\
\hline BOE & 0.625 & - & - & - & - & - \\
KIG & 0.551 & 0.643 & - & - & - & - \\
MUB & 0.553 & 0.622 & 0.625 & - & - & - \\
SEA & 0.549 & 0.615 & 0.614 & 0.632 & - & - \\
KAR & 0.550 & 0.607 & 0.607 & 0.606 & 0.627 & - \\
SEB & 0.549 & 0.613 & 0.611 & 0.610 & 0.610 & 0.623
\end{tabular}

BOE=Boer ( $n=13), K I G=$ Kigezi $(n=29), M U B=M u b e n d e ~(n=29), S E A=S m a l l$ East African $(n=29), K A R=$ Karamojong $(n=15)$ and SEB=Sebei $(n=29)$. 


\subsubsection{Selection signatures in goat populations}

\subsubsection{Selection Signatures - $F_{\mathrm{ST}}$}

There was generally a high level of differentiation between Boer on the one hand, and the indigenous Ugandan breeds on the other. For Boer, the average $F_{S T}$ across all SNPs was 0.123 , while the average $F_{S T}$ for the indigenous breeds was less than 0.050 (Table 5.S1).

Analysis of breed specific differentiation between each of the Ugandan goat breeds including the Boer breed resulted in several putative regions of selection as shown in Table 5.S2 ( $P<0.05$, without Bonferoni correction). In Boer, the 29 putative regions of selection were identified, which spread across 17 autosomes and overlapped with 134 genes. The regions with the highest degree of differentiation were found on $\mathrm{CHI} 11,12,14,18$ and 24 (Figure 5.1). The highest ranked SNP window $\left(\mathrm{maF}_{\mathrm{ST}}\right.$-value= 0.754 ) was found on $\mathrm{CHI} 12$ in a genomic region between $60.170 \mathrm{Mb}$ and $60.711 \mathrm{Mb}$ and overlap with portions of the genes MAB21L1 and NBEA. Analysis of breed specific differentiation for the Ugandan indigenous goat breeds resulted in 394 putative regions of selection distributed across all the breeds showing some candidate genes for traits of economic importance. The regions varied from 66 in Mubende to 79 in the Small East African goats distributed across most of the autosomes (Table 5.S2). The selection signature regions in the indigenous goat breeds are on average numerous and shorter than in the Boer. There is limited overlap between the different breeds indicating signatures are mostly breed specific. Several genes were found spanning the selection signature regions across the autosomes (Table 5.S2). Functional analysis of some of the candidate genes (Figure 5.S1), shows they may be involved in tropical adaptation such as thermo-tolerance and immune response in the indigenous breeds. These include KPNA4 (CHI1), MTOR (CHI16), SH2B1 (CHI25) and MAPK3 (CHI25) in Karamojong; IL1ORB, IFNAR, DNAJC13 (CHI1) in Kigezi; PPP1R36 and HSPA2 (CHI10), DNAJC24 (CHI5) in Mubende; CD80, ADPRH, IGSF11 (CHI), IGF1 (CHI5) in Small East African goats and HOXC12 and HOXC13 (CHI5) in Sebei. The full gene-list is found in Table 5.S2.

\subsubsection{Selection signatures - hapFLK}

The results of the haplotype-based differentiation with hapFLK are shown in Figure 5.2. A significance threshold of $p<0.005$ was considered to identify regions under selection. The hapFLK analysis resulted in six putative selection signature regions on CHI5 (116.662 -118.773 Mb), CHI6 (0.005 - 16.337 Mb), CHI8 (7.766 - $7.941 \mathrm{Mb})$, CHI13(58.709 - 63.989 Mb), CHI15 (14.932 - 23.571Mb) and CHI16 (40.533 - 45.988 $\mathrm{Mb})$. Some of the candidate genes identified, which may be playing a role in tropical 
adaption include; $C F I$ (CHI 6), DEFB genes (CHI 13) and ASIP (CHI 13), MTOR, PIK3CD (CHI 16), and CD44 (CHI 15) (Table S3).

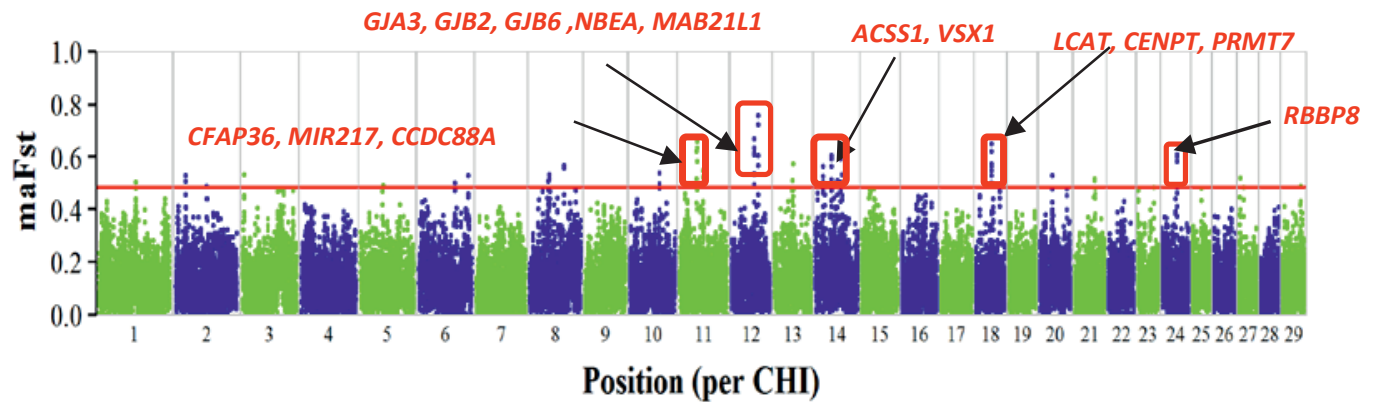

Figure 5.1 | Plot of moving average ${ }_{S T}$-values of SNPs per chromosome. The plot shows comparison of Boer goats with other Ugandan goat breeds and candidate genes in putative selective signatures are shown in red. The horizontal red line (at 0.482) represents the $95 \%$-percentile of raw $F_{S T}$-values.

Four of the six significant regions identified by hapFLK partially overlapped with the 394 significant selective signature regions identified by $F_{\mathrm{ST}}$. Several short overlapping regions were found between hapFLK and $F_{S T}$, with the strongest signals detected on $\mathrm{CHI}$ 6, 13 and 16 (Figure 5.2). Some of the regions were breed specific and contained several genes (Table 5.S4). 


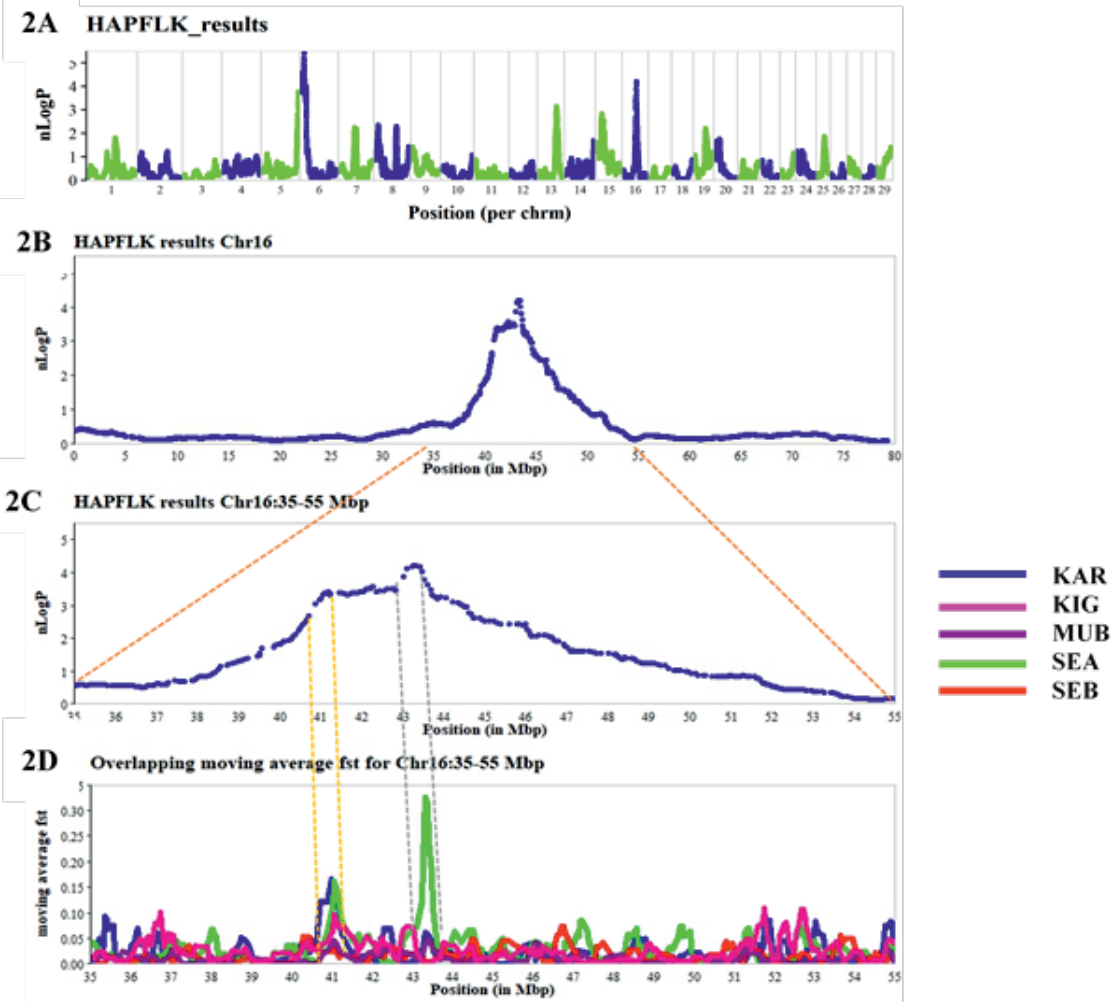

Figure 5.2 Genomeide scan for putative signatures of selection using hapFLK (2 A The negative log of $p$-values is plotted in chromosomal order. The alternating colours green and blue represent the different chromosomes (on the upper panel). On the lower panels (2B, 2C, 2D) is a zoom into the chromosome 16 to show the regions overlapping with high $F_{S T}$ and hapFLK values, defining putative selection signatures over four selected regions in the different breeds $(K A R=$ Karamojong, $K I G=$ Kigezi, $M U B=$ Mubende, SEA = Small East African and SEB = Sebei). 


\subsubsection{Gene enrichment of putative selection signatures}

Within the putative selection regions identified, a list of genes was identified for each of the approaches used: $F_{\mathrm{ST}}$ (Table 5.S2) and hapFLK (Table 5.S3) and were used to perform separate functional analyses using DAVID with default settings on the human gene set (Huang et al., 2009;Jiao et al., 2012). Functional analysis of the $F_{\mathrm{ST}}$ gene-list for each of the breeds yielded 47 significant $(\mathrm{P}<0.05)$ gene ontology (GO) biological process (BP) terms (Table 5.S5) and 15 KEGG pathways were enriched (Table 5.56). The biological processes enriched were related to cell communication, male sex differentiation, microtubule cytoskeleton organization in the Boer; and negative regulation of catalytic activity, homeostasis in number of cells within the tissue, TIR-domain-containing adapter-inducing interferon- $\beta$ (TRIF) - dependent tolllike receptor signalling pathway (GO:0035666), positive regulation of peptidyltyrosine phosphorylation (GO:0050731), cytokinesis (GO:0000910) and angiogenesis (GO:0001525) among others in the indigenous goat breeds.

The DAVID analyses based on hapFLK gene list across the breeds resulted in 18 significant $(P<0.05)$ biological processes (Table 5.S5) and nine significant $(P<0.05)$ KEGG pathways (Table 5.S6). The genes identified, were significantly involved in the defence response to bacterium (GO:0042742; P-value $<0.001$ ), negative regulation of the apoptotic process (GO:0043066; P-value $<0.001$ ) and positive regulation of gene expression (GO:0010628; P-value < 0.001) among others.

\subsubsection{Analysis of ROH and genomic inbreeding - $F_{\mathrm{ROH}}$}

A total of 1,497 ROHs were detected across all individuals. The frequency of ROHs and their length-distribution differed across breeds (Figure 5.3). For all length categories, ROHs were generally more frequent in Boer (a breed selected for meat production) than in Ugandan indigenous goat breeds. Consequently, Boer showed the highest genomic inbreeding coefficients (Table 5.2). For example, the mean $F_{\mathrm{ROH}} \geq 2 \mathrm{Mb}$ in Boer was $13.8 \%$, while for the indigenous breeds, it ranged from $0.8 \%$ (Sebei) to $2.4 \%$ (Karamojong). Shorter $\mathrm{ROH}$ were more frequent than longer $\mathrm{ROH}$ in all breeds except for Karamojong. In the later breed, there were remarkably many $\mathrm{ROH}>16 \mathrm{Mb}$.

$\mathrm{ROH}$ s were located across the whole genome, with some regions showing a higher frequency than other (Figure 5.S2). The mean sum of ROH segment coverage was generally higher for short $\mathrm{ROH}$ s than for long $\mathrm{ROH}$. The highest mean $\mathrm{ROH}$ coverage within the short $\mathrm{ROH}$ category ( $\mathrm{ROH}$ of 2-4 Mb) was found in Boer, while Sebei had the lowest of mean $\mathrm{ROH}$ coverage. For instance, around $65 \%$ of the Boer mean sum of $\mathrm{ROH}$ segment coverage in this study $(219.65 \mathrm{Mb})$ was within the shorter $\mathrm{ROH}$ 
category $2 \mathrm{Mb}-8 \mathrm{Mb}$. However, for the other breeds, the coverage ranged from 4.52 $\mathrm{Mb}$ in Sebei to 20.38 $\mathrm{Mb}$ in Kigezi (Table 5.S7). In the long ROH category $\left(\mathrm{ROH}_{>16 \mathrm{Mb}}\right)$, Boer and Karamojong showed higher $\mathrm{ROH}$ genome coverage (33.67 Mb and $33.60 \mathrm{Mb}$ respectively), which indicates more recent inbreeding. In the remaining breeds, the coverage was between $4.44 \mathrm{Mb}$ in Kigezi and $10.58 \mathrm{Mb}$ in the Small East African breed. Boer showed high genome coverage with both short and long $\mathrm{ROH}$, suggesting that the breed has experienced both recent and ancestral inbreeding compared to Ugandan indigenous breeds. The findings also suggest that among the Ugandan indigenous goat breeds, Karamojong has greater levels of inbreeding compared to the others. The proportion of the genome located on an $\mathrm{ROH}$ differed between breeds and chromosomes. The proportion ranged from $1.50 \%$ on $\mathrm{CHI} 2$ to $93.62 \%$ on $\mathrm{CHI} 23$ in Sebei (Table 5.S8). $\mathrm{ROH}$ segments were identified on all 29 autosomes in Boer, but the number varied in the genomes of the indigenous goat breeds with several autosomes showing no homozygous regions (Table 5.S9).

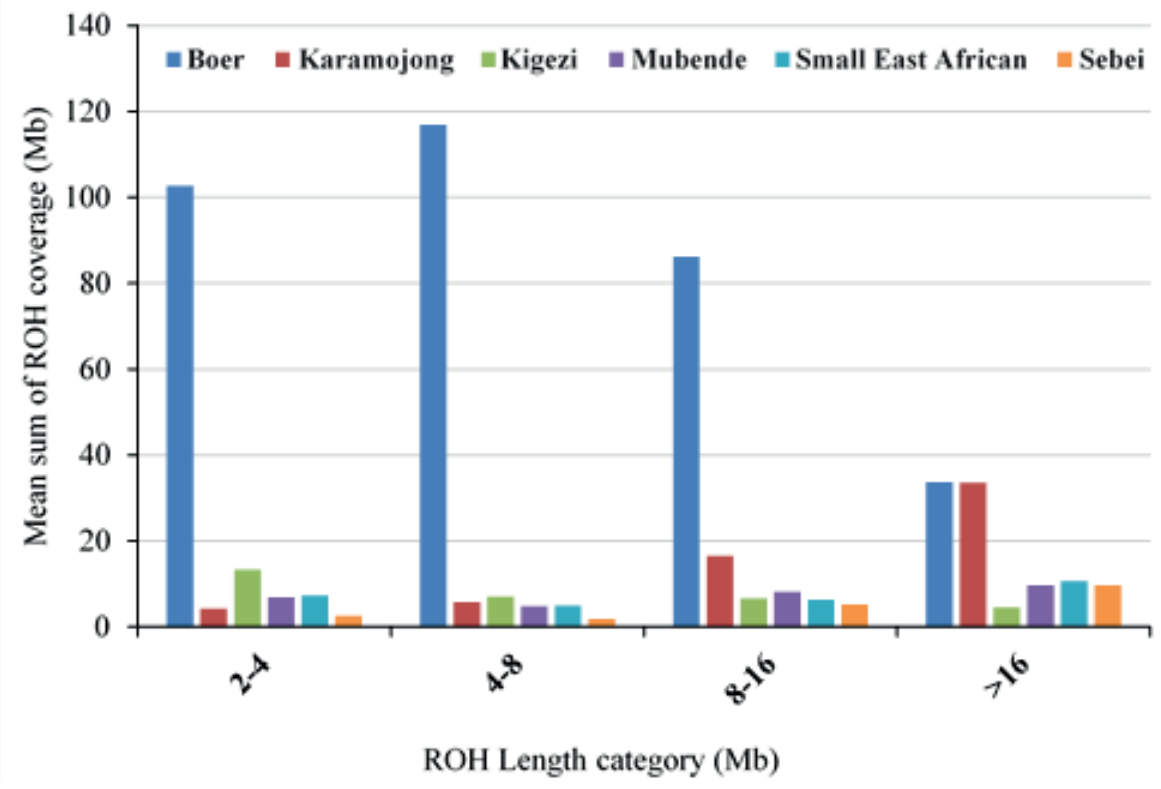

Figure 5 .3Gknome-wide distribution of mean sum of ROH coverage per length category averaged per breed across six Ugandan goat breeds 
Table 5.2 Average percentage genomic inbreeding coefficient $\left(\mathrm{F}_{\mathrm{ROH}}\right)$ for different length categories of $\mathrm{ROH}$ across six goat populations

\begin{tabular}{|c|c|c|c|c|c|c|}
\hline $\begin{array}{l}\text { Length } \\
\text { category } \\
\text { (Mb) }\end{array}$ & $\begin{array}{l}\text { Boer } \\
(n=13)\end{array}$ & $\begin{array}{l}\text { Karamojong } \\
(n=15)\end{array}$ & $\begin{array}{l}\text { Kigezi } \\
(\mathrm{n}= \\
29)\end{array}$ & $\begin{array}{l}\text { Mubende } \\
(n=29)\end{array}$ & $\begin{array}{l}\text { SEA } \\
(n= \\
29)\end{array}$ & $\begin{array}{l}\text { Sebei } \\
(\mathrm{n}= \\
29)\end{array}$ \\
\hline $\mathrm{N}_{0}$ & 0 & 2 & 1 & 5 & 2 & 13 \\
\hline $\mathrm{F}_{\mathrm{ROH}(2-4)}$ & 4.17 & 0.17 & 0.54 & 0.28 & 0.30 & 0.11 \\
\hline $\mathrm{F}_{\mathrm{ROH}(4-8)}$ & 4.75 & 0.23 & 0.28 & 0.20 & 0.20 & 0.08 \\
\hline $\mathrm{F}_{\mathrm{ROH}(8-16)}$ & 3.50 & 0.67 & 0.27 & 0.33 & 0.26 & 0.21 \\
\hline $\mathrm{F}_{\mathrm{ROH}(>16)}$ & 1.37 & 1.36 & 0.18 & 0.40 & 0.43 & 0.39 \\
\hline Total FROH $\geq 2 \mathrm{Mb}$ & 13.79 & 2.44 & 1.27 & 1.20 & 1.18 & 0.78 \\
\hline
\end{tabular}




\subsection{Discussion}

In this study, we unravelled selection signatures and genomic inbreeding coefficients in goat breeds of Uganda using genome-wide SNP data.

Various approaches have been implemented for the detection of selection signatures in several domestic animal species such as , cattle (Msalya et al., 2017; Taye et al., 2017), horses (Petersen et al., 2013), sheep (Kijas et al., 2012; Fariello et al., 2014; Rochus et al., 2018) and goats (Kim et al., 2016; Wang et al., 2016; Brito et al., 2017). In this study, we assessed the genome-wide differences between Ugandan indigenous goat breeds (Karamojong, Kigezi, Mubende, Small East African and Sebei) and exotic Boer goats by using population differentiation, $F_{\mathrm{ST}}$ (Weir and Cockerham, 1984) and the haplotype structure in the populations, hapFLK (Fariello et al., 2013). The statistical power to detect selection signatures may vary among the approaches. In this study, we used $F_{S T}$ and hapFLK for detecting selection signatures. The use of different methods in detecting selection signatures boosts the accuracy of detection and eliminates unknown bias (Simianer, 2014; Ma et al., 2015).

\subsubsection{Selection signatures}

The genomic regions potentially under selection identified in this study spanned a myriad of candidate genes with diverse biological, molecular and cellular functions, which could be because the adaptation processes to environmental stressors is controlled by a complex network of genes acting together, other than single candidate genes. For instance, adaptation to hot and arid environments was found to be mediated by a complex network of genes in Egyptian Barki goats and sheep (Kim et al., 2016), which were directly or indirectly associated with energy and digestive metabolism, autoimmunity, thermo-tolerance (melano-genesis) and, muscular and embryonic development. Similarly, adaptation may also result from interaction of several traits under the influence of several genes (Lv et al., 2014). In this study, we found putative signatures containing a complex of genes involved directly or indirectly in immune response. Moreover, selection for complex traits may also leave limited or none of classic selection signatures due to weak selection acting on the genome (Kemper et al., 2014).

In line with expected selection signatures for such complex traits, the genomic regions identified in this study using genome-wide maker specific fixation index in the populations showed limited overlap. This suggests that the selection on genes involved in adaptation to a tropical environment were breed-specific. Moreover, the selection signatures found in our study do not display classic hard sweep characteristics, which is to be expected for complex traits. This is in contrast to the 
findings with Valdostana goats in Italy (Talenti et al., 2017), This may arise due to the very diverse nature of the populations and absence of hard and long selection signature regions observed within the populations at the 50K SNP marker density. Secondly, our study pooled genotypes from six different breeds and lending to picking out differences between the breeds, unlike in the study of Talenti and colleagues(Talenti et al., 2017), whose focus was on only one breed.

We did find overlap between the selected regions identified with the hapFLK method and breed-specific $F_{\mathrm{ST}}$ signatures. Since hapFLK considers population stratification, the haplotypes in these regions are likely to be selected for in the corresponding breeds. The fact that these regions stand out in the hapFLK results as well as the $F_{\mathrm{ST}}$ results suggests that selection on those regions most closely resembles classic sweeps. Strong selection signatures were observed on $\mathrm{CHI}$ 6, 13 and 16, and they harboured several genes which may be important for adaptation in tropical environments, such as MTOR which is involved in heat stress response and the heat shock family of genes (Shi and Manley, 2007) and DNAJC24 involved in the first apoptosis signal (FAS) pathway and regulation of stress induction of heat shock protein (hsp) in Bos taurus (Roy and Collier, 2012). Several of the genes are involved in immune response particularly the innate immune response pathway (GO:004508). Overall, several of the genes identified in this study are associated with tropical adaptation. Moreover, in the Boer, several candidate genes identified in the putative selection signatures are involved in production related traits, reflecting a more modern selection regime. However, to pin-point the exact genes involved in tropical adaptation and production in the Ugandan goat breeds, there is need for an in-depth study at high resolution.

Generally, most of the regions under selection were subtle and breed-specific, as expected for complex traits under selection. Therefore, the forces driving selection in the genome of the indigenous goat breeds in this study may be associated with adaptation to African tropical environment, such as: thermo-tolerance, disease and parasite resistance, and the ability to perform under limited (quality and quantity) feed and water resources. The genome-wide scans identified candidate genes within the putative selective signatures associated with specific biological pathways and functions, which may be shaping the genomic architecture of Ugandan goat breeds for survival in stressful environment. Although most signatures were breed-specific, some interesting similarities could be found in the adaptive processes the genes in selected regions were involved in. 


\subsubsection{Thermo-tolerance genes}

Several candidate genes were identified, which are associated with adaptation to thermal stress. The homeobox genes HOXC12 and HOXC13 genes identified in Sebei are involved in the anterior/posterior pattern specification (GO:0009952). The genes play a role in hair follicle differentiation, growth and development by regulating the keratin differentiation - specific genes (Wu et al., 2009; Taye et al., 2017). The HOXC13 gene has been reported to influence skin thickness. Skin thickness and number of hair follicles impacts positively on thermoregulation. For instance, in cattle, thicker skin is associated with thermo-tolerant cattle (Bos indicus) as opposed to heat susceptible cattle (Bos taurus) breeds (Alfonzo et al., 2016). Relatedly, PPP1R36 and Heat Shock Protein A2 (HSPA2) (CHI10, 26.402 - 26.719 Mb) identified in Mubende are involved in heat stress response and, HSPA2, DNAJC24 and DNAJC13 are associated with the heat shock family of genes (Shi and Manley, 2007). The presence of multiple genes associated with heat stress would seem to suggest that the trait is under intense selection pressure in tropically adapted breeds. Genes such as KPNA4 (CHI1), MTOR (CHI16), SH2B1 (CHI25) and MAPK3 (CHI25) were also identified in Karamojong goats. They have been reported to be involved in the FAS (First Apoptosis Signal) pathway and regulation of stress induction of heat shock protein (hsp) in Bos taurus (Roy and Collier, 2012). Furthermore, we identified the gene IGF1 (CHI5, $64.576-65.310 \mathrm{Mb}$ ). IGF1 encodes a protein that is similar to insulin and it is involved in regulation of carbohydrate and lipid metabolism. IGF1 facilitates post-absorptive nutrient partitioning during heat stress and accumulation of insulin is often an adaptation mechanism to heat stress (Sanz Fernandez et al., 2015).

\subsubsection{Adaptive and innate immunity genes}

Several candidate genes in the putative selection regions are involved in regulating innate and adaptive immunity in mammals. For example, we identified diacylglycerol kinase beta, DGKB gene in Small East African (CHI4 position 97.794 - $97.991 \mathrm{Mb}$ ). The gene is involved in the glycerolipid, glycerophospholipid and phosphatidylinositol metabolic pathways and has been found to be associated with QTL for strongyles that includes Haemonchus sp (Zvinorova, 2017). Other candidate genes identified include IL1ORB and IFNLR1 on CHI1(0.693 - $0.959 \mathrm{Mb})$ in Kigezi goats. These genes are involved in type III Interferon Signalling Pathway and confer immunity (Ferrao et al., 2016). Similarly, we also identified candidate genes in Sebei such as BCL2L1 (CHI13, 60.489-60.748 Mb), and in Small East African goats such as ERBB2 (CHI19, 39.703-40.129 Mb), and ENO1 (CHI16, 43.006-43.669 Mb). These 
genes are directly or indirectly associated with immuno-regulation e.g. ENO1 in humans (Ryans et al., 2017).

The identification of cytokines such as IL17RE, IL17RC and IL23A in this study may be associated with gastrointestinal parasite resistance. Some of the cytokines have been reported to be significantly upregulated in Haemonchus contortus infected sheep and are known to be involved in adaptive immune response (GO:0002250) (Guo et al., 2016). These results would suggest that immunity genes are hotspots for natural selection in Ugandan goat breeds in response to high burden of pathogen/ parasite challenge in the local environment (Thumbi et al., 2014; Bahbahani and Hanotte, 2015). Indigenous goat breeds vary in the degree of response to parasite infestation (Chiejina and Behnke, 2011; Onzima et al., 2017). We hypothesize that the variation between the breeds may be due to the genes allowing for selection on resistance traits either naturally or artificially.

One of the regions in Boer on CHI3 (84.128 Mb - 84.373 Mb) harbours a gene PRMT6, which is reported to influence early embryonic development in Zebra fish (Zhao et al., 2016). The gene VAV3 (CHI3, $84.730 \mathrm{Mb}-84.962 \mathrm{Mb}$ ) is also associated with the immune system (Shen et al., 2017). Interleukin 12A (IL12A) gene is another cytokine that was identified on $\mathrm{CHI} 1$ in Karamojong which may be associated with immune response. The gene family is reported to be involved with the immune system in humans through series of biological processes (Reitberger et al., 2017). Moreover, it is cytokine that acts as a growth factor for activated T and Natural Killer (NK) cells, enhances the NK/ lymphokine activated killer cells and stimulates the production of IFN-gamma.

\subsubsection{Genes associated with production traits}

The candidate gene NBEA (Neurobeachin) in the region on CHI12 (maFST $=0.754$ ) (Table 5.S2) is associated with human body weight (Fox et al., 2007). Another gene of interest that we identified is VAV3 (CHI3; $84.730-84.962 \mathrm{Mb}$ ) on a homozygous region in Boer. The gene has been identified as a candidate gene for efficiency of food conversion in swine (Wang et al., 2015) and in goats (Brito et al., 2017). These genes are particularly significant to be identified in Boer goats, which have been extensively selected for high body weight and growth rate. Earlier studies have also identified this gene as a top candidate in Draa goats in Morocco (Benjelloun et al., 2015). However, in that study it was not conclusive if the candidate gene was associated with body weight.

Other genes identified in Boer such as the gap junction protein genes GJB2, GJB6 and GJA3 belong to the family of genes involved in cell communication (GO:0007154). 
They encode proteins that influence body size, skeletal and embryonic development and testicular embryogenesis, and may indirectly influence traits such as growth (Kim et al., 2016). The region ( $41.943-42.086 \mathrm{Mb})$ on $\mathrm{CHI} 13$ contains another gene ACSS1 (acyl-CoA Synthetase Short-chain Family Member 1), which has been associated with body weight, food intake, post-natal growth rate and susceptibility to weight loss among others (Liu et al., 2017).

\subsubsection{Gene enrichment analysis}

Our findings indicated that pathways associated with production and mechanisms of environmental adaptation, such as immune response, male reproduction, energy production and heat stress, may be under selection in Ugandan goat breeds. This is in agreement with findings in East African Short - horn Zebu cattle (Bahbahani et al., 2015; Bahbahani et al., 2017; Bahbahani et al., 2018), South African cattle (Makina et al., 2015) and indigenous goats in Morocco and Egypt (Benjelloun et al., 2015; Kim et al., 2016). Gene ontology analysis shows that multiple pathways are expressed in the Ugandan goat breeds, which may indicate an adaptation to varied environmental conditions. This is also confirmed by recent studies with indigenous Sudanese goats which similarly implicated several biological processes (Rahmatalla et al., 2017). The multiplicity in the number of candidate regions and genes detected in the present study confirms findings from livestock species in stressful environments (Kim et al., 2016; Kim et al., 2017; Mwacharo et al., 2017). These studies and the current one, reaffirm the fact that adaptation is generally a complex trait, involving several biological processes and quantitative trait loci with each contributing a small but cumulative effect to the overall phenotype.

Although, the results based on raw p-values yielded very interesting biological pathways which may be overrepresented, the results of the more stringent multiple testing corrections such as Bonferoni correction, were not significant. This may be attributed to the small sample size involved in this study. Nonetheless, these results provide a useful indication of mechanisms involved in environmental adaptation in the indigenous goat breeds.

\subsubsection{Genomic inbreeding based on $\mathrm{ROH}\left(F_{\mathrm{ROH}}\right)$}

In the absence of pedigree records, $\mathrm{ROH}$ may be useful to infer the level of inbreeding. Computing the proportion of an individual's genome occurring as an $\mathrm{ROH}$ of particular length (e.g. $>1 \mathrm{Mb},>2 \mathrm{Mb}$ or $>4 \mathrm{Mb}$ ) provides information on the level of inbreeding relative to a population several generations ago (Curik et al., 2014; Forutan et al., 2018). At $\mathrm{ROH}$ threshold of $>2 \mathrm{Mb}$, the indigenous breeds showed 
very low levels of genomic inbreeding, as compared to the higher inbreeding levels found in the exotic Boer (Table 5.2). The low genomic inbreeding level reported in this study is consistent with findings in Swiss goat breeds (Burren et al., 2016) and Barki goats (Kim et al., 2016). Genomic inbreeding based on $\mathrm{ROH}$ provides an accurate estimate of an individual's autozygosity than pedigree based inbreeding due to either incomplete or non-existent pedigree information (Ferenčaković et al., 2013a; Ferenčaković et al., 201 Bobyitan et al., 2018).

Runs of homozygosity usually emanate from identical haplotypes being transmitted from parents to offspring (Purfield et al., 2012; lacolina et al., 2016). The frequency of their existence provides a clue on the demographic history and management of the population over time (Kirin et al., 2010; Ceballos et al., 2018). The mean sum of $\mathrm{ROH}$ segment coverage was generally higher for short ROHs than for long ROHs (Figure 5.3). However, Karamojong showed a higher average sum of $\mathrm{ROH}>16 \mathrm{Mb}$. The distribution of $\mathrm{ROH}$ coverage reported in this study is in agreement with other studies in goats (Brito et al., 2017), sheep (Purfield et al., 2017) and cattle (Ferenčaković et al., 201 BMastrangelo et al., 2016), in which long ROH segments were found less frequently compared to shorter ones. Although the short $\mathrm{ROH}$ were more frequent in the genome of the indigenous goat breeds, their absolute contribution to the genome was substantially low (except in Kigezi goats) (Table 5.S7). This result is consistent with findings of Bosse et al. (2012), who reported that short $\mathrm{ROH}$ were abundant in the porcine genome but contributed less to the genome as compared to large $\mathrm{ROH}$ (>5Mb). This may be due to differences in selection events in the more recent or ancestral populations. However, the short $\mathrm{ROH}$ in the Boer and indigenous Kigezi goats contributed more to the absolute coverage of the genome by the SNPs. The higher proportion of ROH segments within the short ROH categories indicates a relatively larger contribution of distant inbreeding, whereas the higher coverage of long ROH observed in Karamojong suggests a larger effect of more recent inbreeding. Karamojong goats are reared under pastoral production systems and may be subject to selection of best performing males by their keepers. This coupled with smaller effective population size could be contributing to the high recent inbreeding observed. On the other hand, the Kigezi goats are isolated populations that have undergone limited more recent selection, which could explain the high frequency of short $\mathrm{ROH}$ segments attributed to more distant inbreeding. The longer stretches of $\mathrm{ROH}$ in the exotic Boer goats may be due to the stringent artificial selection for production traits on few selection candidates (narrow genetic base) and may thus explain the higher levels of genomic inbreeding. Longer stretches of ROH were also observed in exotic goat breeds when compared to Barki goats in Egypt (Kim et al., 2016). Generally, shorter ROH is associated with more ancient 
inbreeding, while longer $\mathrm{ROH}$ tend to show a more recent inbreeding (Browning and Browning, 2012; Browning and Browning, 2013).

Although there are limited quantitative trait loci in goats, our study provides a basis for future research in goat genomics of tropically adapted breeds. Using medium density SNPs, we could detect selection signatures associated with adaptation to tropical environmental conditions. With the release of the caprine50K SNP chip (Tosser-Klopp et al., 2014), several efforts are underway including improvements in the annotation of the goat genome assembly (Bickhart et al., 2017). Arguably, these developments will change the landscape of genomic research in goats, allowing for inclusion of genomic evaluations in goat breeding programs. The integration of genomic information will undoubtedly lead to better management and sustainable utilization of genetic resources. The results of this study will advance our understanding of environmentally driven adaptation and its potential application in functional genomics and selective breeding as well as in design of management programs to conserve livestock genetic diversity to cope with the current and future predicted effects of climate change.

\subsection{Conclusion}

Using genome-wide SNP data, we investigated for the first-time selection signatures in Ugandan goat breeds that may be shaping their adaptation to varied environmental conditions. The study identified several putative genomic regions and genes in Ugandan goat populations, which may be underlying adaptation to local environmental conditions such as heat tolerance, disease and parasite resistance, and production traits. Generally, non-classical sweeps with limited overlap were observed which is typical of complex traits.

In the absence of pedigree data, genomic information through ROH provides a useful tool for quantifying the level of genomic inbreeding in the populations.

The study provides a foundation for detailed analysis of the identified putative selection signatures in the goat genome particularly of the tropically adapted breeds and provides an avenue for a well-structured breed improvement.

\section{Ethics statement}

The animals sampled specifically for this study had their processes evaluated and approved by the Ethics Committee of Uganda National Council of Science and Technology (UNCST; SBLS/REC/15/131). 


\section{Data accessibility and supplementary material}

Data from samples used in the present study are available from the Zenodo Digital Repository: https://doi.org/10.5281/zenodo.1184716

Supplementary material related to this chapter is available online through the journal website at:

https://www.frontiersin.org/articles/10.3389/fgene.2018.00318/full\#supplementar y-material

\section{Author contribution}

RBO, MRU and MB conceived the study. RBO drafted the manuscript. HD, MRU, LFB and RBO participated in the data analysis. MAMG, EK, RPMAC, MB supervised the study. All authors read and approved the manuscript.

\section{Funding}

This work was financially supported by the National Agricultural Research Organization (NARO) in Uganda, through a World Bank-supported project, Agricultural Technology and Agribusiness Advisory Services (ATAAS) (P109224).

\section{Conflict of Interest Statement}

The authors declare no conflict of interest and that the study was conducted in the absence of any commercial or financial relationships that could be construed as a potential conflict of interest.

\section{Acknowledgement}

Bert Dibbits - Wageningen University \& Research, Animal Breeding and Genomics for processing genomic DNA samples for genotyping. Paul Kashaija and Dr. Benda Kirungi from the National Livestock Resources Research Institute and Kachwekano Zonal Agricultural Research and Development Institute for support in DNA extraction and field sampling respectively. Robert Mukiibi brainstorming discussions on the subject to shape-up the study. The smallholder farmers for allowing their animals to be sampled for the study. 


\section{References}

Alfonzo, E.P.M., Barbosa Da Silva, M.V.G., Dos Santos Daltro, D., Stumpf, M.T., Dalcin, V.C., Kolling, G., Fischer, V., and Mcmanus, C.M. (2016). Relationship between physical attributes and heat stress in dairy cattle from different genetic groups. International Journal of Biometeorology 60, 245-253. doi: 10.1007/s00484-015-1021-y.

Arias, J.A., Keehan, M., Fisher, P., Coppieters, W., and Spelman, R. (2009). A high density linkage map of the bovine genome. BMC Genetics 10, 10. doi:10.1186/1471-2156-10-18.

Ashburner, M., Ball, C.A., Blake, J.A., Botstein, D., Butler, H., Cherry, J.M., Davis, A.P., Dolinski, K., Dwight, S.S., Eppig, J.T., Harris, M.A., Hill, D.P., Issel-Tarver, L., Kasarskis, A., Lewis, S., Matese, J.C., Richardson, J.E., Ringwald, M., Rubin, G.M., and Sherlock, G. (2000). Gene Ontology: tool for the unification of biology. 25, 25. doi: 10.1038/75556.

Bahbahani, H., Clifford, H., Wragg, D., Mbole-Kariuki, M.N., Van Tassell, C., Sonstegard, T., Woolhouse, M., and Hanotte, O. (2015). Signatures of positive selection in East African Shorthorn Zebu: A genome-wide single nucleotide polymorphism analysis. Science Reports 5, 11729. doi: 10.1038/srep11729.

Bahbahani, H., and Hanotte, O. (2015). Genetic resistance - tolerance to vectorborne diseases and the prospects and challenges of genomics. OIE Scientific and Technical Review 34, 185 - 197.

Bahbahani, H., Salim, B., Almathen, F., Al Enezi, F., Mwacharo, J.M., and Hanotte, O. (2018). Signatures of positive selection in African Butana and Kenana dairy zebu cattle. PLOS ONE 13, e0190446. doi: 10.1371/journal.pone.0190446.

Bahbahani, H., Tijjani, A., Mukasa, C., Wragg, D., Almathen, F., Nash, O., Akpa, G.N., Mbole-Kariuki, M., Malla, S., Woolhouse, M., Sonstegard, T., Van Tassell, C., Blythe, M., Huson, H., and Hanotte, O. (2017). Signatures of Selection for Environmental Adaptation and Zebu $\times$ Taurine Hybrid Fitness in East African Shorthorn Zebu. Frontiers in Genetics 8. doi: 10.3389/fgene.2017.00068.

Benjelloun, B., Alberto, F.J., Streeter, I., Boyer, F., Coissac, E., Stucki, S., Benbati, M., Ibnelbachyr, M., Chentouf, M., Bechchari, A., Leempoel, K., Alberti, A., Engelen, S., Chikhi, A., Clarke, L., Flicek, P., Joost, S., Taberlet, P., Pompanon, F., and, N.C. (2015). Characterizing neutral genomic diversity and selection signatures in indigenous populations of Moroccan goats (Capra hircus) using WGS data. Frontiers in Genetics 6. doi: 10.3389/fgene.2015.00107. 
Bickhart, D.M., Rosen, B.D., Koren, S., Sayre, B.L., Hastie, A.R., Chan, S., Lee, J., Lam, E.T., Liachko, I., Sullivan, S.T., Burton, J.N., Huson, H.J., Nystrom, J.C., Kelley, C.M., Hutchison, J.L., Zhou, Y., Sun, J., Crisà, A., Ponce De León, F.A., Schwartz, J.C., Hammond, J.A., Waldbieser, G.C., Schroeder, S.G., Liu, G.E., Dunham, M.J., Shendure, J., Sonstegard, T.S., Phillippy, A.M., Van Tassell, C.P., and Smith, T.P.L. (2017). Single-molecule sequencing and chromatin conformation capture enable de novo reference assembly of the domestic goat genome. Nature Genetics 49, 643-650. doi:10.1038/ng.3802.

Bosse, M., Megens, H.-J., Madsen, O., Paudel, Y., Frantz, L.a.F., Schook, L.B., Crooijmans, R.P.M.A., and Groenen, M.A.M. (2012). Regions of Homozygosity in the Porcine Genome: Consequence of Demography and the Recombination Landscape. PLOS Genetics 8, e1003100. doi: 10.1371/journal.pgen.1003100.

Brito, L.F., Kijas, J.W., Ventura, R.V., Sargolzaei, M., Porto-Neto, L.R., Cánovas, A., Feng, Z., Jafarikia, M., and Schenkel, F.S. (2017). Genetic diversity and signatures of selection in various goat breeds revealed by genome-wide SNP markers. BMC Genomics 18, 229. doi: 10.1186/s12863-015-0220-1.

Broman, K.W., and Weber, J.L. (1999). Long homozygous chromosomal segments in reference families from the centre d'étude du polymorphisme humain. American Journal of Human Genetics 65, 1493-1500. doi: 10.1086/302661.

Browning, B., and Browning, S. (2013). Improving the accuracy and efficiency of identity by descent detection in population data. Genetics. 194. doi: 10.1534/genetics.113.150029.

Browning, S.R., and Browning, B.L. (2012). Identity by Descent Between Distant Relatives: Detection and Applications. Annual Review of Genetics 46, 617-633. doi: 10.1146/annurev-genet-110711-155534.

Burren, A., Neuditschko, M., Signer-Hasler, H., Frischknecht, M., Reber, I., Menzi, F., Drögemüller, C., and Flury, C. (2016). Genetic diversity analyses reveal first insights into breed-specific selection signatures within Swiss goat breeds. Animal Genetics 47, 727-739. doi:10.1111/age.12476.

Ceballos, F.C., Joshi, P.K., Clark, D.W., Ramsay, M., and Wilson, J.F. (2018). Runs of homozygosity: windows into population history and trait architecture. Nature Reviews Genetics 19, 220-234. doi:10.1038/nrg.2017.109.

Chang, C.C., Chow, C.C., Tellier, L.C., Vattikuti, S., Purcell, S.M., and Lee, J.J. (2015). Second-generation PLINK: rising to the challenge of larger and richer datasets. GigaScience 4, 1-16. doi: 10.1186/s13742-015-0047-8.

Chiejina, S.N., and Behnke, J.M. (2011). The unique resistance and resilience of the Nigerian West African Dwarf goat to gastrointestinal nematode infections. Parasites \& Vectors 4, 12. doi: 10.1186/1756-3305-4-12. 
Curik, I., Ferenčaković, M., and Sölkner, J. ( $\left(\begin{array}{llll}2 & 0 & 1 & 4\end{array}\right)$. Inbreeding and runs of homozygosity: A possible solution to an old problem. Livestock Science 166, 26-34. doi: 10.1016/j.livsci.2014.05.034.

Doekes, H.P., Veerkamp, R.F., Bijma, P., Hiemstra, S.J., and Windig, J.J. (2018). Trends in genome-wide and region-specific genetic diversity in the Dutch-Flemish Holstein-Friesian breeding program from 1986 to 2015. Genetics Selection Evolution 50, 15. doi: 10.1186/s12711-018-0385-y.

Fariello, M.-I., Servin, B., Tosser-Klopp, G., Rupp, R., Moreno, C., International Sheep Genomics, C., Cristobal, M.S., and Boitard, S. (2014). Selection Signatures in Worldwide Sheep Populations. PLOS ONE 9, e103813. doi: 10.1371/journal.pone.0103813.

Fariello, M.I., Boitard, S., Naya, H., Sancristobal, M., and Servin, B. (2013). Detecting Signatures of Selection Through Haplotype Differentiation Among Hierarchically Structured Populations. Genetics 193, 929 - 941. doi: 10.1534/genetics.112.147231.

Ferenčaković, M., Hamzic, E., Gredler, B., Curik, I., and Sölkner, J. (2 $\begin{array}{llll}2 & 1 & 1\end{array}$ ). Rưns o homozygosity reveal genome-wide autozygosity in the Austrian fleckvieh cattle. Agric Conspec Sci 76.

Ferenčaković, M., Hamzić, E., Gredler, B., Solberg, T.R., Klemetsdal, G., Curik, I., and Sölkner, J. (2013a). Estimates of autozygosity derived from runs of homozygosity: empirical evidence from selected cattle populations. Journal of Animal Breeding and Genetics 130, 286-293. doi: 10.1111/jbg.12012.

Ferenčaković, M., Sölkner, J., and Curik, I. ( $\begin{array}{lllll}2 & 0 & 1 & 3\end{array}$ bttli.mEating autozygosity from high-throughput information: effects of SNP density and genotyping errors. Genetics Selection Evolution 45, 42. doi: 10.1186/1297-9686-45-42.

Ferrao, R., Wallweber, Heidi j.A., Ho, H., Tam, C., Franke, Y., Quinn, J., and Lupardus, Patrickj. (2016). The Structural Basis for Class II Cytokine Receptor Recognition by JAK1. Structure 24, 897-905. doi: 10.1016/i.str.2016.03.023.

Fisher, R.A. (1954). A fuller theory of "Junctions" in inbreeding. 8, 187-197. doi: 10.1038/hdy.1954.17.

Forutan, M., Ansari Mahyari, S., Baes, C., Melzer, N., Schenkel, F.S., and Sargolzaei, M. (2018). Inbreeding and runs of homozygosity before and after genomic selection in North American Holstein cattle. BMC Genomics 19, 98. doi: 10.1186/s12864-018-4453-z.

Fox, C.S., Heard-Costa, N., Cupples, L.A., Dupuis, J., Vasan, R.S., and Atwood, L.D. (2007). Genome-wide association to body mass index and waist circumference: the Framingham Heart Study 100K project. BMC Medical Genetics 8, S18. doi: 10.1186/1471-2350-8-S1-S18. 
Guo, Z., González, J.F., Hernandez, J.N., Mcneilly, T.N., Corripio-Miyar, Y., Frew, D., Morrison, T., Yu, P., and Li, R.W. (2016). Possible mechanisms of host resistance to Haemonchus contortus infection in sheep breeds native to the Canary Islands. Scientific Report 6, 26200. doi: 10.1038/srep26200.

Heidaritabar, M., Vereijken, A., Muir, W.M., Meuwissen, T., Cheng, H., Megens, H.J., Groenen, M.a.M., and Bastiaansen, J.W.M. (2014). Systematic differences in the response of genetic variation to pedigree and genome-based selection methods. Heredity 113, 503 - 513. doi: 10.1038/hdy.2014.55.

Howrigan, D., Simonson, M., and Keller, M. (2011). Detecting autozygosity through runs of homozygosity: a comparison of three autozygosity detection algorithms. BMC Genomics 12, 460. doi: 10.1186/1471-2164-12-460.

Huang, D.W., Sherman, B.T., and Lempicki, R.A. (2009). Systematic and integrative analysis of large gene lists using DAVID bioinformatics resources. Nature Protocols 4, 44 - 57. doi: 10.1038/nprot.2008.211.

lacolina, L., Stronen, A.V., Pertoldi, C., Tokarska, M., Nørgaard, L.S., Muñoz, J., Kjærsgaard, A., Ruiz-Gonzalez, A., Kamiński, S., and Purfield, D.C. (2 $\begin{array}{llll}2 & 0 & 1 & 6\end{array}$ ). Novel Graphical Analyses of Runs of Homozygosity among Species and Livestock Breeds. International Journal of Genomics 2016, 8. doi: 10.1155/2016/2152847.

Jiao, X., Sherman, B.T., Huang, D.W., Stephens, R., Baseler, M.W., Lane, H.C., and Lempicki, R.A. (2012). DAVID-WS: a stateful web service to facilitate gene/protein list analysis. Bioinformatics 28, 1805-1806. doi: 10.1093/bioinformatics/bts251.

Kanehisa, M., Goto, S., Sato, Y., Furumichi, M., and Tanabe, M. (2012). KEGG for integration and interpretation of large-scale molecular data sets. Nucleic Acids Research 40, D109-D114. doi: 10.1093/nar/gkr988.

Kemper, K.E., Saxton, S.J., Bolormaa, S., Hayes, B.J., and Goddard, M.E. (2014). Selection for complex traits leaves little or no classic signatures of selection. BMC Genomics 15, 246. doi: 10.1186/1471-2164-15-246.

Kijas, J.W., Lenstra, J.A., Hayes, B., Boitard, S., Porto Neto, L.R., San Cristobal, M., Servin, B., Mcculloch, R., Whan, V., Gietzen, K., Paiva, S., Barendse, W., Ciani, E., Raadsma, H., Mcewan, J., Dalrymple, B., and Other Members of the International Sheep Genomics, C. (2012). Genome-Wide Analysis of the World's Sheep Breeds Reveals High Levels of Historic Mixture and Strong Recent Selection. PLOS Biology 10, e1001258. doi: 10.1371/journal.pbio.1001258.

Kim, E.S., Elbeltagy, A.R., Aboul-Naga, A.M., Rischkowsky, B., Sayre, B., Mwacharo, J.M., and Rothschild, M.F. (2016). Multiple genomic signatures of selection in 
goats and sheep indigenous to a hot arid environment. Heredity 116, 255-264. doi: $10.1038 /$ hdy.2015.94.

Kim, J., Hanotte, O., Mwai, O.A., Dessie, T., Bashir, S., Diallo, B., Agaba, M., Kim, K., Kwak, W., Sung, S., Seo, M., Jeong, H., Kwon, T., Taye, M., Song, K.-D., Lim, D., Cho, S., Lee, H.-J., Yoon, D., Oh, S.J., Kemp, S., Lee, H.-K., and Kim, H. (2017). The genome landscape of indigenous African cattle. Genome Biology 18, 34. doi: 10.1186/s13059-017-1153-y.

Kirin, M., McQuillan, R., Franklin, C.S., Campbell, H., Mckeigue, P.M., and Wilson, J.F. (2010). Genomic Runs of Homozygosity Record Population History and Consanguinity. PLOS ONE 5, e13996. doi: 10.1371/journal.pone.0013996.

Liu, L., Cui, H., Fu, R., Zheng, M., Liu, R., Zhao, G., and Wen, J. (2017). The regulation of IMF deposition in pectoralis major of fast- and slow- growing chickens at hatching. Journal of Animal Science and Biotechnology 8, 77. doi: 10.1186/s40104-017-0207-z.

Lv, F.-H., Agha, S., Kantanen, J., Colli, L., Stucki, S., Kijas, J.W., Joost, S., Li, M.-H., and Ajmone Marsan, P. (2014). Adaptations to Climate-Mediated Selective Pressures in Sheep. Molecular Biology and Evolution 31, 3324-3343. doi: 10.1093/molbev/msu264.

Ma, Y., Wei, J., Zhang, Q., Chen, L., Wang, J., Liu, J., and Ding, X. (2015). A Genome Scan for Selection Signatures in Pigs. PLOS ONE 10, e0116850. doi: 10.1371/journal.pone.0116850.

MAAIF (2011). Statistical Abstrac. (Entebbe - Uganda: Ministry of Agriculture Animal Industry and Fisheries (MAAIF)).

MAAIF and UBOS (2009). THE NATIONAL LIVESTOCK CENSUS REPORT 2008. Ministry of Agriculture, Animal Industry and Fisheries (MAAIF), Entebbe/Uganda Bureau of Statistics, Kampala, Uganda.

Makina, S.O., Muchadeyi, F.C., Van Marle-Köster, E., Taylor, J.F., Makgahlela, M.L., and Maiwashe, A. (2015). Genome-wide scan for selection signatures in six cattle breeds in South Africa. Genetics Selection Evolution 47, 92. doi: 10.1186/s12711-015-0173-x.

Malécot, G. (1948). The mathematics of heredity. pp.63 pp. Masson and Cie, Paris, France.

Marras, G., Gaspa, G., Sorbolini, S., Dimauro, C., Ajmone-Marsan, P., Valentini, A., Williams, J.L., and Macciotta, N.P.P. (2015). Analysis of runs of homozygosity and their relationship with inbreeding in five cattle breeds farmed in Italy. Animal Genetics 46, 110-121. doi: 10.1111/age.12259. 
Mason, I.L., and Maule, J.P. (1960). The Indigenous livestock of eastern and southern Africa. In: Commonwealth Bureau of Animal Breeding and Genetics. (UK: CAB (Commonwealth Agricultural Bureaux)).

Mastrangelo, S., Tolone, M., Di Gerlando, R., Fontanesi, L., Sardina, M.T., and Portolano, B. (2016). Genomic inbreeding estimation in small populations: evaluation of runs of homozygosity in three local dairy cattle breeds. animal 10, 746-754. doi: 10.1017/s1751731115002943.

Maynard, J., and Haigh, J. (2007). The hitch-hiking effect of a favourable gene. Genetics Research 89, 391-403. doi: 10.1017/s0016672308009579.

McQuillan, R., Leutenegger, A.-L., Abdel-Rahman, R., Franklin, C.S., Pericic, M., BaracLauc, L., Smolej-Narancic, N., Janicijevic, B., Polasek, O., Tenesa, A., Macleod, A.K., Farrington, S.M., Rudan, P., Hayward, C., Vitart, V., Rudan, I., Wild, S.H., Dunlop, M.G., Wright, A.F., Campbell, H., and Wilson, J.F. (2008). Runs of Homozygosity in European Populations. The American Journal of Human Genetics 83, 359-372. doi: 10.1016/i.ajhg.2008.08.007.

McRae, K.M., McEwan, J.C., Dodds, K.G., and Gemmell, N.J. (2014). Signatures of selection in sheep bred for resistance or susceptibility to gastrointestinal nematodes. BMC Genomics 15, 637. doi: 10.1186/1471-2164-15-637.

Msalya, G., Kim, E.S., Laisser, E.L., Kipanyula, M.J., Karimuribo, E.D., Kusiluka, L.J., Chenyambuga, S.W., and Rothschild, M.F. (2017). Determination of Genetic Structure and Signatures of Selection in Three Strains of Tanzania Shorthorn Zebu, Boran and Friesian Cattle by Genome-Wide SNP Analyses. PLoS One 12, e0171088. doi: 10.1371/journal.pone.0171088.

Mwacharo, J.M., Kim, E.-S., Elbeltagy, A.R., Aboul-Naga, A.M., Rischkowsky, B.A., and Rothschild, M.F. (2017). Genomic footprints of dryland stress adaptation in Egyptian fat-tail sheep and their divergence from East African and western Asia cohorts. Scientific Reports 7, 17647. doi: 10.1038/s41598-017-17775-3.

Nsubuga, H.S.K. (1996). Small Ruminant: Goats and Sheep in Uganda: In: Small Ruminant Research and Development in Africa: Proceedings of the Third Biennial Conference of the African Small Ruminant Research Network, p. 326. UICC, Kampala, Uganda, 5-9 December, 1994. ILRI (International Livestock Research Institute) Nairobi, Kenya).

Onzima, R.B., Mukiibi, R., Ampaire, A., Benda, K.K., and Kanis, E. (2017). Betweenbreed variations in resistance/resilience to gastrointestinal nematodes among indigenous goat breeds in Uganda. Tropical Animal Health and Production 49, 1763-1769. doi: 10.1007/s11250-017-1390-9.

Onzima, R.B., Upadhyay, M.R., Mukiibi, R., Kanis, E., Groenen, M.A.M., and Crooijmans, R.P.M.A. (2018). Genome-wide population structure and 
admixture analysis reveals weak differentiation among Ugandan goat breeds. Animal Genetics 49, 59-70. doi: 10.1111/age.12631.

Peripolli, E., Stafuzza, N.B., Munari, D.P., Lima, A.L.F., Irgang, R., Machado, M.A., Panetto, J.C.D.C., Ventura, R.V., Baldi, F., and Da Silva, M.V.G.B. (2018). Assessment of runs of homozygosity islands and estimates of genomic inbreeding in Gyr (Bos indicus) dairy cattle. BMC Genomics 19, 34. doi: 10.1186/s12864-017-4365-3.

Petersen, J.L., Mickelson, J.R., Rendahl, A.K., Valberg, S.J., Andersson, L.S., Axelsson, J., Bailey, E., Bannasch, D., Binns, M.M., Borges, A.S., Brama, P., Da Câmara Machado, A., Capomaccio, S., Cappelli, K., Cothran, E.G., Distl, O., FoxClipsham, L., Graves, K.T., Guérin, G., Haase, B., Hasegawa, T., Hemmann, K., Hill, E.W., Leeb, T., Lindgren, G., Lohi, H., Lopes, M.S., Mcgivney, B.A., Mikko, S., Orr, N., Penedo, M.C.T., Piercy, R.J., Raekallio, M., Rieder, S., Røed, K.H., Swinburne, J., Tozaki, T., Vaudin, M., Wade, C.M., and Mccue, M.E. (2013). Genome-Wide Analysis Reveals Selection for Important Traits in Domestic Horse Breeds. PLOS Genetics 9, e1003211. doi: 10.1371/journal.pgen.1003211.

Porto-Neto, L.R., Lee, S.H., Lee, H.K., and Gondro, C. (2013). Detection of Signatures of Selection Using Fst, in Genome-Wide Association Studies and Genomic Prediction, eds. C. Gondro, J. Van Der Werf \& B. Hayes. (Totowa, N J: Humana Press), 423-436. doi:10.1007/978-1-62703-447-0 19.

Porto-Neto, L.R., Lee, S.H., Sonstegard, T.S., Tassell, C.P., Lee, H.K., and Gibson, J.P. (2014). Genome-wide detection of signatures of selection in Korean Hanwoo cattle. Animal Genetics 45, 180 - 190. doi: 10.1111/age.12119.

Purfield, D.C., Berry, D.P., McParland, S., and Bradley, D.G. (2012). Runs of homozygosity and population history in cattle. BMC Genetics 13, 70. doi: 10.1186/1471-2156-13-70.

Purfield, D.C., McParland, S., Wall, E., and Berry, D.P. (2017). The distribution of runs of homozygosity and selection signatures in six commercial meat sheep breeds. PLOS ONE 12, e0176780. doi: 10.1371/journal.pone.0176780.

Rahmatalla, S.A., Arends, D., Reissmann, M., Said Ahmed, A., Wimmers, K., Reyer, H., and Brockmann, G.A. (2017). Whole genome population genetics analysis of Sudanese goats identifies regions harboring genes associated with major traits. BMC Genetics 18, 92. doi: 10.1186/s12863-017-0553-z.

Reitberger, S., Haimerl, P., Aschenbrenner, I., Esser-Von Bieren, J., and Feige, M.J. (2017). Assembly-induced folding regulates interleukin 12 biogenesis and secretion. Journal of Biological Chemistry 292, 8073-8081. doi: 10.1074/jbc.M117.782284. 
Reynolds, J., Weir, B.S., and Cockerham, C.C. (1983). Estimation of the co-ancestry coefficient: Basis for a short genetic distance. Genetics 105, 767-779.

Rochus, C.M., Tortereau, F., Plisson-Petit, F., Restoux, G., Moreno-Romieux, C., Tosser-Klopp, G., and Servin, B. (2018). Revealing the selection history of adaptive loci using genome-wide scans for selection: an example from domestic sheep. BMC Genomics 19, 71. doi: 10.1186/s12864-018-4447-x.

Roy, K.S., and Collier, R.J. (2012). "Regulation of Acclimation to Environmental Stress," in Environmental Physiology of Livestock. Wiley-Blackwell), 49-63. doi: 10.1002/9781119949091.ch4.

Ryans, K., Omosun, Y., Mckeithen, D.N., Simoneaux, T., Mills, C.C., Bowen, N., Eko, F.O., Black, C.M., Igietseme, J.U., and He, Q. (2017). The immunoregulatory role of alpha enolase in dendritic cell function during Chlamydia infection. BMC Immunology 18, 27. doi: 10.1186/s12865-017-0212-1.

Sanz Fernandez, M.V., Stoakes, S.K., Abuajamieh, M., Seibert, J.T., Johnson, J.S., Horst, E.A., Rhoads, R.P., and Baumgard, L.H. (2015). Heat stress increases insulin sensitivity in pigs. Physiological Reports 3. doi: 10.14814/phy2.12478.

Shen, Y., Zhang, Y., Han, Y., Su, P., Gou, M., Pang, Y., Li, Q., and Liu, X. (2017). A Novel Vav3 Homolog Identified in Lamprey, Lampetra japonica, with Roles in Lipopolysaccharide-Mediated Immune Response. International Journal of Molecular Sciences 18, 2035. doi:10.3390/ijms18102035.

Shi, Y., and Manley, J.L. (2007). A Complex Signaling Pathway Regulates SRp38 Phosphorylation and Pre-mRNA Splicing in Response to Heat Shock. Molecular Cell 28, 79-90. doi:10.1016/i.molcel.2007.08.028.

Simianer, H. (2014). Statistical problems in livestock population genomics. In: 10th World Congress on Genetics Applied to Livestock Production. Vancouver Canada.

Talenti, A., Bertolini, F., Pagnacco, G., Pilla, F., Ajmone-Marsan, P., Rothschild, M.F., and Crepaldi, P. (2017). The Valdostana goat: a genome-wide investigation of the distinctiveness of its selective sweep regions. Mammalian Genome 28, 114-128. doi: 10.1007/s00335-017-9678-7.

Taye, M., Lee, W., Caetano-Anolles, K., Dessie, T., Hanotte, O., Mwai, O.A., Kemp, S., Cho, S., Oh, S.J., Lee, H.-K., and Kim, H. (2017). Whole genome detection of signature of positive selection in African cattle reveals selection for thermotolerance. Animal Science Journal 88, 1889-1901. doi: 10.1111/asj.12851.

Thompson, E.A. (2013). Identity by Descent: Variation in Meiosis, Across Genomes, and in Populations. Genetics 194, 301-326. doi: 10.1534/genetics.112.148825. 
Thumbi, S.M., Bronsvoort, B.M.D.C., Poole, E.J., Kiara, H., Toye, P.G., Mbole-Kariuki, M.N., Conradie, I., Jennings, A., Handel, I.G., Coetzer, J.a.W., Steyl, J.C.A., Hanotte, O., and Woolhouse, M.E.J. (2014). Parasite Co-Infections and Their Impact on Survival of Indigenous Cattle. PLOS ONE 9, e76324. doi: 10.1371/journal.pone.0076324.

Tosser-Klopp, G., Bardou, P., Bouchez, O., Cabau, C., Crooijmans, R., Dong, Y., Donnadieu-Tonon, C., Eggen, A., Heuven, H.C.M., Jamli, S., Jiken, A.J., Klopp, C., Lawley, C.T., Mcewan, J., Martin, P., Moreno, C.R., Mulsant, P., Nabihoudine, I., Pailhoux, E., Palhière, I., Rupp, R., Sarry, J., Sayre, B.L., Tircazes, A., Jun, W., Wang, W., Zhang, W., and And the International Goat Genome, C. (2014). Design and Characterization of a 52K SNP Chip for Goats. PLOS ONE 9, e86227. doi: 10.1371/journal.pone.0086227.

UBOS (2015). Statistical Abstract. Uganda Bureau of Statistics, Kampala - Uganda.

Wang, M.S., Li, Y., Peng, M.S., Zhong, L., Wang, Z.J., Li, Q.Y., Tu, X.L., Dong, Y., Zhu, C.L., and Wang, L. (2015). Genomic analyses reveal potential independent adaptation to high altitude in Tibetan chickens. Molecular Biology and Evolution 32, 1880 - 1889. doi: 10.1093/molbev/msv071.

Wang, X., Liu, J., Zhou, G., Guo, J., Yan, H., Niu, Y., Li, Y., Yuan, C., Geng, R., Lan, X., An, X., Tian, X., Zhou, H., Song, J., Jiang, Y., and Chen, Y. (2016). Wholegenome sequencing of eight goat populations for the detection of selection signatures underlying production and adaptive traits. Scientific Reports 6, 38932. doi: 10.1038/srep38932, PMC5150979.

Weir, B.S., and Cockerham, C.C. (1984). Estimating F-statistics for the analysis of population structure. Evolution 38, 1358-1370. doi: 10.2307/2408641.

Wright, S. (1949). THE GENETICAL STRUCTURE OF POPULATIONS. Annals of Eugenics 15, 323-354. doi: 10.1111/j.1469-1809.1949.tb02451.x.

Wu, J.-H., Zhang, W.-G., Li, J.-Q., Yin, J., and Zhang, Y.-J. (2009). Hoxc13 Expression Pattern in Cashmere Goat Skin During Hair Follicle Development. Agricultural Sciences in China 8, 491-496. doi: 10.1016/S1671-2927(08)60237-0.

Yang, J., Li, W.-R., Lv, F.-H., He, S.-G., Tian, S.-L., Peng, W.-F., Sun, Y.-W., Zhao, Y.-X., Tu, X.-L., Zhang, M., Xie, X.-L., Wang, Y.-T., Li, J.-Q., Liu, Y.-G., Shen, Z.-Q., Wang, F., Liu, G.-J., Lu, H.-F., Kantanen, J., Han, J.-L., Li, M.-H., and Liu, M.-J. (2016). Whole-Genome Sequencing of Native Sheep Provides Insights into Rapid Adaptations to Extreme Environments. Molecular Biology and Evolution 33, 2576-2592. doi: 10.1093/molbev/msw129.

Zhang, Q., Guldbrandtsen, B., Bosse, M., Lund, M.S., and Sahana, G. (2015). Runs of homozygosity and distribution of functional variants in the cattle genome. BMC Genomics 16, 542. doi: 10.1186/s12864-015-1715-x. 
Zhao, F., McParland, S., Kearney, F., Du, L., and Berry, D.P. (2015). Detection of selection signatures in dairy and beef cattle using high-density genomic information. Genetics, Selection, Evolution 47, 49. doi: 10.1186/s12711-0150127-3.

Zhao, X.-X., Zhang, Y.-B., Ni, P.-L., Wu, Z.-L., Yan, Y.-C., and Li, Y.-P. (2016). Protein Arginine Methyltransferase 6 (Prmt6) Is Essential for Early Zebrafish Development through the Direct Suppression of gadd4 5 aa Stress Sensor Gene. Journal of Biological Chemistry 291, 402-412. doi: 10.1074/jbc.M115.666347.

Zvinorova, P.I. (2017). A genome-wide association study on mechanisms underlying genetic resistance to gastrointestinal parasites in goats, Zimbabwe. PhD, Stellenbosch University. 


\section{6}

General Discussion 


\subsection{Introduction}

Indigenous goat breeds represent an important genetic resource for improvement of livelihoods of millions of smallholder farmers in developing countries. The indigenous goats are constrained by slow growth rate, low carcass weight and small body size. However, they possess unique adaptive traits such as disease and heat resistance, water scarcity tolerance and the ability to cope with poor quality feed. It is these traits of indigenous goats which enables them to survive and remain productive in various environmental conditions. Attributes like flexibility, resistance and diversity in the indigenous breeds is what endears them to the complex, diverse and risk-prone rural livelihood systems (Anderson, 2003). Therefore, to protect the indigenous breeds, there is an increasing need to promote sustainable use and conservation of the breeds in sub-Saharan African countries including Uganda. To facilitate any meaningful breed improvement program under the current and future scenarios, there is a need to understand the production environment as well as the breeds themselves.

Therefore, the aim of this thesis was to characterise goat production systems and to explore the use of genomic tools in genetic characterization with the goal of promoting the sustainable use and conservation of goat breeds in Uganda. As indicated in Chapter 2, understanding the production environment in which the goats must produce, and considering the needs and perceptions of the key stakeholders in defining breed preferences in the breeding strategy, is crucial. For example, under smallholder production systems characterized by minimum use of anthelminthics, a breed of choice is one that can withstand parasite infestation, especially of gastrointestinal nematodes. Differences in the infection dynamics between goat breeds could provide a useful decision support (Chapter 3 ). We explored genetic diversity, population structure and selection signatures in Ugandan goat breeds using information derived from genotyped animals with the caprine SNP50 beadChip array (Chapter 4 and 5). In the present chapter I discuss the significance of knowledge about the production systems and genetic resources/breeds in developing sustainable breeding and conservation programs, for indigenous goats in Uganda in a broader perspective. 


\subsection{Need for participatory approaches in defining breeding objective traits}

Participatory approaches have been proposed as a viable strategy for defining successful and sustainable breeding goals for livestock in the tropics (Wurzinger et al., 2006; Gizaw et al., 2010; Omasaki et al., 2016). Improvement programs for indigenous breeds in tropical developing countries have largely been unsuccessful due to the lack of participation of the key stakeholders in breed improvement programs, namely the smallholder farmers (Kosgey, 2004; Kosgey et al., 2006). For example, a breeding program with the Ugandan goat breeds, including the Boer breed, on centralized government farms for improving meat production under smallholder conditions did not lead to improved production on the farmers' herds (Onzima et al., 2014). This confirms the failing of similar goat breeding programs like in Ethiopia (Ayalew et al., 2003). Such examples of failed breeding programs are abounded in many Sub-Saharan countries. The reasons for failure include lack of functional infrastructure to support breeding activities, and lack of involvement and engagement of farmers and other key stakeholders in breed improvement programs (Rewe et al., 2009; Wurzinger et al., 2011). This differs sharply from genetic improvement programs in developed countries which are based on highly structured and systematic breeding programs (Zonabend et al., 2013). These programs emphasize livestock identification and performance recording, thus enabling use of information for selection of superior breeding stock.

To address the deficiencies arising from lack of involvement of key stakeholders in breed improvement, in Chapter 2 participatory approaches were implemented in identifying breeding goals. These approaches enable the smallholder farmers to express and analyse their production situations. In so doing, they rank and prioritize their resources and consider the opportunities and constraints based on their situation. The involvement of smallholder farmers in identifying breeding objectives ensures that their needs and interests are catered for by the breeding program. This increases the probability of successfully implementing a breed improvement program. For example, using participatory approaches, breeding objectives have been defined under mixed livestock and pastoral systems for sheep (Gizaw et al., 2010), dairy goats (Bett et al., 2009), small ruminants (Kosgey et al., 2008), and Nile Tilapia breeding programs in Kenya (Omasaki et al., 2016). Therefore, to develop a successful breeding program for local goats for resource constrained smallholder farmers, there is need for well-defined breeding objective traits which are preferred by the famers. Interestingly, smallholder farmers in Uganda prefer high survivability contrary to the widely held view of highly ranking production related traits. The 
farmers' preferred breed is one which ranks high in survival and is well productive (meat mainly) in the local environment. Generally, local breeds tend to exhibit higher survivability and performance than the exotic breeds and their crosses under tropical conditions. Scientific literature suggests the differences may be due to the inability of the genes in exotic breeds to express under tropical conditions (Collier et al., 2008; Baumgard and Jr., 2013; Kim et al., 2016). Evidence from field studies suggests that the local breeds were particularly preferred by the smallholder farmers under low input production systems (Chapter 2). The reasons for farmers' preference include the inherent benefits of the local breeds, such as disease resistance, heat tolerance and ability to utilize low quality feeds. This is because smallholder farmers are risk averse and will rarely specialize in one or few traits. This multiplicity of farmer preference makes designing of effective breeding programs for smallholder farmers very challenging, since often production goals tend to conflict with survival traits especially where there is strong negative correlation. The rate of genetic improvement for both trait types will be low. Although there is high preference for survival traits, production traits also rank appreciably high (Chapter 2). A breed or breeding program which optimally combines the production and survival traits represents a win-win scenario for the farmer. Emanating from the findings, a breeding program which balances between incorporating production as well as survival traits and farmer involvement in defining the breeding goal is a highly recommended part of a successful improvement program, especially under similar smallholder production systems.

\subsection{Sustainable utilization and conservation of local goat breeds}

Genetic improvement of indigenous goat breeds can be achieved through within breed selective breeding or by introgression of other breeds (by cross-breeding) and selective breeding. The motivation for this thesis was to clarify the impact of introducing exotic goat breeds, especially Boer goats, for faster growth and higher body weight, at the expense of the well adapted, but slow growing and smaller indigenous Ugandan goats. This was anticipated to result in improvement in the livelihood of the smallholder farmers (Nsubuga, 1996; MAAIF, 2001). However, the introduction of exotic goat breeds, such as Boer, for crossbreeding has had the effect of disrupting the traditional breeding practices of the smallholder farmers (Onzima et al., 2014). As expected, farmers were attracted to the alternative breeds with high genetic potential to increase production through crossbreeding. Arguably, there is a wide gap in production performance between the selected breeds (e.g. Boer and 
Savanna goats for meat) in developed countries and the local populations from developing countries, making crossbreeding attractive to quickly improve the performance of local livestock populations. Indeed, when local conditions allow proper and systematic implementation, crossbreeding can result in substantial increases in animal performance and thus farmer income (Roschinsky et al., 2015). However, systematic crossbreeding programs with proper recording are lacking in smallholder farming systems in Uganda, raising fears among conservationists and smallholder farmers for breed replacements with un-adapted crossbreds. Despite expectations of improvement, crossbreeding between indigenous and exotic breeds has not resulted in increased net improvement in production of the crossbreds compared to the indigenous goat breeds (Ayalew et al., 2003; Onzima et al., 2014). The reasons for the lack in improved production may be the increased management costs associated with housing, feeding and health in crossbreds with exotic breeds. These costs which may be as high as $50 \%$ of the total costs are enormous for the resource limited smallholder farmers, thus eroding possible benefits of crossbreeding schemes over the indigenous breeds (Ayalew et al., 2003; Onzima et al., 2014; Leroy et al., 2016). So, crossbreeding programs with exotic breeds in subSaharan Africa, often driven by external funding, have had limited benefits for the smallholder farmers. Therefore, crossbreeding with exotic goats may not provide a sustainable approach to breed improvement and conservation under low input smallholder systems in sub-Saharan Africa.

The most rational and sustainable strategy to conserve local livestock breeds is to improve their competitiveness through sustainable breed improvements for the unique attributes of the breeds. Genetic selection within local breeds can result in sustainable long-term genetic improvement. This is well-established in sheep breeding (Gizaw et al., 2010). Through continuous within-breed selection of the best performing animals for desired traits, the performance of the local breeds can be enhanced over several generations. Despite the advantages of pure line breeding, crossbreeding with exotic breeds is often advocated for breed improvement since it is fast and less costly to implement. Additionally, the use of indigenous breeds for production also supports sustainable conservation. Conservation of Animal Genetic Resources (AGR) in developing countries entails rational use of existent local genotypes and protection from introgression with exotic genotypes. This can be achieved through preservation, maintenance, improvement and sustainable use of the local breeds (FAO, 1986). Therefore, the approach of conservation through use of local breeds may be more sustainable than ex situ conservation. To enhance utilization of the indigenous breeds, there is need to improve the breeds for production as well as adaptation traits such as improved disease resistance, 
survivability and ability to utilize poor quality feeds. This could be achieved through within breed selection and targeted introgression with genes of desired traits. However, in general these approaches are difficult to implement in developing countries due to funding constraints and the lack of a breeding infrastructure in these countries.

\subsection{Genetic selection for resistance to gastrointestinal parasite Haemonchus contortus}

Ugandan indigenous goat breeds have superior adaptability to extreme and stressful local environments because of natural selection (exposure to stressors in time). Infection with the gastrointestinal parasite Haemonchus contortus is present in significant populations under smallholder goat production systems (Nsereko et al., 2015). Genetic diversity in livestock regarding disease or parasite resistance is critical, given that disease-causing organisms and parasites are continuously evolving and developing resistance to drugs. In Chapter 3, we assessed three local goat breeds (Kigezi, Mubende and Small East African) for variation in response to Haemonchus contortus. The results showed variation in the level of resistance/tolerance to the parasite, but the breed differences were generally not significant and therefore not very convincing. We also could not establish whether the differences between the breeds occurred due to genetic predisposition or were due to environmental factors, mainly because of the limited number of animals used. Earlier studies reported low to moderate heritability for faecal egg counts (FEC) (Vagenas et al., 2002; Mandonnet et al., 2006; Heckendorn et al., 2017), suggesting that resistance could be improved through systematic selection of individuals for low FEC. To quantify the heritability under the current environment, there is a need for large and well-structured datasets which often are difficult to obtain under smallholder goat production systems. Emanating from these findings, I suggest that FEC should be considered in future selection programs especially within a reference population for improving the Ugandan indigenous goat breeds.

Several studies on genetic control of disease resistance, particularly those associated with infestations with gastrointestinal nematode parasites in sub-Saharan small ruminants, have shown some degree of resistance to nematode species (Baker et al., 2001; Marshall et al., 2013; Bahbahani and Hanotte, 2015; Guo et al., 2016; Zvinorova et al., 2016). These studies suggest that there is genetic variation in resistance to gastrointestinal nematodes. This should be further studied by developing selection lines of goats divergently selected for resistance, to disentangle the underlying mechanisms and to identify the genes involved in resistance to 
gastrointestinal nematodes. The information generated from such selection lines can be incorporated in sustainable breed improvement programs. Different approaches for future selection programs are possible for goats in Uganda. First, conventional breeding involving phenotypic selection of individuals and estimating breeding values (EBV) for traits of interest, such as parasite resistance traits. This requires recording of phenotypes and pedigree information. Secondly, the potential of genomic selection with additional information derived from genomic data can be explored. Genomic information (e.g. single nucleotide polymorphisms (SNPs)) provides a basis for undertaking genome-wide association studies to map genes associated with resistance, in this case to the gastrointestinal nematode Haemonchus contortus. However, the application of genomic selection in breeding programs in small ruminant production in developing countries is at its infancy, and unlikely to be applied soon due to inherent infrastructural and logistical challenges like the costs of genotyping large numbers of individuals. Conventional breeding approaches will probably remain relevant in smallholder production systems in subSaharan Africa.

\subsection{Genetic diversity in goat breeds and its relevance to conservation genetics}

To conserve any population, there is need for in-depth knowledge of ecology, population structure and genetic diversity at the molecular level. Genetic characterisation of local Ugandan goat breeds can provide insight into their adaptation to tropical environments and opportunities for further developing improved goat breeds.

Earlier characterization of Ugandan goat breeds was based on 19 microsatellites (Chenyambuga et al., 2004), which revealed genetic distinctiveness and evolutionary relationships at neutral loci. Neutral genetic marker data acts as a proxy or estimate of the likelihood of important functional genetic variation within breeds or breed groups (FAO, 2011). Unlike SNPs (particularly the non-neutral ones), genetic variation at neutral loci as in microsatellites does not necessarily correlate with variation at particular functional loci (Helyar et al., 2011). The number of microsatellite alleles (repeats) at population level may change more rapidly than the conserved protein coding regions. Therefore, microsatellites were previously used to deduce a populations' genetic structure, but they cannot be used to explain selection events (positive or negative) due to the neutral nature of the loci involved. Whereas, analysis of non-neutral loci such as SNPs may reveal further sources of 
population differentiation, thereby making the use of SNPs more robust than using microsatellites.

High density SNP panels provide highly reliable genomic information for population structure analysis and estimating genetic diversity (Kijas et al., 2013), and as such are suitable in conservation genetics. SNP genotypes as well as whole genome sequence data provide more accurate estimates for relationships between animals than pedigree records which may be incomplete (Eynard et al., 2015). This is particularly relevant in smallholder production systems in Uganda where pedigree recording is non-existent. Genomic information will then be crucial in community-based breeding schemes.

To successfully implement breed improvement programs, there is need to understand the genetic diversity in the population under consideration. To decipher the genetic diversity, population structure and admixture in the local goat populations, we used SNP genotype data (Chapter 4). Until 2016 when sampling was done, the results showed very limited Boer admixture in the Ugandan goat populations and suggest no danger of breed replacement by the exotic Boer goat breed. In practical terms, this offers an opportunity for researchers, development workers and policy makers to organize the breeding program in a more efficient manner along pure breeding and cross-breeding programs. This will thus facilitate breed conservation and promote sustainable utilization of the breeds.

Furthermore, Ugandan indigenous goat breeds show limited breed differences. This suggests recent breed separation and continuous gene flow among the breeds resulting in low breed differentiation among the current goat populations. This could be due to admixture between the breeds or because breeds are descending from a common founder population. To disentangle admixture and common founder effects, a more comprehensive breed history is required, e.g. using whole genome sequencing and mitochondrial DNA (MtDNA) to reveal maternal origins and demographic dynamics in the indigenous goat breeds. For example, by using MtDNA Ethiopian indigenous goat breeds have been categorised into two haplogroups (Mekuriaw et al., 2018). MtDNA is highly conserved in the maternal linage and can be used to trace mitochondrial genetic information back to the original female individual or group of females. This makes it useful for deriving population history of a species.

\subsection{Use of selection signatures and genetic adaptation}

The availability of the goat genome sequence (Dong et al., 2013; Dong et al., 2015; Bickhart et al., 2017) has accelerated the identification of a considerable number of 
SNPs and their use in genome-wide studies. This has enabled the creation of goat SNP arrays, allowing each goat to be genotyped for 53,437 SNPs in one assay (TosserKlopp et al., 2014). The developed SNP array help to differentiate between local goat breeds that are well adapted to extreme environmental conditions. Local Ugandan breeds mostly dwell in environments which are less amenable to their commercial counterparts that lack the genetic potential to adapt (Thornton et al., 2009; Rothschild and Plastow, 2014). The continuous exposure to extreme climatic conditions and environments has shaped the adaptation of the local breeds over many generations such that they have developed tolerance as seen for example in tropically adapted cattle (Porto-Neto et al., 2014) and small ruminants (Kim et al., 2016). Therefore, in line with these studies, indigenous goats are generally found to be highly adapted to local environmental conditions contrary to exotic breeds (Mdladla et al., 2018). Analysis of the Ugandan goat population revealed genomic regions/genes associated with adaptation. Examples of genes associated with adaptation as detected by selection signatures include Interleukin 10 Receptor subunit Beta (IL1ORB) and Interleukin 23 subunit Alpha (IL23A) which are involved in immune response, and Mammalian Target Of Rapamycin (MTOR) and MitogenActivated Protein Kinase 3 (MAPK3) involved in thermo-tolerance. The genomic variation for adaptation seen within the local populations, most likely is the result of adaptation to survive in harsh environments. Because of natural selection pressure and known genetic loci involved in different breeds/populations, insights into genetic mechanisms underlying local adaptation in marginal areas can be inferred from genomic information. This is crucial in guiding breed characterization, conservation, and selection strategies and programs for the different populations (Mdladla et al., 2018).

\subsection{SNP markers for genomic selection in indigenous goat breeds}

The livestock industry has witnessed dramatic improvements in animal production in the last century, mostly due to intense artificial selection for production traits. The indigenous breeds have largely lacked such selection and are thus generally associated with low production. Due to selection, specific regions of the genome that control important production traits and adaptation to heterogeneous environments are expressed. Identifying these regions, or selection signatures, is important for understanding the identities of genes and mutations associated with important phenotypes in the populations of interest. This has been made possible by the identification of SNPs and development of SNP genotyping arrays. In Chapter $\mathbf{5}$ we 
detected selection signatures in the genomes of different goat populations using population specific differentiation (FST) and haplotype differentiation (hapFLK). The selection signature regions are expected to contain functionally important sequence variants (Qanbari and Simianer, 2014). Characterization of selection signature regions is vital in designing strategies for sustainable use and conservation of populations. Selection signature regions may be associated with quantitative trait loci (QTL) for important traits. The identification of genes or regions associated with adaptation aids in matching the animals to the environment in which they must produce.

\subsection{Breeding Programs for indigenous goats - what can genomic information contribute?}

Genetic improvement of livestock is often a complex set of tasks requiring high input of labour and long-term vision. It remains a challenge for many developing countries due to the lack of supportive infrastructure, lack of equipped personnel and institutional arrangements (Kosgey and Okeyo, 2007; Mohammad et al., 2017). Goat production in developing countries, including Uganda, is dominated by indigenous breeds which are predominantly raised under smallholder livestock production systems. In Uganda, like in many developing countries, there are hardly any elaborated genetic improvement programs for goats and yet the advances in genomics offer an opportunity to speed-up genetic improvement programs. Genomic selection (GS), one such advance in genomic technologies, is a breeding tool which incorporates the use of SNP markers spread across the genome and that are in linkage disequilibrium with quantitative trait loci (QTL) influencing a trait of interest (Meuwissen et al., 2001; Hayes et al., 2009). GS involves establishment of a reference population which is genotyped and recorded for the traits of interest. Prediction equations can be developed for determining the relationships between genomic markers and traits of interest, and thereafter for each animal the effect of each marker on a particular trait is estimated. All marker/ SNP effects are then summed up to predict the overall genomic breeding value of each animal. This way, the genetic information can be used for making selection decisions to improve indigenous goat breeds. Application of GS in goat breeding programs in developing countries can lead to rapid genetic progress once the necessary infrastructure and conditions to support it are established. Contrary to conventional selection schemes which rely on pedigree information and phenotyping, GS uses genomic information from a proportion (reference population) of the selection population in which phenotypes are recorded for estimating accurate genomic breeding values 
(Schaeffer, 2006). Genomic information can be obtained early in the life of potential breeding animals. Therefore, the generation interval is lowered compared to, for example, progeny testing, own performance testing and testing of sibs in conventional breeding. Moreover, SNP markers allow for description of relationships between individuals at a genomic level rather than based on pedigree, making it more accurate to establish the relationships. GS can be interesting for goat improvement programs in many developing countries in sub Saharan Africa such as Uganda (Shumbusho et al., 2013; Mukiibi et al., 2017; Mrode et al., 2018). This is particularly appealing where there is lack of recording of important phenotypical and pedigree information used in estimating breeding values of selection candidates. In a GS scheme, a reference population, which is a portion of the total population, is established. The reference population is genotyped and recorded for the traits of interest, and used to develop prediction equations for genomic breeding values of the selection candidates (Boichard et al., 2016; Meuwissen et al., 2016; Ducrocq et al., 2018) as illustrated in Figure 6.1.

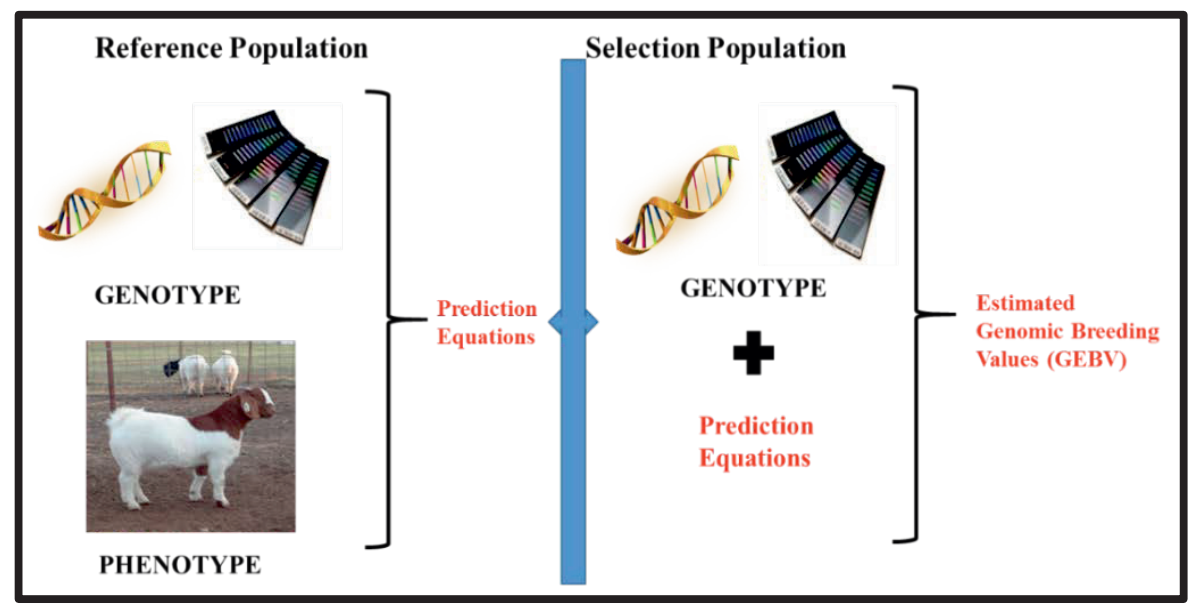

Figure 6.1: Estimating breeding values by genomic selection. Left: Reference population with phenotype recorded and genomic data used to develop prediction equations. Right: In the population under selection, genomic information is input in prediction equations to estimate genomic breeding values. 
Assuming the caprine SNP50K with 53,000 SNPs is used to genotype individual goats, the SNP effects are simultaneously estimated in the reference population using the model:

$$
\mathrm{y}_{\mathrm{i}}=\mu+\mathrm{X}_{1 \mathrm{i}} \times \mathrm{b}_{1}+\mathrm{X}_{2 \mathrm{i}} \times \mathrm{b}_{2}+\cdots+\mathrm{X}_{53000 \mathrm{i}} \times \mathrm{b}_{53000}+\varepsilon_{\mathrm{i}}
$$

Where $y_{i}$ is phenotype of animal i for a trait, for example body weight or FEC; $\mu$ is the overall mean; $\mathrm{X}_{1 \mathrm{i}}$ is the genotype of animal i for SNP marker 1 with effect on trait of interest and $\varepsilon_{\mathrm{i}}$ is the residual error. $\mathrm{b}_{1}, \mathrm{~b}_{2} \ldots . . . . \mathrm{b}_{\mathrm{n}}$ refer to the estimated SNP effects. The GS model (SNP-BLUP) uses a prior assumption that the SNP effects are normally distributed with a constant variance. The genomic breeding value of a selection candidate $\mathrm{j}$ for a certain trait, for example body weight or FEC, in the selection population is then predicted as:

$$
\mathrm{GEBV}_{\mathrm{j}}=\mathrm{X}_{1 \mathrm{j}} \times \mathrm{b}_{1}+\mathrm{X}_{2 \mathrm{j}} \times \mathrm{b}_{2}+\cdots+\mathrm{X}_{53000 \mathrm{j}} \times \mathrm{b}_{53000}
$$

Where $b_{1}$ is the estimated contribution of SNP1 and $X_{1 j}$ is the genotype of animal $j$ for SNP1.

There are several possible scenarios that can be adopted and improved with genomic information in goat breed improvement programs. These programs are discussed below.

\section{Community based breeding programs}

Community based breeding programs (CBBP) are farmer-participatory programs, usually with a common interest to conserve and improve genetic resources under low-input production systems. CBBPs are cognizant of farmers' needs, views, decisions, and their active participation from inception to implementation. The success of CBBPs is premised upon proper consideration of farmers' breeding objectives (rather than the researcher/ policy led objectives), infrastructure considerations, their participation and ownership (Wurzinger et al., 2011; Mueller et al., 2015). Analysis of the smallholder goat farmers and production systems in Uganda has revealed the farmers' probable breeding objectives, production constraints and the production system characteristics (Chapter 1). A scheme that is mindful of these characteristics will ensure the full participation of the farmers, and the breeding objectives identified by the farmers can be incorporated in the design and implementation of CBBPs. Considering the farmers' needs (technical as well as logistical) increases the chance of success of these schemes. Moreover, the scheme is dependent on internal resources and is thus a sustainable breeding option for smallholder farmers. The farmers currently practice "reserve the best bucks" (usually the bigger bucks) for improving their herds. Short-term gains, where the best goats 
are sold for slaughter, is also common, especially in the more commercially oriented production systems. Incorporating GS in CBBPs will ultimately improve the productivity and income of smallholder goat producers. GS increases the genetic gain due to increased accuracy of selection, and since selection decisions can be taken before productive or reproductive age, and it eliminates the need for progeny testing. Due to accurate estimation of relationships at genomic level, it is easy to identify unrelated individuals for mating, thus inbreeding rate per generation can also be kept low. In GS, SNP effects estimated in a population can be used over a few generations. GS is also useful for scarcely recorded or novel traits such as dry matter intake and methane emission in dairy cattle (Pszczola, 2013). The traits can be intensely recorded in the reference population and used to predict GEBV in the target population. However, the use of GS is limited by low across population selection accuracy because marker effects are only valid in populations in which they will be used. Ugandan goat populations show a high degree of homogeneity making it possible to apply the same prediction equations across populations for estimating GEBVs. GS also requires a large set of animals in the reference population especially for low heritability traits. With traits of low heritability, it is difficult to identify SNPs with a large effect that can be used in the prediction equations. The high cost of genotyping especially for goats under smallholder farmer conditions in sub-Saharan Africa, and the lack of dense marker arrays in species such as goats may also influence the use of GS in small ruminant breeding programs in Africa. Examples of CBBPs with high potential for GS are "FARM-Africa dairy goat and animal healthcare" projects in Kenya, Tanzania, Ethiopia and Uganda (Peacock, 2008; Peacock and Hastings, 2011). These programs incorporate a rotational buck exchange, making GS of bucks feasible using SNP genotypes. The genotyping and genomic breeding value estimation should be done by government institutions such as National Animal Genetic Resources Centre and Data Bank (NAGRC\&DB) which may have the necessary infrastructure and means to support breeding activities. Whereas, private/commercial breeding companies in developing countries are not yet well developed and often highly technological innovations such as GS are too costly with low returns for these institutions

\section{National breeding program for goats in Uganda}

Livestock breeding activities in Uganda are regulated by NAGRC\&DB under the Animal Breeding Act 2001. The act provides for development of open nucleus breeding schemes and reproduction extension services to farmers. The act mandates NAGRC\&DB to sell quality breeding stock and recorded superior quality livestock to farmers, and to rear sire studs for production of semen for sale and conservation of 
the indigenous animal genetic resources. The NAGRC\&DB and National Agricultural Research System (NARS) farms, and private breeding organizations, provide the source of breed improvement (semen, breeding stock, ova) for the key livestock species including cattle, sheep, pigs, chicken and goats.

NAGRC\&DB runs breeding centres for goats in almost all agro-ecological zones of Uganda. These breeding centres can be used for running organized breeding programs for goats. Currently, selection is based on phenotypic data, mainly for improving growth traits. Similarly, NARS centres are also spread across the country and carry out breed improvement. Being publicly funded, they possess basic breeding infrastructure and recording of phenotypes can easily be enforced. The limitation of the current schemes is lack of a structured data collection setup which need to be improved. A possible set-up of a goat breed improvement program is illustrated in Figure 6.2.

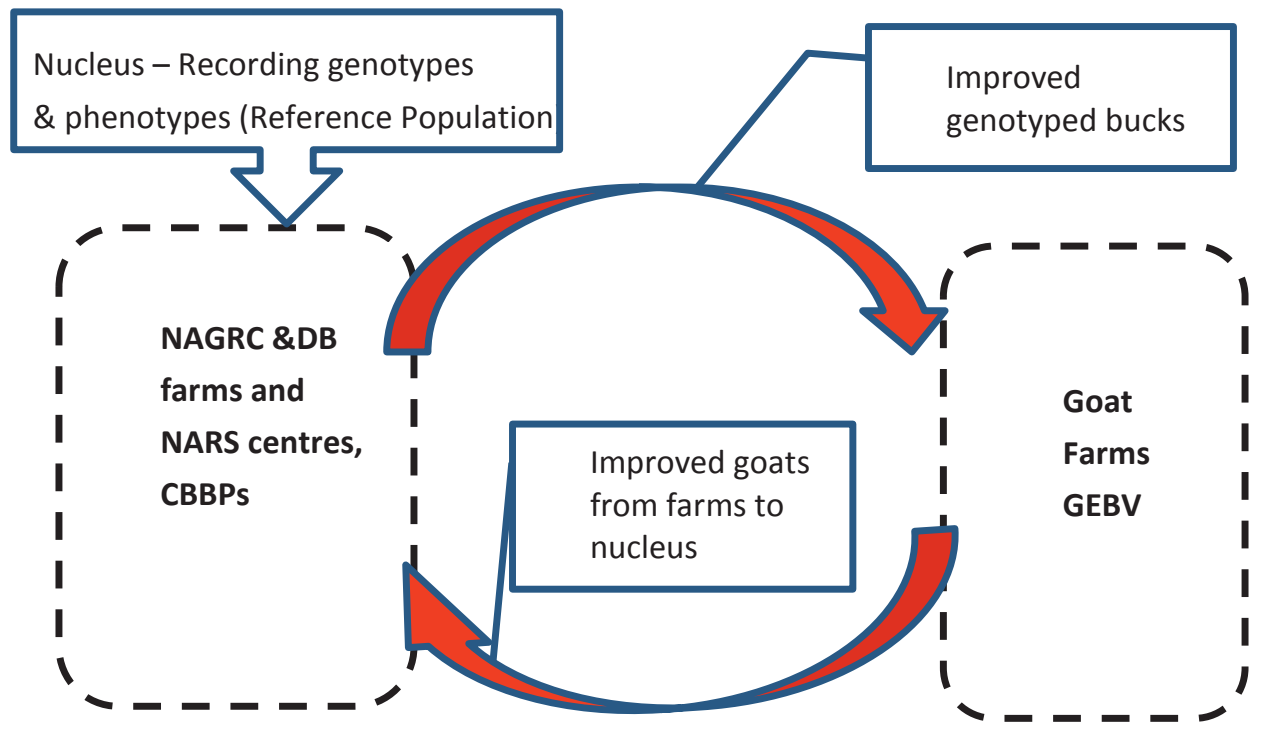

Figure 6.2: Illustration for set up of a genomic selection breeding scheme for goats. Individual recording of phenotypes and genotypes of bucks occurs on the government farms (NAGRC\&DB and NARS). Individuals on goat farms are genotyped and genomic breeding values (GEBV) for individual goats are estimated from prediction equations.

One national program should be advocated for since the indigenous goat breeds do not differ significantly at the genetic level as discussed in Chapter $\mathbf{4}$ of this thesis. 
The national program should include adaptation traits as well as production traits in the breeding goal. A program combining all indigenous populations will benefit from economies of scale to develop and perfect new technologies such as GS. Extending the selection population (technically the effective population size), increases the efficiency of selection. Also, the decreasing costs, for example for genotyping, will eventually lead to optimized breeding and management.

In this scheme, selection initially occurs mainly in the nucleus, which in this case is a governmental farm. The improvement in the nucleus is disseminated to the rest of the herd through supply of improved breeding materials. Farmers outside the nucleus may also carry out some selection in their herd. Eventually, after several generations, the whole chain benefits from the selection in the nucleus. The nucleus herd is intensely recorded, and a reference population created from which genomic data are generated using SNP array. Also, in the nucleus, goats are tested for traits of interest. Using prediction equations developed by combining all marker genotypes with their effects, GEBVs are estimated for each animal in the reference population (nucleus) which may be a government farm. The prediction equations generated can be used on animals outside the nucleus (selection population) which are not phenotyped, to estimate their GEBVs. Individual goats and bucks are ranked on their estimated breeding values in the nucleus. The superior bucks are supplied to the farms where production takes place. Goats born on these farms may also be genotyped at young age and those with high GEBVs can be supplied to the nucleus. The goat farms outside the nucleus may therefore also act as a source of breed improvement. In comparison to classical selection schemes, GS can result in increasing the rate of genetic improvement by $20-100 \%$ in livestock species and can be effective in improving hard-to measure traits (Van der Werf, 2013). In terms of economic efficiency, genomic evaluation in small ruminant breeding programs may be more profitable than classic selection programs. Using simulation, Shumbusho et al. (2013) assessed the economic efficiency of three genomic evaluation models in small ruminants namely: GS model (selection based only on genomic information), GS-phenotype model (genomic information combined with phenotypes) and GSprogeny testing model (genomic information as well as progeny testing). GSphenotype model generated the best economic efficiency. This confirms that some form of GS in small ruminant breeding programs can result in positive net economic returns, however due to increase in associated costs, the rate of economic returns is generally lower than the rate of genetic gain (Shumbusho et al., 2013).

In the selection population, genomic information is required for estimating GEBVs for adaptation and production traits in the breeding goal on which selection decisions are based. Based on prediction equations developed in the reference 
population, the GEBVs can be estimated for goats in the selection population. If genotype $x$ environment interactions play a limited role, individual animals can then be ranked on their GEBV on which selection decisions can be made.

Owing to the logistical and technical challenges, GS under smallholder conditions in Uganda may be successful if the nucleus acts as a testing centre with intense recording of phenotypes and genotypes. Then genetic gain generated by genomic selection in the nucleus can be transferred to farmers' herds.

\subsection{Future perspectives for goat breeding in Uganda}

To genetically improve indigenous goats under smallholder farming conditions, conscious balancing between adaptive and production traits in the breeding goal is of paramount importance. To implement a successful breed improvement program, there is need to understand the breed characteristics and the production systems under which breed improvement can occur. This study shows the possibilities and importance of genomic characterization of indigenous animal genetic resources to enhance breed improvement programs for indigenous goat breeds under smallholder production systems in Uganda. Genomic characterization of indigenous breeds contributes to knowledge of genetic relationships, genetic diversity and population structure of these breeds, and this information is useful in conservation of breeds (Tixier-Boichard, 2014). This knowledge can be used in selection for increased productivity and thus for a larger contribution of indigenous breeds to food security. To fully exploit the available genetic resources, knowledge of the farmers' production practices is paramount in defining the breeding goals. The use of participatory approaches of involving farmers at every step of a breeding program enhances the successful design and implementation of sustainable breed improvement programs. In this regard, smallholder farmers are risk averse and they will tend to promote rearing of livestock that is well adapted to the local environment. However, benefits arising from improved production are desirable for improving the livelihood of the farmers and probably the farmers will easily adopt the new breeding techniques. This calls for critical consideration of the delicate balance between adaptation as well as production traits. Generally, successful implementation of improvement programs under the smallholder conditions in Uganda and elsewhere in sub-Saharan Africa, should aim at incorporating adaptation traits in the breeding objective. This could occur through systematic and strategic crossbreeding of indigenous breeds with either exotic breeds, or preferably crossbreeding within indigenous breeds with good production attributes such as high growth rate and carcass weight. Although, strategic crossbreeding will hasten 
genetic progress in improving these traits, within-breed selection for production and adaptation traits is required for sustainable improvement.

Advances in genome technology, especially SNP genotyping, have made it possible to identify specific regions of the genome that may be under selection (selection signatures). The knowledge generated can be used to select genomic regions that can be prioritized for conservation and for developing sustainable breeding programs for indigenous goat genetic resources in Uganda. Besides for characterization of genetic resources, selection signatures are important for identification of genes or regions of the genome involved in the control and expression of important production and adaptation traits. This knowledge can be used in breeding programs for improving and conserving indigenous goat breeds of Uganda.

Overall, this thesis provides baseline knowledge that can be used for developing systematic breeding programs for local goat breeds. The implementation of genomic selection schemes in CBBPs and/or in the national goat breeding program will hasten breed improvement for low input production systems in sub-Saharan Africa. However, application of GS in the short term may be curtailed by small population sizes (often associated with indigenous breeds), the absence of a sufficient number of (accurately) recorded animals for important traits of interest, and the limited genotyping infrastructure and prohibitive cost of SNP array genotyping. Technological advances and the current trend in reduction of cost of genotyping offer hope for implementation of GS schemes under smallholder farming conditions provided the attendant limitations can be addressed. 


\section{References}

Anderson, S. (2003). Animal genetic resources and sustainable livelihoods. Ecological Economics 45, 331-339.

Ayalew, W., Rischkowsky, B., King, J.M., and Bruns, E. (2003). Crossbreds did not generate more net benefits than indigenous goats in Ethiopian smallholdings. Agricultural Systems 76, 1137-1156.

Bahbahani, H., and Hanotte, O. (2015). Genetic resistance - tolerance to vectorborne diseases and the prospects and challenges of genomics. OIE Scientific and Technical Review 34, 185 - 197.

Baker, R., Audho, J., Aduda, E., and Thorpe, W. (2001). Genetic resistance to gastrointestinal nematode parasties in Galla and Small East African goats in the sub-humid tropics. Animal Science-Glasgow 73, 61-70.

Baumgard, L.H., and Jr., R.P.R. (2013). Effects of Heat Stress on Postabsorptive Metabolism and Energetics. Annual Review of Animal Biosciences 1, 311337.

Bett, R.C., Bett, H.K., Kahi, A.K., and Peters, K.J. (2009). Evaluation and effectiveness of breeding and production services for dairy goat farmers in Kenya. Ecological Economics 68, 2451-2460.

Bickhart, D.M., Rosen, B.D., Koren, S., Sayre, B.L., Hastie, A.R., Chan, S., Lee, J., Lam, E.T., Liachko, I., Sullivan, S.T., Burton, J.N., Huson, H.J., Nystrom, J.C., Kelley, C.M., Hutchison, J.L., Zhou, Y., Sun, J., Crisà, A., Ponce De León, F.A., Schwartz, J.C., Hammond, J.A., Waldbieser, G.C., Schroeder, S.G., Liu, G.E., Dunham, M.J., Shendure, J., Sonstegard, T.S., Phillippy, A.M., Van Tassell, C.P., and Smith, T.P.L. (2017). Single-molecule sequencing and chromatin conformation capture enable de novo reference assembly of the domestic goat genome. Nature Genetics 49, 643-650.

Boichard, D., Ducrocq, V., Croiseau, P., and Fritz, S. (2016). Genomic selection in domestic animals: Principles, applications and perspectives. Comptes Rendus Biologies 339, 274-277.

Chenyambuga, S.W., Hanotte, O., Hirbo, J., Watts, P.C., Kemp, S.J., Kifaro, G.C., Gwakisa, P.S., Petersen, P.H., and Rege, J.E.O. (2004). Genetic characterization of indigenous goats of sub-Saharan Africa using microsatellite DNA markers. Asian-Australasian Journal of Animal Sciences $17,445-452$.

Collier, R.J., Collier, J.L., Rhoads, R.P., and Baumgard, L.H. (2008). Invited Review: Genes Involved in the Bovine Heat Stress Response. Journal of Dairy Science 91, 445-454. 
Dong, Y., Xie, M., Jiang, Y., Xiao, N., Du, X., Zhang, W., Tosser-Klopp, G., Wang, J., Yang, S., Liang, J., Chen, W., Chen, J., Zeng, P., Hou, Y., Bian, C., Pan, S., Li, Y., Liu, X., Wang, W., Servin, B., Sayre, B., Zhu, B., Sweeney, D., Moore, R., Nie, W., Shen, Y., Zhao, R., Zhang, G., Li, J., Faraut, T., Womack, J., Zhang, Y., Kijas, J., Cockett, N., Xu, X., Zhao, S., Wang, J., and Wang, W. (2013). Sequencing and automated whole-genome optical mapping of the genome of a domestic goat (Capra hircus). Nature Biotechnology 31, 135-141.

Dong, Y., Zhang, X., Xie, M., Arefnezhad, B., Wang, Z., Wang, W., Feng, S., Huang, G., Guan, R., Shen, W., Bunch, R., Mcculloch, R., Li, Q., Li, B., Zhang, G., Xu, X., Kijas, J.W., Salekdeh, G.H., Wang, W., and Jiang, Y. (2015). Reference genome of wild goat (capra aegagrus) and sequencing of goat breeds provide insight into genic basis of goat domestication. BMC Genomics 16, 431.

Ducrocq, V., Laloe, D., Swaminathan, M., Rognon, X., Tixier-Boichard, M., and Zerjal, T. (2018). Genomics for Ruminants in Developing Countries: From Principles to Practice. Frontiers in Genetics 9:251. doi: 10.3389/fgene.2018.0025.

Eynard, S.E., Windig, J.J., Leroy, G., Van Binsbergen, R., and Calus, M.P. (2015). The effect of rare alleles on estimated genomic relationships from whole genome sequence data. BMC Genetics 16, 24.

FAO (1986). Animal genetic resources data banks 2. Descriptor lists for cattle, buffalo, pigs, sheep and goats. Animal Production and Health Paper 59/2 (Rome).

FAO (2011). Molecular genetic characterization of animal genetic resources. In: FAO Animal Production and Health Guidelines. (Rome).

Gizaw, S., Komen, H., and Van Arendonk, J.A.M. (2010). Participatory definition of breeding objectives and selection indexes for sheep breeding in traditional systems. Livestock Science 128, 67-74.

Guo, Z., González, J.F., Hernandez, J.N., Mcneilly, T.N., Corripio-Miyar, Y., Frew, D., Morrison, T., Yu, P., and Li, R.W. (2016). Possible mechanisms of host resistance to Haemonchus contortus infection in sheep breeds native to the Canary Islands. Scientific Reports 6, 26200.

Hayes, B.J., Bowman, P.J., Chamberlain, A.J., and Goddard, M.E. (2009). Invited review: Genomic selection in dairy cattle: Progress and challenges. Journal of Dairy Science 92, 433-443.

Heckendorn, F., Bieber, A., Werne, S., Saratsis, A., Maurer, V., and Stricker, C. (2017). The genetic basis for the selection of dairy goats with enhanced resistance to gastrointestinal nematodes. Parasite 24, 32. 
Helyar, S.J., Hemmer-Hansen, J., Bekkevold, D., Taylor, M.I., Ogden, R., Limborg, M.T., Cariani, A., Maes, G.E., Diopere, E., Carvalho, G.R., and Nielsen, E.E. (2011). Application of SNPs for population genetics of nonmodel organisms: new opportunities and challenges. Molecular Ecology Resources 11, 123136.

Kijas, J.W., Ortiz, J.S., Mcculloch, R., James, A., Brice, B., Swain, B., Tosser-Klopp, G., and The International Goat Genome, C. (2013). Genetic diversity and investigation of polledness in divergent goat populations using 52088 SNPs. Animal Genetics 44, 325-335.

Kim, E.S., Elbeltagy, A.R., Aboul-Naga, A.M., Rischkowsky, B., Sayre, B., Mwacharo, J.M., and Rothschild, M.F. (2016). Multiple genomic signatures of selection in goats and sheep indigenous to a hot arid environment. Heredity $116,255-$ 264.

Kosgey, I.S. (2004). Breeding objectives and breeding strategies for small ruminants in the tropics. PhD, Animal Breeding and Genetics Group, PhD Thesis Wageningen University, The Netherlands. 272pp.

Kosgey, I.S., Baker, R.L., Udo, H.M.J., and Van Arendonk, J.A.M. (2006). Successes and failures of small ruminant breeding programmes in the tropics: a review. Small Ruminant Research 61, 13-28.

Kosgey, I.S., and Okeyo, A.M. (2007). Genetic improvement of small ruminants in low-input, smallholder production systems: Technical and infrastructural issues. Small Ruminant Research 70, 76-88.

Kosgey, I.S., Rowlands, G.J., Van Arendonk, J.A.M., and Baker, R.L. (2008). Small ruminant production in smallholder and pastoral/extensive farming systems in Kenya. Small Ruminant Research 77, 11-24.

Leroy, G., Baumung, R., Boettcher, P., Scherf, B., and Hoffmann, I. (2016). Review: Sustainability of crossbreeding in developing countries; definitely not like crossing a meadow.... Animal 10 (2), 262-273.

MAAIF (2001). Livestock Production, marketing Strategy and Sectoral Development Framework, Plan for Modernization of Agriculture. Ministry of Agriculture, Animal Industry and Fisheries (MAAIF).

Mandonnet, N., Menendez-Buxadera, A., Arquet, R., Mahieu, M., Bachand, M., and Aumont, G. (2006). Genetic variability in resistance to gastro-intestinal strongyles during early lactation in Creole goats. Animal Science 82, 283287.

Marshall, K., Mugambi, J.M., Nagda, S., Sonstegard, T.S., Tassell, C.P., Baker, R.L., and Gibson, J.P. (2013). Quantitative trait loci for resistance to Haemonchus 
contortus artificial challenge in Red Maasai and Dorper sheep of East Africa. Animal Genetics 44, 285-295.

Mdladla, K., Dzomba, E.F., and Muchadeyi, F.C. (2018). Landscape genomics and pathway analysis to understand genetic adaptation of South African indigenous goat populations. Heredity, 369-378.

Mekuriaw, T.G., Kassahun, T., Ally, M.O., Appolinaire, D., Tadelle, D., Josephine, B., Sarah, O., Netsanet, Z., Alubel, A., Gloria, A., Jack, T., Collins, M., Joyce, N., and M., M.J. (2018). Mitochondrial DNA variation reveals maternal origins and demographic dynamics of Ethiopian indigenous goats. Ecology and Evolution 8, 1543-1553.

Meuwissen, T., Hayes, B., and Goddard, M. (2016). Genomic selection: A paradigm shift in animal breeding. Animal Frontiers 6, 6 -14.

Meuwissen, T.H.E., Hayes, B.J., and Goddard, M.E. (2001). Prediction of Total Genetic Value Using Genome-Wide Dense Marker Maps. Genetics 157, 1819.

Mohammad, S.A.B., Fazlul Haque Bhuiyan, A.K., Lee, J.H., and Lee, S.H. (2017). Community based livestock breeding programs in Bangladesh: Present status and challenges. Journal of Animal Breeding and Genomics 1, 77 - 84.

Mrode, R., Tarekegn, G.M., Mwacharo, J.M., and Djikeng, A. (2018). Invited review: Genomic selection for small ruminants in developed countries: how applicable for the rest of the world? Animal 12(7), 1333-1340. doi: 10.1017/S1751731117003688

Mueller, J.P., Rischkowsky, B., Haile, A., Philipsson, J., Mwai, O., Besbes, B., Valle Zárate, A., Tibbo, M., Mirkena, T., Duguma, G., Sölkner, J., and Wurzinger, M. (2015). Community-based livestock breeding programmes: essentials and examples. Journal of Animal Breeding and Genetics 132, 155-168.

Mukiibi, R., Katali, K.B., Masembe, C., and Onzima, R.B. (2017). Genomic Selection: Does it hold a future for Genetic Improvement of Indigenous Goats in Uganda. In: International Plant and Animal Genome (PAG XXV), P1105.

Nsereko, G., Emudong, P., Mulindwa, H., and Okwee-Acai, J. (2015). Prevalence of common gastro-intestinal nematode infections in commercial goat farms in Central Uganda. Uganda Journal of Agricultural Sciences 16, 99-106.

Nsubuga, H.S.K. (1996). Small Ruminant: Goats and Sheep in Uganda: ILRI (International Livestock Research Institute) Nairobi, Kenya. 326.

Omasaki, S.K., van Arendonk, J.A.M., Kahi, A.K., and Komen, H. (2016). Defining a breeding objective for Nile tilapia that takes into account the diversity of smallholder production systems. Journal of Animal Breeding and Genetics 133, 404-413. 
Onzima, R.B., Aheisibwe, A.R., Katali, B.K., Kanis, E., and Van Arendonk, J.A.M. (2014). Economic Analysis of Cross Breeding Programs for Indigenous Goat Breeds in Uganda. In: Proceedings of the 10th World Congress on Genetics Applied to Livestock Production (WCGALP). 399.

Peacock, C. (2008). Dairy goat development in East Africa: A replicable model for smallholders? Small Ruminant Research 77, 225-238.

Peacock, C., and Hastings, T. (2011). Meru dairy goat and animal healthcare project. International Journal of Agricultural Sustainability 9, 203-211.

Porto-Neto, L.R., Reverter, A., Prayaga, K.C., Chan, E.K.F., Johnston, D.J., Hawken, R.J., Fordyce, G., Garcia, J.F., Sonstegard, T.S., Bolormaa, S., Goddard, M.E., Burrow, H.M., Henshall, J.M., Lehnert, S.A., and Barendse, W. (2014). The Genetic Architecture of Climatic Adaptation of Tropical Cattle. PLOS ONE 9, e113284.

Pszczola, M. (2013). Optimizing genomic selection for scarcely recorded traits. PhD Thesis Wageningen University, The Netherlands.158p

Qanbari, S., and Simianer, H. (2014). Mapping signatures of positive selection in the genome of livestock. Livestock Science 166, 133-143.

Rewe, T.O., Herold, P., Kahi, A.K., and Zárate, A.V. (2009). Breeding Indigenous Cattle Genetic Resources for Beef Production in Sub-Saharan Africa. Outlook on Agriculture 38, 317-326.

Roschinsky, R., Kluszczynska, M., Sölkner, J., Puskur, R., and Wurzinger, M. (2015). Smallholder experiences with dairy cattle crossbreeding in the tropics: from introduction to impact. Animal 9, 150-157.

Rothschild, M.F., and Plastow, G.S. (2014). Applications of genomics to improve livestock in the developing world. Livestock Science 166, 76-83.

Schaeffer, L.R. (2006). Strategy for applying genome-wide selection in dairy cattle. Journal of Animal Breeding and Genetics 123, 218-223.

Shumbusho, F., Raoul, J., Astruc, J.M., Palhiere, I., and Elsen, J.M. (2013). Potential benefits of genomic selection on genetic gain of small ruminant breeding programs1. Journal of Animal Science 91, 3644-3657.

Thornton, P.K., Van De Steeg, J., Notenbaert, A., and Herrero, M. (2009). The impacts of climate change on livestock and livestock systems in developing countries: A review of what we know and what we need to know. Agricultural Systems 101, 113-127.

Tixier-Boichard, M. (2014). Status and gaps in characterization of animal genetic resources, In: Proceedings of the World Congress on Genetics Applied to Livestock Production. 028. 
Tosser-Klopp, G., Bardou, P., Bouchez, O., Cabau, C., Crooijmans, R., Dong, Y., Donnadieu-Tonon, C., Eggen, A., Heuven, H.C.M., Jamli, S., Jiken, A.J., Klopp, C., Lawley, C.T., Mcewan, J., Martin, P., Moreno, C.R., Mulsant, P., Nabihoudine, I., Pailhoux, E., Palhière, I., Rupp, R., Sarry, J., Sayre, B.L., Tircazes, A., Jun, W., Wang, W., Zhang, W., and And the International Goat Genome, C. (2014). Design and Characterization of a 52K SNP Chip for Goats. PLOS ONE 9, e86227.

Vagenas, D., Jackson, F., Russel, A.J.F., Merchant, M., Wright, I.A., and Bishop, S.C. (2002). Genetic control of resistance to gastro-intestinal parasites in crossbred cashmere-producing goats: responses to selection, genetic parameters and relationships with production traits. Animal Science 74, 199-208.

Van der Werf, J. (2013). Genomic Selection in Animal Breeding Programs. In: Gondro C., van der Werf J., Hayes B. (eds). Genome-Wide Association Studies and Genomic Prediction. Methods in Molecular Biology (Methods and Protocols), vol 1019, 543-61. doi: 10.1007/978-1-62703-447-0_26. Humana Press, Totowa, NJ.

Wurzinger, M., Ndumu, D., Baumung, R., Drucker, A., Okeyo, A.M., Semambo, D.K., Byamungu, N., and Sölkner, J. (2006). Comparison of production systems and selection criteria of Ankole cattle by breeders in Burundi, Rwanda, Tanzania and Uganda. Tropical Animal Health and Production 38, 571-581.

Wurzinger, M., Sölkner, J., and Iñiguez, L. (2011). Important aspects and limitations in considering community-based breeding programs for low-input smallholder livestock systems. Small Ruminant Research 98, 170-175.

Zonabend, E., Okeyo, A.M., Ojango, J.M.K., Hoffmann, I., Moyo, S., and Philipsson, J. (2013). Infrastructure for sustainable use of animal genetic resources in Southern and Eastern Africa. Animal Genetic Resources 53, 79-93.

Zvinorova, P.I., Halimani, T.E., Muchadeyi, F.C., Matika, O., Riggio, V., and Dzama, K. (2016). Breeding for resistance to gastrointestinal nematodes - the potential in low-input/output small ruminant production systems. Veterinary Parasitology 225, 19-28. 


\section{Summary}




\section{Summary}

The indigenous Ugandan goat breeds are poorly characterised, and they are at risk of extinction, due to the introduction of exotic breeds. To prevent undesired loss of genetic diversity, there is need to characterize the production environment as well as the breeds to properly assess the value of breeds and to guide decision making in livestock development and breeding programs. The development of genetic markers and fast genotyping methods in the last decade, have created important tools for genetic characterization of breeds. However, the molecular information on its own does not capture the economic value and adaptive capacity of breeds in local conditions. An important adaptation trait is the resistance to nematode parasites. But the degree of resistance to these parasites of goat breeds is difficult to quantify. To conserve an indigenous breed, breed improvement programs are required which are tailored towards the needs of the farmers and fit with the local conditions. In this thesis, we first assessed the production systems and undertook a farmer participatory definition of breeding goal traits (Chapter 2). Next, we evaluated between breed variation in resistance to the gastrointestinal parasite Haemonchus contortus in three indigenous breeds in Uganda (Chapter 3). Secondly, using genome-wide SNP data, we assessed the genetic diversity, population structure and admixture levels in Ugandan goat breeds (Chapter 4), and analysed signatures of selection and genomic inbreeding in the goat breeds (Chapter 5 ).

Descriptive statistics showed that the indigenous goat production systems did not differ significantly in the nature of the farms and producers' trait preferences for goats. Adaptive traits were generally considered more important than or equally important as production traits. Therefore, sustainable breeding programs should emphasize breeding goal traits that maintain adaptation to local environmental conditions, biodiversity, and economic benefits (Chapter 2).

Evaluation of between breed differences showed the indicator traits for resistance and resilience i.e. faecal egg count (FEC) and packed cell volume (PCV) to be weakly significant at later stages of infection with a higher parasite burden, suggesting potential variation in resistance to Haemonchus contortus (Chapter 3). These differences can be exploited in designing breeding programs with disease resistance in indigenous goat breeds.

Genome-wide analysis using the Goat SNP50 BeadChip showed weak population sub-structuring among Ugandan goat breeds (Chapter 4). This suggests a common ancestry but also some level of geographical differentiation. Admixture analysis and $f_{4}$-statistics revealed gene-flow from the South African breed Boer and varying levels of genetic admixture among the breeds. Generally, moderate to high levels of genetic variability were observed.

In Chapter 5, we assessed signatures of selection and genomic inbreeding. The study identified several putative genomic regions and genes in Ugandan goat populations, which may be underlying adaptation to local environmental conditions such as heat tolerance, disease and parasite resistance, and production traits. The genomic regions were enriched with genes involved in signalling pathways associated directly 
or indirectly with environmental adaptation, such as immune response (e.g. IL1ORB and IL23A), growth and fatty acid composition (e.g. FGF9 and IGF1), and thermotolerance (e.g. MTOR and MAPK3). The study revealed little overlap in genomic regions under selection and generally did not display the typical classic selection signatures as expected due to the complex nature of the traits. In the Boer breed, candidate genes associated with production traits, such as body size and growth (e.g. GJB2 and GJA3) were also identified.

In the absence of pedigree data, the genomic information based on the runs of homozygosity $(\mathrm{ROH})$ reveals the level of genomic inbreeding. Generally, the Ugandan indigenous goat breeds showed very low levels of genomic inbreeding as compared to the higher levels observed in Boer goats. Short $\mathrm{ROH}$ were more frequent than long $\mathrm{ROH}$, except in the indigenous breed Karamojong, suggesting long-term relatedness during the developmental history of the goat breeds.

Finally, the salient issues in this thesis were discussed in Chapter 6. It is worth noting that sustainable breed improvement programs require knowledge of the production environment and of the breeds. Production system characterization and participatory definition of breeding goal traits ensure sustainability of the breeding programs. Advances in genomic technologies yet provide an accurate method to decipher the variation between and within breeds. I therefore conclude that combining knowledge of production systems and breeds, both at the phenotypic and genotypic level, will significantly improve breeding programs in Uganda. Moreover, the community-based breeding programs advocated for the rest of sub-Saharan Africa, could be improved by utilizing genomic selection as genotyping costs become affordable. 
Samenvatting 


\section{Samenvatting}

De inheemse Oegandese geitenrassen zijn slecht gekarakteriseerd en door de introductie van exotische rassen lopen ze het risico om verloren te gaan. Om ongewenst verlies van genetische diversiteit te voorkomen, is het noodzakelijk om de diverse productieomstandigheden en rassen in kaart te brengen. Daarmee kan een juiste inschatting van de waarde van de diverse rassen verkregen worden die de besluitvorming over de ontwikkeling van de veehouderij en fokprogramma's kan ondersteunen. De ontwikkeling van genetische merkers en methoden voor snelle genotypering tijdens het afgelopen decennium, hebben belangrijke hulpmiddelen opgeleverd voor de genetische typering van rassen. Moleculaire informatie alleen is echter niet voldoende om de economische waarde en het aanpassingsvermogen van de rassen onder lokale omstandigheden te beschrijven. Een belangrijk kenmerk m.b.t. adaptatie is resistentie tegen parasitaire nematoden. Maar de mate van resistentie van geitenrassen tegen deze parasieten is moeilijk te kwantificeren.

Om een inheems ras te behouden, is het noodzakelijk specifieke fokprogramma's voor rasverbetering op te zetten die toegesneden zijn op de behoeften van de lokale boeren en die passen bij de lokale omstandigheden. In dit proefschrift hebben we allereerst de productiesystemen in kaart gebracht en hebben we samen met boeren de fokdoelen gedefinieerd (hoofdstuk 2). Vervolgens hebben we de tussen-ras variatie in resistentie tegen de maag-darm parasiet Haemonchus contortus bepaald voor drie inheemse rassen in Oeganda (hoofdstuk 3). Als tweede, hebben we, met gebruikmaking van genoomwijde SNP data, de genetische diversiteit, populatiestructuur en mate van genetische vermenging (admixture) bepaald voor Oegandese geitenrassen (hoofdstuk 4). Daarna hebben we signaturen van selectie geanalyseerd en de mate van inteelt in kaart gebracht (hoofdstuk 5).

Statistisch kon worden aangetoond dat inheemse geitenproductiesystemen niet wezenlijk verschillen qua aard van de bedrijven en qua voorkeuren van boeren voor fokdoelkenmerken. Adaptatiekenmerken werden in het algemeen minstens zo belangrijk gevonden als productiekenmerken. Daarom zouden duurzame fokprogramma's fokdoelen moeten hebben die gericht zijn op behoud van aanpassingsvermogen aan lokale omstandigheden en biodiversiteit, en op verhoging van de economische waarde van geiten (hoofdstuk 2).

De rasverschillen lieten zien dat de indicator kenmerken voor resistentie en veerkracht, zoals het aantal eieren van parasieten in mest (FEC) en de hematocrietwaarde (PCV), licht significant verschillen tussen rassen tijdens de latere fase van infectie wanneer er sprake is van een hogere parasitaire last. Dit suggereert verschillen in resistentie tegen Haemonchus contortus (hoofdstuk 3) die benut kunnen worden bij de ontwikkeling van fokprogramma's voor ziekteresistentie van inheemse geitenrassen.

Genoomwijde analyses met de 50K geit SNP chip toonden aan dat binnen de Oegandese geitenpopulatie de genetische structuur van de rassen weinig verschilt (hoofdstuk 4). Dit suggereert een gezamenlijke oorsprong maar ook een beperkte mate van geografische differentiatie. Admixture analyses en $f_{4}$-statistics toonden 
genetische influx aan van het Zuid-Afrikaanse geitenras Boer alsmede een variabele mate van genetische vermenging tussen de rassen. In het algemeen werd een matig tot hoog niveau van genetische variatie gevonden.

In hoofdstuk 5 onderzochten we aanwijzingen in het genoom die wijzen op selectie en inteelt. Hierbij vonden we diverse regio's in het genoom van de Oegandese geitenpopulaties die mogelijk een rol spelen bij de aanpassing aan lokale omstandigheden zoals tolerantie tegen hitte, ziekte en parasitaire infecties alsmede bij productiekenmerken. Deze genomische regio's bleken verrijkt voor genen die direct of indirect betrokken zijn bij adaptatie aan de omgeving zoals o.a. immuun respons (b.v. IL10RB en IL23A), groei en vetzuursamenstelling (b.v. FGF9 en IGF1) en thermo-tolerantie (b.v. MTOR en MAPK3). De studie liet zien dat de genomische regio's onder selectie weinig overlap vertonen tussen de rassen. In het algemeen vertoonden deze regio's ook niet de typische klassieke signaturen van selectie, waarschijnlijk als gevolg van het complexe karakter van de kenmerken. In het ras Boer, werd een aantal kandidaat genen (b.v. GJB2 en GJA3) voor productiekenmerken als groei en lichaamsgrootte gevonden.

Bij afwezigheid van afstammingsgegevens kan genomische informatie zoals "runs of homozygosity ( $\mathrm{ROH})$ " inzicht geven in de mate van inteelt. In het algemeen vertoonden de Oegandese inheemse geitenrassen erg lage niveaus van inteelt, dit in tegenstelling tot de hogere inteeltniveaus in de Boer geiten. Korte ROH's kwamen vaker voor dan lange $\mathrm{ROH}^{\prime}$ s, behalve in het inheemse geitenras Karamojong, wat een langdurige verwantschap suggereert tussen de verschillende geitenrassen.

In hoofdstuk 6 tenslotte, bediscussieer ik een aantal in het oog springende zaken uit dit proefschrift. Vermeldenswaardig is dat voor duurzame fokprogramma's kennis nodig is van zowel de productieomstandigheden als de gebruikte rassen. Karakterisering van productiesystemen en participatie van boeren bij de vaststelling van fokdoelkenmerken garanderen de duurzaamheid van fokprogramma's. Voortuitgang in genoomtechnologie biedt mogelijkheden voor het nauwkeurig in kaart brengen van de variatie tussen en binnen rassen. Daarom concludeer ik dat het combineren van kennis over productiesystemen en rassen, zowel m.b.t. de fenotypen als de genotypen, zal resulteren in een significante verbetering van fokprogramma's in Oeganda. Tevens kunnen, zodra genotypeerkosten betaalbaar worden, de door de gemeenschap vastgestelde fokprogramma's, die aanbevolen worden voor de rest van sub-Sahara Afrika, verbeterd worden door het toepassen van genomische selectie. 
About the author 


\section{About the author}

Robert Boyle Onzima was born on $30^{\text {th }}$ October 1974 in Arua district in the West Nile region of Uganda. During the formative years, he raised swine from which his tuition was derived. Between 1988 and 1994, he was enrolled at St. Charles Lwanga College, Koboko for ordinary level Uganda Certificate of Education and Entebbe Secondary School for Uganda Advanced Certificate of Education. In 2000, with state scholarship, he obtained an honours Bachelor of Science degree in Agriculture specializing in animal science. In 2003, he was awarded a Netherlands Fellowship Program (NFP) fellowship from the Dutch Government to pursue a Master of Science degree program in Aquaculture and Animal Science with a thesis on the role of MHC genes (TAP and Tapasin) in immune response in chicken lines selected for low and high immune response to Sheep Red Blood Cells (SRBC). In 2005, he was awarded a Master of Science degree in Aquaculture and Animal Science(MAS) with specialty in Animal Breeding and Genetics. The same year, he returned to his native country Uganda and worked as an Animal Breeder with the National Animal Genetic Resources Centre and Data Bank (NAGRC\&DB) and later joined National Agricultural Research Organization (NARO) in 2006, as a Research Scientist for Animal Production. During his time in NARO, Robert contributed to establishing participatory research programs for improving indigenous goat breeds for growth and meat production among smallholder farmers in south western Uganda. In 2013, Robert was awarded a scholarship, under the Agricultural Technology and Agribusiness Advisory Services (ATAAS) project that was funded by the Government of Uganda and the World Bank Group. The project facilitated Robert to enrol for a $\mathrm{PhD}$ program in Animal Breeding and Genetics at the Animal Breeding and Genomics Group of Wageningen University and Research. During the PhD, Robert investigated production systems and genetic diversity in Indigenous goat breeds of Uganda, where he assessed the production systems for goats in Uganda, and using SNP genome-wide data, analysed genetic variation, population structure, admixture, selection signatures and runs of homozygosity in Ugandan indigenous goat breeds. The results of the work are presented in this thesis. Robert's PhD was the result of collaboration between the National Agricultural Research Organization (NARO) in Uganda and Wageningen University \& Research Animal Breeding and Genomics. Since, June 2018 he has resumed his duties at NARO as a Livestock Research Scientist. 
List of publications 


\section{List of Publications}

\section{Peer reviewed Journal articles}

1. Onzima, R. B.; Upadhyay, M.R.; Doekes, H. P.; Brito, L. F.; Bosse, M.; Kanis, E.; Groenen, M. A. M and Crooijmans, R. P.M.A., 2018. Genome-wide characterization of signatures of selection and runs of homozygosity in Ugandan goat breeds. Frontiers in Genetics - Livestock Genomics. 9:318. Doi: https://doi.org/10.3389/fgene.2018.00318.

2. Onzima, R. B.; Gizaw, S.; Kugonza, D. R.; van Arendonk, J. A. M.; Kanis, E., 2018. Production system and participatory identification of breeding objective traits for indigenous goat breeds of Uganda. Small Ruminant Research.163: 51 - 59. https://doi.org/10.1016/j.smallrumres.2017.07.007.

3. Onzima, R.B. ; Upadhyay, M.R. ; Mukiibi, R. ; Kanis, E. ; Groenen, M.A.M. ; Crooijmans, R.P.M.A., 2018. Genome-wide population structure and admixture analysis reveals weak differentiation among Ugandan goat breeds. Animal Genetics, 49: 59-70. https://doi:10.1111/age.12631).

4. Onzima, R. B; Mukiibi, R.; Ampaire, A.; Benda, K. K.; Kanis, E., 2017. Between breed variation in resistance/ resilience to gastrointestinal nematodes among indigenous goat breeds in Uganda. Tropical Animal Health and Production Journal, 49: 1763 - 1769. DOI: https://doi.org/10.1007/s11250017-1390-9.

5. Benda, K. K., Ampaire, A., Komungyeyo, J., Mukiibi, R., Masembe, C., Onzima, R. B., 2015. Efficacy of commercially available anthelminthics in controlling gastrointestinal nematodes in goats managed under natural conditions in South western highlands of Uganda. American Journal of Clinical and Experimental Medicine 2015; 3(6): 355-363. doi: 10.11648/j.ajcem.20150306.16

\section{Conference Proceedings}

6. Onzima, R. B., Doekes, H. P.; Brito, L. F., Upadhyay, M. R.,. Kanis, E.; Groenen, M. A. M and Crooijmans, R. P.M.A., 2018. Genome-wide characterization of runs of homozygosity and estimation of genomic inbreeding in Ugandan goat breeds. In: 11th World Congress on Genetics Applied to Animal Production (WCGALP 2018), Auckland, New Zealand. Paper 166 
7. Onzima, R. B., Upadhyay, M. R., Mukiibi, R., Kanis, E., Crooijmans, R. P. M. A., 2017. Genetic admixture in indigenous Ugandan goat breeds using genome-wide SNP data. 36th International Society of Animal Genetics (ISAG 2017), Dublin, Ireland. Conference Proceedings 193-194.

8. Mukiibi, R., Katali, K.B., Masembe, C., and Onzima, R.B. (2017). Genomic Selection: Does it hold a future for Genetic Improvement of Indigenous Goats in Uganda. In: International Plant and Animal Genome (PAG XXV), P1105.

9. Onzima, R. B., Mukiibi, R., Benda, K. K., van Arendonk, J. A. M., Kanis, E., Komens, H., 2016. Participatory definition of breeding objectives and trait preference by smallholder farmers for indigenous goats in Uganda. Book of Abstracts 12th International Conference on Goats, ICG2016 Antalya, Turkey. 107.

10. Onzima, R. B., Mukiibi, R., Benda, K. K., van Arendonk, J. A. M., Kanis, E., Komen, H., 2016. Between breed variation in resistance to $H$. contortus in three indigenous goat breeds in Uganda. Book of Abstracts of the 67th Annual Meeting of the European Federation of Animal Science. EAAP 2016. Belfast, Northern Ireland, United Kingdom. 427

11. Onzima, R. B., Mukiibi, R., Benda, K. K., van Arendonk, J. A. M., Kanis, E. and Komen, H., 2016. Definition of breeding objectives by smallholder indigenous goat farmers in Uganda. In: $1^{\text {st }}$ World Congress on Innovations for Livestock Development (WCILD), Nakuru, Kenya. PS404.

12. Onzima, R. B., Aheisibwe, A. R., Benda, K. K., Kanis, E., van Arendonk, J. A. M., 2014. Economic Analysis of Cross Breeding Programs for Indigenous Goat Breeds in Uganda. In: 10th World Congress on Genetics Applied to Livestock Production (WCGALP 2014) Vancouver, Canada. 399.

13. Poel, J.J. van der; Berry, N.U.; Onzima, R. B; Lamont, S.J. (2005). Polymorphism in TAP1, TAP2, and TAPASIN genes: refine definition of MHC haplotypes In: Genetics of Animal Health symposium, lowa State University, Ames, July 13-15, 2005.

14. Onzima, R. B (2005). Genetic Polymorphism in the genes of the Major Histocompatibility Complex (MHC) in Immune Response in Chicken. Seminar International Livestock Research Institute (ILRI) August 2005. 
Training and Education 
Training and Supervision Plan

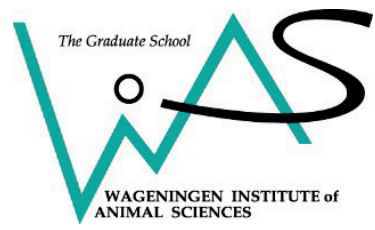

The Basic Package (5.0 ECTS)

WIAS Introduction Course 2013

Ethics and Philosophy in Life Sciences 2013

Introduction Course, European Graduate School for Animal 2013

Breeding \& Genetics.

\section{Scientific Exposure (15.3 ECTS)}

International conferences (8.4 ECTS)

10th World Congress on Genetics Applied to Livestock 2014

Production, Vancouver, Canada.

1st World Congress on Innovations for Livestock Development 2016

(WCILD), Nakuru, Kenya.

67th Annual Conference of the European Association of Animal 2016 Production (EAAP), Belfast - Northern Ireland, UK.

12th International Conference on Goats (ICG) Antalya, Turkey. 2016

National Agricultural Research Organization (NARO) - Makerere 2016

University Kampala (MAK) Dissemination Conference, Kampala, Uganda.

36th Internal Society of Animal Genetics (ISAG) Conference,

Dublin, Ireland.

Seminars and workshops (0.9 ECTS)

How to write a world class paper - Mini symposium,

Wageningen, The Netherlands

Genomic selection for novel traits, Wageningen, The Netherlands 2013

WIAS Science Day (2X)

2016-17 
Presentations (6.0 ECTS)

10th World Congress on Genetic Applied to Livestock Production 2014

(WCGALP), Vancouver, Canada. (Poster)

1st World Congress on Innovations for Livestock Development 2016

(WCILD), Nakuru, Kenya. (Poster)

Annual Meeting of European Association of Animal Production 2016 (EAAP), Belfast-N. Ireland UK. (Poster)

12th International Conference on Goats (ICG) Antalya, Turkey. 2016

(Oral)

National Agricultural Research Organization (NARO) - Makerere 2016

University Kampala (MAK) Dissemination Conference, Kampala, Uganda. (Oral)

36th Internal Society of Animal Genetics (ISAG)Conference,

2017

Dublin, Ireland. (Poster)

\section{In-Depth Studies (11.0 ECTS)}

Disciplinary and interdisciplinary courses (8.0 ECTS)

Food Security in developing countries - European Graduate

2013

School in Animal Breeding and Genetics, ILRI Addis-Ababa,

\section{Ethiopia}

Genetic Analysis using ASREML 4.0, Wageningen University, The

Netherlands

Bioinformatic Tools for Analysis of genomic data, BeCA-ILRI Hub,

2014

NARL-Kawanda, Kampala, Uganda.

Animal Quantitative Genetics and Genomics Training, BeCA-ILRI 2015

Hub, Nairobi - Kenya.

Design and implementation of breeding programs for

2015

smallholder poultry farmers. ILRI - Addis-Ababa, Ethiopia.

Advanced statistics courses (3.0 ECTS)

Advanced statistics - Design of experiments, Wageningen

2013

University, The Netherlands

Statistics for life sciences, Wageningen University, The

2016

Netherlands

\section{Professional Skills Support Courses (4.3 ECTS)}

Scientific Writing 2017

The Essentials of Scientific Writing \& Presenting 2016 
Scientific Publishing 2016

Reviewing a scientific paper 2016

WGS PhD Workshop Carousel 2016

WIAS Course; The Final Touch: Writing the General Introduction 2017

\& Discussion

Research Skills Training (6.9 ECTS)

Preparing own PhD research proposal 2013-14

Getting started with ASREML, Wageningen, The Netherlands 2014

$R$ for statistical analysis 2016

Didactic Skills Training (1.0 ECTS)

Supervising BSc Student 2013

Education and Training Total

$\underline{43.5 \mathrm{ECTS}}$ 


\section{Acknowledgements}


This project was a realization of collaboration between the Ugandan National Agricultural Research Organization (NARO) and Wageningen University. I thank the main funders, the Government of Uganda and World Bank through the ATAAS project under NARO, for offering me the opportunity to undertake this study. Support from NARO top management is acknowledged. Godrine, when you came on board the training committee, you almost immediately sorted out student issues. Thank you for always ensuring our welfare is catered for, and timely arranging for our subsistence and tuition. Thank you, and may you be richly rewarded.

What started as a wild dream several years back has finally come to pass. It all started with a simple but now famous email enquiry to Martien about the possibility of undertaking a project on genetic diversity of Ugandan indigenous goats. Subsequently, several email exchanges followed with Johan, whom I am greatly indebted to for accepting to consider my proposal and developing it for a Wageningen University fund. Although, our proposal was not considered for funding, I wish to sincerely thank Johan for taking me on for a PhD training with the limited funds I had secured. I am forever grateful for the trust you bestowed on my work. I enjoyed your open-door approach that enabled me to settle faster into the PhD. Unfortunately, for a while I did not know what to expect when you left ABGC. I thank Hans who stepped in to fill the gap. Although short-lived, you provided useful insights into my work, which shaped my later research objectives. As if fate had already decided earlier, Martien you joined my supervisory team as my eventual promotor. I am sincerely grateful to you for reinvigorating my PhD project. You guided me to stare off the wildness and stay on course. I am proud to be among the first fruits under your stewardship as chair of Animal Breeding and Genomics. I pray that this journey we have started grows into huge collaborative projects to address food nutrition security concerns of millions in Africa. Richard, many thanks for working with me, initially while I conceived the project and eventually as part of my supervisory team. Thank you for accepting to read through my work and ask the challenging questions, which helped shape my understanding of the ever-changing world of genomics. Egbert, you were more than a supervisor, our weekly meetings and attention to detail inculcated in me the urge to always have another view. Thank you very much for your timely feedback and learning about "goats for meat". I have been with you throughout my PhD, you welcomed me and frequently had dinner with your family, which helped me to always feel at home. I am humbled by your humility and that of your wife Loes. Thank you very much "Weebale munonga, awadifo saaru, asanteni". Mirte, thank you for your insightful thoughts in my wild 
ideas, I drew a lot of inspiration from you. Bert for lab support, Maulik and Harmen, those brainstorming sessions were very helpful in putting flesh to my work.

The management team of Ada, Lisette and Maya, you made my stay at ABGC comfortable. Rosilde, you took very good care of my financials, thank you.

Arnold Kuzniar and Marko Schreuders, you have been blood brothers. You made my stay in Netherlands an enjoyable one. Thank you for the special evening walks and star-watching expeditions, the diners often followed by the spontaneous drinks made my stay enjoyable.

To my co-authors especially Luiz from University of Guelph, thank you for your insightful contribution.

Marco, Andre, Zhou, Annabelle, Langqing, Claudia, Simion, Grum and Harmen, you were my special people. The foosball games in the evening were relaxing, let alone our spontaneous game nights, Efteling, castlefest and dumplings. Xuwen, Wassie, Lisanne, Sanne, Chiara, Maria, Claudia, Samuel, Tom, Yvonne, Zih-Hua, Sonia, Jovana, Tessa, Floor, Mandy, Esther, Gareth, Setegn, Markos, Andre, Katrijn, Merina, Mathieu, Hadi, Hamed, Coralia, Mahlet, Amabel and Charles, you were awesome company. Thank you Harmen and Zhou for accepting to be my paranymphs.

At Kachwekano, Alex you provided the necessary logistics for the field work, thank you. Benda and Robert, and Herbert, Felix, Patrick, Joseph, you became my field assistants. Colleague students from NARO, Prossy and Cathy, thank you for keeping and supporting each other. The Ugandan community at Wageningen, thank you for the warmth and special get-togethers. Kaggwa and Bridget thank you for welcoming us. The melodious voices of the African choir, Mucha, Maureen, Moonga, Tereza, Plaxidis, Esther, Noah, Lilly, Joshua, Thomas, Leah, Omari, Levine, Ben, Aika; the music was relaxing.

My family, sorry for being away from you for this long. Grace you did an awesome task of raising our son Joshua while I was away, not an easy task. But I had to inevitably be away from you. Joshua thank you for being a good child. Timothy will surely have a lot from us all. Thank you, mum, for loving me and dad, thank you for instilling in me the spirit of hard work, am sure you would be smiling now.

Robert Boyle 


\section{Colophon}




\section{Colophon}

The research described in this thesis was financially supported by the Government of Uganda and the World Bank through the Agricultural Technology and Agribusiness Advisory Services (ATAAS) project (P109224) under the National Agricultural Research Organization (NARO).

Thesis cover designed by Harmen Doekes

This thesis was printed by Digiforce| Proefschriftmaken.nl, De Limiet 26, 4131 NR Vianen, the Netherlands. 


\section{Propositions}

1. Genome-wide SNP data are important for conserving genetic diversity in indigenous breeds.

(this thesis)

2. Conservation through use is a better approach than ex-situ conservation for preserving livestock genetic diversity.

(this thesis)

3. Even the best software generates suspicious results.

4. African agriculture can better be transformed by translation of research findings than by generation of new innovations.

5. The right to voluntarily end one's own life is equally important to respect as the right to live.

6. A PhD is only useful when it leads to improved quality of life.

Propositions belonging to the thesis entitled:

Genome-wide analysis of goat genetic diversity and production systems in Uganda

Robert B. Onzima

Wageningen, $3^{\text {rd }}$ May 2019 
Genome-wide analysis of goat genetic diversity and production systems in Uganda

Robert B. Onzima

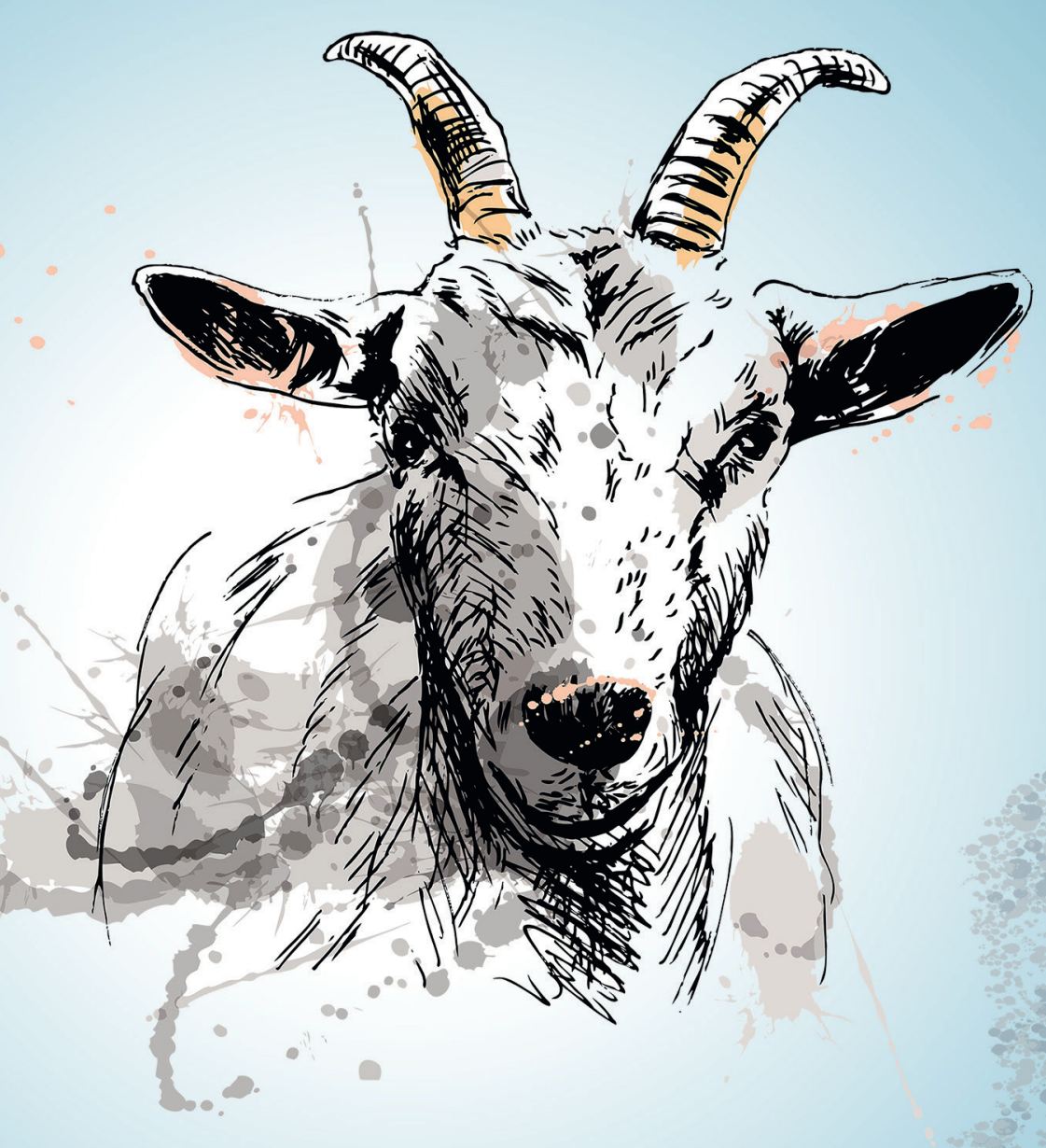

Invitation

You are cordially invited to doctoral thesis:

"Genome-wide analysis of production systems in Uganda"

on Friday 3rd of May 2019 at 11:00am in the Aula of Wageningen University

(Generaal Foulkesweg 1, Wageningen)

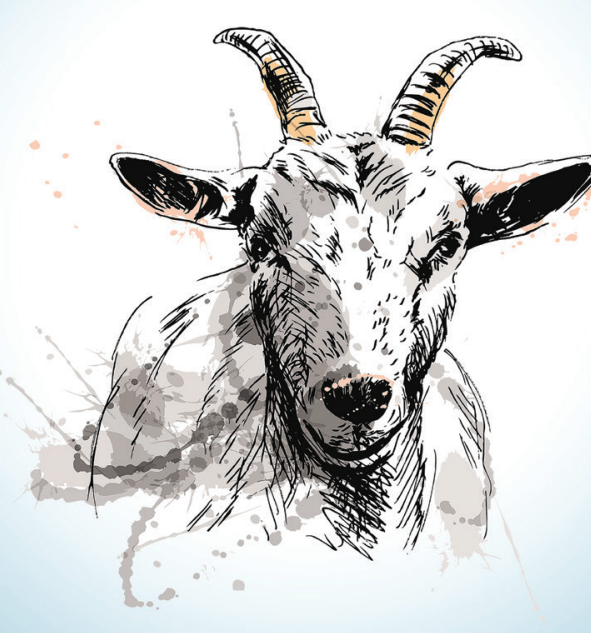

The defence will be followed by a reception at the Aula.

Robert B. Onzima robertonzima@gmail.com

Paranymphs

Harmen Doekes harmen.doekes@wur.nl Zhou Wu zhou.wu@wur.nl 